Herdabilidade e Estudo de Associação Genômica Ampla

(GWAS) de Atividade Física Autorreportada:

uma investigação de famílias brasileiras

\author{
Jean Michel Rocha Sampaio Leite \\ DISSERTAÇÃO APRESENTADA \\ $\mathrm{AO}$ \\ Instituto De MatemáticA E EstatísticA \\ DA \\ Universidade DE SÃo PaUlo \\ PARA \\ OBTEnÇÃO DO TÍTUlO \\ DE \\ Mestre em Bioinformática \\ Programa: Mestrado em Bioinformática \\ Orientador: Prof. Dra. Júlia Maria Pavan Soler
}

Durante o desenvolvimento deste trabalho o autor recebeu auxílio financeiro do CNPq

São Paulo, Agosto de 2019 


\title{
Herdabilidade e Estudo de Associação Genômica Ampla (GWAS) de Atividade Física Autorreportada: uma investigação de famílias brasileiras
}

\author{
Esta versão da dissertação contém as correções e alterações sugeridas \\ pela Comissão Julgadora durante a defesa da versão original do trabalho, \\ realizada em 09/08/2019. Uma cópia da versão original está disponível no \\ Instituto de Matemática e Estatística da Universidade de São Paulo.
}

Comissão Julgadora:

- Prof. Dr. Anatoly Yambartsev - IME-USP

- Prof. Dr. Guilherme Giannini Artioli - EEFE-USP

- Prof. Dra. Marília dos Santos Andrade - EPM-UNIFESP 


\section{Agradecimentos}

Agradeço primeiramente à minha amada mãe Átila Rocha, pelo imenso amor, suporte e educação exemplares; a senhora é meu maior orgulho! A toda minha família, em especial à minha irmã Gabriela, minhas tias Cláudia Fernanda e Fabíola, meu avô Renato e avó Clarice, os quais sempre estiveram tão presentes. Agradeço também ao meu companheiro e amigo Marcus Aloisio, pelo imenso amor, respeito e paciência, bem como por suas contribuições Foucaultianas.

À professora, minha orientadora e amiga Dra. Júlia Pavan Soler, por acreditar e estimular meu crescimento profissional e pessoal, contribuindo para o desenvolvimento de meu trabalho com muita alegria e gratidão. À minha coorientadora Dra. Andréa Horimoto, por seus comentários sempre tão sensatos e espírito calmo, me ajudando a seguir em frente com as análises e reflexões científicas. Aos meus colegas de pós-graduação e companheiros de trabalho do IME, em especial à Ana Ciconelle, Adèle Ribeiro e Francisco Fernandes, que estiveram presentes desde o início de meu Mestrado.

Aos colegas do grupo Atletas do Futuro, com os quais desenvolvi colaboração e muita troca de conhecimento, em especial ao professor João Bosco Pesquero, professora Marília Andrade, Cristiane Antônio e Giscard Lima. Agradeço também a tantas pessoas queridas do InCor, que colaboraram com meu projeto e me acolheram super bem em seu ambiente de trabalho. Agradeço em especial ao Vinícius, pela disponibilidade sem igual em me ajudar nos problemas computacionais.

A todxs que passaram positivamente por minha jornada, muito obrigado pelas contribuições, conversas e abraços ternos. Que continuemos lutando por uma sociedade mais empática, justa e igualitária. Que a luz se sobressaia às sombras. 


\section{Resumo}

LEITE, J. M. R. S. Herdabilidade e Estudo de Associação Genômica Ampla (GWAS) de Atividade Física Autorreportada - uma investigação de famílias brasileiras. 2019. Dissertação de Mestrado - Instituto de Matemática e Estatística, Universidade de São Paulo, São Paulo, 2019.

O advento das tecnologias de sequenciamento de DNA e sua revolução na ciência tem gerado uma quantidade imensa e sem precedentes de informações moleculares. Assim, estudos atuais em diversas áreas objetivam principalmente analisar a associação entre centenas a milhões de variantes genéticas e fenótipos de interesse. Dentre essas variações moleculares, destaque tem sido dado aos SNPs (polimorfismos de nucleotídeo único) e CNVs (variações no número de cópias), os quais têm sido implicados na variabilidade e manifestação de diversos fenótipos, incluindo os relacionados à atividade fisica e desempenho esportivo. No Brasil, algumas iniciativas têm trazido luz à contribuição genética nessas características, como o Projeto Atletas do Futuro e o Projeto Corações de Baependi. Considerando a alta miscigenação que caracteriza a população brasileira, a qual traz grandes desafios, e levando em conta que este último estudo é pioneiro em considerar a estrutura familiar com uma riqueza de informações moleculares e fenotípicas única, nosso objetivo neste trabalho é, fazendo uso desses dados, investigar o papel de variantes genéticas, em particular SNPs e CNVs, na manifestação de comportamentos sedentários e no engajar em atividade física leve, moderada e intensa, verificando a possível existência de heterogeneidades relativamente ao sexo dos indivíduos. As informações referentes a SNPs e CNVs são provenientes do Affymetrix Genome-Wide Human SNP Array 6.0 que, após processamento e limpeza, consiste de um número final de cerca de 843.039 SNPs e 8.974 CNVs. Dados fenotípicos de atividade física e sedentarismo para 760 indivíduos foram derivados do questionário IPAQ-SF e ajustados por uma medida de gasto energético de equivalentes metabólicos de tarefa (METs). A análise descritiva dessas variáveis mostrou uma prevalência de atividade física de 55,3\%, sendo maior para homens que para mulheres. Além disso, utilizando os modelos lineares mistos poligênicos e a abordagem de componentes de variância, estimamos a herdabilidade $\left(\mathrm{h}^{2}\right)$ desses fenótipos obtendo valores de $0,21,0,11,0,22$ e 0,28 para atividade física total, leve, moderada-vigorosa e sedentarismo, respectivamente. Foi identificado heterogeneidade em relação ao sexo, em geral com $\mathrm{h}^{2}$ de homens sendo maiores que a de mulheres. O mapeamento gênico (GWAS) de SNPs e CNVs identificou potenciais picos de associação sob a correção de Bonferroni e sob um critério mais flexível, especialmente nos cromossomos 3, 5 e 6. Essas variantes carecem ainda de informação quanto às suas funções biológicas, as quais podem ser melhor compreendidas através de procedimentos de anotação usando bases de dados como o SCAN.

Palavras-chave: GWAS, SNPs, CNVs, Herdabilidade, Atividade Física, Interação Gene-Ambiente. 


\title{
Abstract
}

\author{
LEITE, J. M. R. S. Heritability and Genome-Wide Association Study of Self-reported \\ Physical Activity - A brazilian family-based investigation. 2019. Master's Thesis - Institute \\ of Mathematics and Statistics, University of São Paulo, São Paulo, Brazil, 2019.
}

The onset of DNA sequencing technologies and its revolution in Science generates an unprecedent and large amount of molecular information. Thus, the current studies in multiple areas aim to evaluate the association between hundreds to thousands of genetic variants and phenotypes of interest. Among these variants, the ones that have received most of the focus are Single Nucleotide Polymorphisms (SNPs) and Copy Number Variations (CNVs), which have been implicated in the variability and manifestation of multiple phenotypes, including the ones related to physical activity and sports performance. In Brazil, some initiatives have brought light to the genetic contribution in these features, such as the project Atletas do Futuro and the project Corações de Baependi. The later is a pioneer study that considers the pedigree structure of a highly admixed population with a unique and rich amount of molecular and phenotypic information. Thus, our role is to investigate the role of genetic variants, in particular SNPs and CNVs, in the manifestation of sedentary behaviour and practice of light, moderate and vigorous physical activity, checking for the existence of heterogeneity related to sex. SNP and CNV information was acquired through the Affymetrics TM 6.0 SNP Array, processed and cleaned, leading to a final number of 843,039 SNPs. and 8,794 CNVs. Sedentarism and physical activity data of 760 individuals were gathered through the IPAQ-SF and adjusted by a measure of metabolic energy cost named metabolic equivalent tasks (METs). The descriptive analysis showed a total physical activity prevalence of $55.3 \%$ and men's one was higher than women's. In addition, using linear mixed polygenic model and the variance components approach, we estimated the heritability of these phenotypes obtaining the values $0.21,0.11,0.22$ e 0.28 for total, weak, moderate-vigorous physical activities and sedentary behaviour, respectively. There was sex-related heterogeneity in the $\mathrm{h}^{2}$, with men having higher estimates than women for most of the evaluated phenotypes. In addition, GWAS of SNPs and CNVs showed several potential candidate markers, especially after using a more flexible significance criteria. These markers were present mainly in chromosomes 3, 5 and 6 , and their possible biological functions remain to be clarified through annotation procedures, using databases such as SCAN.

Keywords: GWAS, SNPs, CNVs, Heritability, Physical Activity, Gene-Environment Interaction 


\section{Sumário}

$\begin{array}{ll}\text { Lista de Siglas } & \text { vi }\end{array}$

Lista de Símbolos $\quad$ vii

Lista de Figuras $\quad$ viii

Lista de Tabelas $\quad$ xi

1 Introdução $\quad 1$

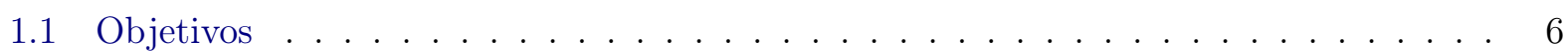

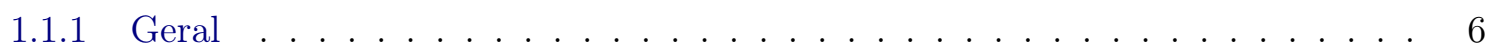

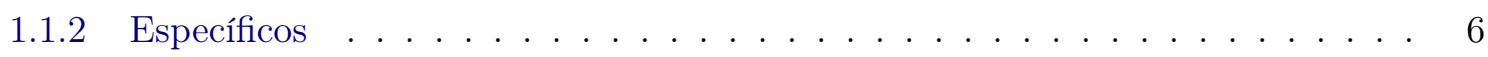

$\begin{array}{lll}2 & \text { Atividade Física e Variantes Genéticas } & 7\end{array}$

3 Material e Métodos $\quad 13$

3.1 Dados de SNPs e CNVs . . . . . . . . . . . . . . . . . . . . . . 13

3.2 O Projeto Corações de Baependi . . . . . . . . . . . . . . . . . . . . . 15

3.3 Fenótipos da Atividade Física . . . . . . . . . . . . . . . . . . . . . 16

3.4 Modelos Estatísticos . . . . . . . . . . . . . . . . . . . 17

3.5 Herdabilidade de Fenótipos da Atividade Física . . . . . . . . . . . . . . . . . 18

3.6 Associação de SNPs e CNVs com Fenótipos da Atividade Física . . . . . . . . . . . . 20

4 Resultados e Discussão $\quad 22$

4.1 Banco de Dados . . . . . . . . . . . . . . . . . . . . . . . . . . 22

4.2 Análise Descritiva . . . . . . . . . . . . . . . . . . . . . 24

4.3 Seleção de Modelos e Herdabilidade . . . . . . . . . . . . . . . . . . . . . 30

4.4 GWAS - Associação de SNPs e CNVs com fenótipos de atividade física . . . . . . . . 39

4.4 .1 GWAS com SNPs . . . . . . . . . . . . . . . . . . . 39

4.4.2 GWAS com CNVs como covariáveis categóricas . . . . . . . . . . . . . . 45

4.4.3 GWAS com CNVs como covariáveis dicotômicas . . . . . . . . . . . . . . . . . 49

5 Conclusão e Considerações Finais $\quad 56$

A Questionário Internacional de Atividade Física - Versão Curta (IPAQ-SF) 59

B Ajuste Inicial de Modelos para os fenótipos de AF do IPAQ-SF 62 
D Gráficos Manhattan de SNPs e de CNVs para variáveis transformadas pelo log 64

E Tabelas dos 20 menores $p$-valores dos GWAS de SNPs e de CNVs para variáveis transformadas pelo log

F Anotação de SNPs candidatos sob critério flexível

Referências Bibliográficas 


\section{Lista de Siglas}

GWAS Estudo de Associação Genômica de Ampla Cobertura (Genome-Wide Association Study)

SNP Polimorfismo de Nucleotídeo Único(Single Nucleotide Polymorphism)

CNV Variação no número de cópias (Copy Number Variation)

MET Equivalentes Metabólicos de Tarefa (Metabolic Equivalent Task)

AFT Atividade Física Total

WK Atividade Física Leve (Walking Time)

MPA Atividade Física Moderada (Moderate Physical Activity)

VPA Atividade Física Vigorosa (Vigorous Physical Activity)

MVPA Atividade Física Moderada-Vigorosa (Moderate-Vigorous Physical Activity)

SCAN Base de dados de Anotação de SNP e CNV (SNP and CNV Annotation Database) 


\section{Lista de Símbolos}

$\Omega \quad$ Matriz de (co)variânca fenotípica

$\Phi \quad$ Matriz kinship

$\phi \quad$ Ou função probit da normal ou coeficiente kinship

$\mu \quad$ Média do traço

$h^{2} \quad$ Herdabilidade

$\sigma_{g}^{2} \quad$ Variância do componente genético aditivo

$\sigma_{e}^{2} \quad$ Variância do componente ambiental

$\epsilon$ Componente aleatório de erro 


\section{Lista de Figuras}

3.1 Pipeline do processamento de probes para chamada de CNVs. Retirado de Ciconelle [2018] . . . . . . . . . . . . . . . . . . . . . . . . . . 14

3.2 Mapa do município de Baependi-MG. Retirado de https://pt.wikipedia.org/wiki/Baependi/media/Fich

4.1 Heredograma da família hipotética 1 mostrando as relações de parentesco entre seus membros. Quadrados indicam indivíduos do sexo masculino e círculos indicam os do

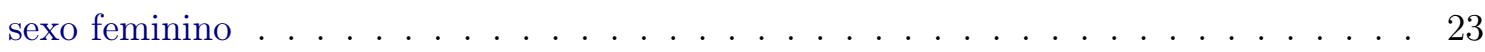

4.2 Distribuição do número de dias da semana nos quais homens, mulheres e total de indivíduos praticam atividade física leve. . . . . . . . . . . . . . 24

4.3 Distribuição do número de dias da semana nos quais homens, mulheres e total de indivíduos praticam atividade física moderada. . . . . . . . . . . . 25

4.4 Distribuição do número de dias da semana nos quais homens, mulheres e total de indivíduos praticam atividade física vigorosa. . . . . . . . . . . . 25

4.5 Boxplots das distribuições do tempo diário de atividade física nos perfis WK (atividade em caminhada), MPA (atividade moderada) e VPA (atividade vigorosa) estra-

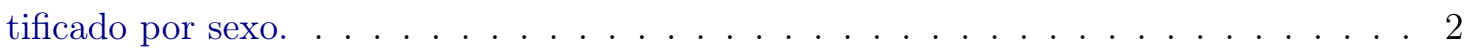

4.6 Gráfico de dispersão de Atividade Física Total em MET*min/sem em função da idade para homens e mulheres. Triângulos e círculos correspondem a homens e mulheres,

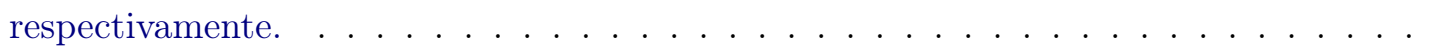

4.7 Boxplots das distribuições de Atividade Física nos perfis AFT (atividade física total), WK (atividade em caminhada), MPA (atividade moderada) e VPA (atividade vigorosa) estratificado por sexo, medida em equivalentes metabólicos de tarefa (MET) x $\min /$ semana. . . . . . . . . . . . . . . . . . . .

4.8 Atividade Física estratificado por sexo nos perfis médios AFT (atividade física total), WK (atividade em caminhada), MPA (atividade moderada) e VPA (atividade vigorosa), medida em equivalentes metabólicos de tarefa (MET) x min /semana em 760 indivíduos. . . . . . . . . . . . . . . . . . . .

4.9 Tempo médio em min/semana gasto em posições sentadas para homens, mulheres e total de indivíduos. . . . . . . . . . . . . . . . . . . . . .

4.10 Gráfico Manhattan de associação de SNPs com atividade física total (inv AFT). O eixo y indica o $-\log _{10}(p)$ valor dos testes de associação para cada SNP. Por sua vez, o eixo x indica em pb dos SNPs ao longo dos 22 autossomos e cromossomos sexuais,

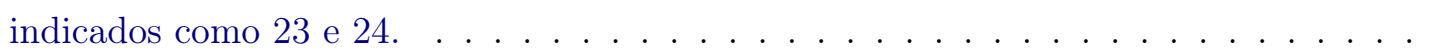


4.11 Gráfico Manhattan de associação de SNPs com atividade física leve (inv WK). O eixo y indica o $-\log _{10}(p)$ valor dos testes de associação para cada SNP. Por sua vez, o eixo $\mathrm{x}$ indica em pb dos SNPs ao longo dos 22 autossomos e cromossomos sexuais,

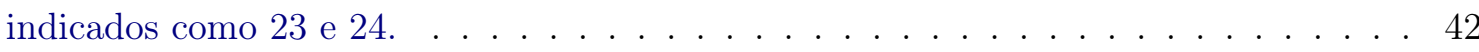

4.12 Gráfico Manhattan de associação de SNPs com atividade física leve (inv MVPA). O eixo y indica o $-\log _{10}(p)$ valor dos testes de associação para cada SNP. Por sua vez, o eixo $\mathrm{x}$ indica em pb dos SNPs ao longo dos 22 autossomos e cromossomos sexuais, indicados como 23 e $24 \ldots \ldots \ldots \ldots$. . . . . . . . . . . . . . . . . 42

4.13 Gráfico Manhattan de associação de SNPs com atividade física leve (inv SB). O eixo y indica o $-\log _{10}(p)$ valor dos testes de associação para cada SNP. Por sua vez, o eixo $\mathrm{x}$ indica em pb dos SNPs ao longo dos 22 autossomos e cromossomos sexuais,

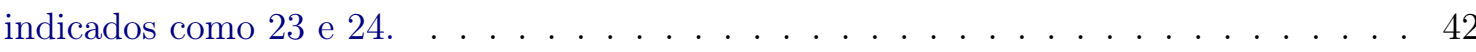

4.14 Gráfico Manhattan de associação de CNVs com atividade física total (invAFT MET). O eixo y indica o $-\log _{10}(p)$ valor dos testes de associação para cada CNV. Por sua vez, o eixo x indica a posição central em pb dos CNVs ao longo dos 22 autossomos. . 46

4.15 Gráfico Manhattan de associação de CNVs com atividade física total (invWK MET). O eixo y indica o $-\log _{10}(p)$ valor dos testes de associação para cada CNV. Por sua vez, o eixo x indica a posição central em pb dos CNVs ao longo dos 22 autossomos. . 46

4.16 Gráfico Manhattan de associação de CNVs com atividade física total (invMVPA MET). O eixo y indica o $-\log _{10}(p)$ valor dos testes de associação para cada CNV. Por sua vez, o eixo x indica a posição central em pb dos CNVs ao longo dos 22

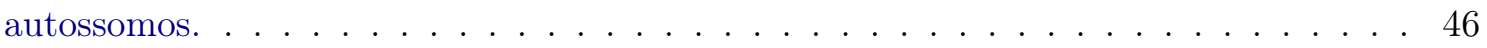

4.17 Gráfico Manhattan de associação de CNVs com sedentarismo (inv SB). O eixo y indica o $-\log _{10}(p)$ valor dos testes de associação para cada CNV. Por sua vez, o eixo x indica a posição central em pb dos CNVs ao longo dos 22 autossomos. . . . . . . . 47

4.18 Gráfico Manhattan de associação de CNVs com atividade física total (invAFT MET). O eixo y indica o $-\log _{10}(p)$ valor dos testes de associação para cada CNV. Por sua vez, o eixo x indica a posição central em pb dos CNVs ao longo dos 22 autossomos. . 50

4.19 Gráfico Manhattan de associação de CNVs com atividade física total (invWK MET). O eixo y indica o $-\log _{10}(p)$ valor dos testes de associação para cada CNV. Por sua vez, o eixo x indica a posição central em pb dos CNVs ao longo dos 22 autossomos. . 50

4.20 Gráfico Manhattan de associação de CNVs com atividade física total (invMVPA MET). O eixo y indica o $-\log _{10}(p)$ valor dos testes de associação para cada CNV. Por sua vez, o eixo x indica a posição central em pb dos CNVs ao longo dos 22

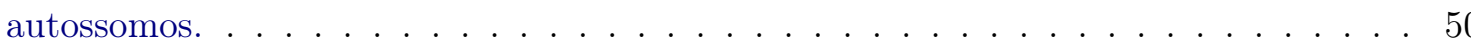

4.21 Gráfico Manhattan de associação de CNVs com atividade física total (invSB). O eixo y indica o $-\log _{10}(p)$ valor dos testes de associação para cada CNV. Por sua vez, o eixo x indica a posição central em pb dos CNVs ao longo dos 22 autossomos. . . . . . 51

D.1 Gráfico Manhattan de associação de SNPs com atividade física leve (logAFT MET). O eixo y indica o $-\log _{10}(p)$ valor dos testes de associação para cada SNP. Por sua vez, o eixo x indica em pb dos SNPs ao longo dos 22 autossomos. . . . . . . . . . . . 64 
D.2 Gráfico Manhattan de associação de SNPs com atividade física leve (logWK MET). O eixo y indica o $-\log _{10}(p)$ valor dos testes de associação para cada SNP. Por sua vez, o eixo x indica em pb dos SNPs ao longo dos 22 autossomos. . . . . . . . . . . . 64

D.3 Gráfico Manhattan de associação de SNPs com atividade física leve (logMVPA MET). O eixo y indica o $-\log _{10}(p)$ valor dos testes de associação para cada SNP. Por sua vez, o eixo x indica em pb dos SNPs ao longo dos 22 autossomos. . . . . . . . 65

D.4 Gráfico Manhattan de associação de SNPs com atividade física leve (logSB). O eixo y indica o $-\log _{10}(p)$ valor dos testes de associação para cada SNP. Por sua vez, o eixo $\mathrm{x}$ indica em pb dos SNPs ao longo dos 22 autossomos. . . . . . . . . . . . . . 65

D.5 Gráfico Manhattan de associação de CNVs com atividade física total (log AFT MET). O eixo y indica o $-\log _{10}(p)$ valor dos testes de associação para cada CNV. Por sua vez, o eixo x indica a posição central em pb dos CNVs ao longo dos 22 autossomos. . 65

D.6 Gráfico Manhattan de associação de CNVs com atividade física leve (log WK MET). O eixo y indica o $-\log _{10}(p)$ valor dos testes de associação para cada CNV. Por sua vez, o eixo x indica a posição central em pb dos CNVs ao longo dos 22 autossomos. . 66

D.7 Gráfico Manhattan de associação de CNVs com atividade física moderada-vigorosa $\left(\log\right.$ MVPA). O eixo y indica o $-\log _{10}(p)$ valor dos testes de associação para cada CNV. Por sua vez, o eixo x indica a posição central em pb dos CNVs ao longo dos 22 autossomos.

D.8 Gráfico Manhattan de associação de CNVs com sedentarismo (log SB). O eixo y indica o $-\log _{10}(p)$ valor dos testes de associação para cada CNV. Por sua vez, o eixo x indica a posição central em pb dos CNVs ao longo dos 22 autossomos. . . . . . . . . 66 


\section{Lista de Tabelas}

4.1 Indivíduos pertencentes à família hipotética 1 e suas relações de parentesco. FID = Identificação da família do indivíduo, IID = Identificação do indivíduo, $\mathrm{PAT}=$ Identificação do pai do indivíduo, MAT = Identificação da mãe do indivíduo, SEX $=$ Sexo do indivíduo . . . . . . . . . . . . . . . . . . . . 22

4.2 Dados fenotípicos de $\mathbf{n}=\mathbf{6}$ indivíduos do banco de dados utilizado. FID $=$ Identificação da família, IID = Identificação do indivíduo, PAT = Identificação do pai, MAT $=$ Identificação da mãe, SEX $=$ sexo, AFT_MET $=$ Atividade Física Total em METs*min/sem, SB = Tempo gasto em posição sentada (sedentarismo) em $\mathrm{min} / \mathrm{sem}, \mathrm{IMC}=$ Índice de Massa Corpórea, Depressão $=$ escore de intensidade de depressão do questionário Beck. . . . . . . . . . . . . . . . . . . 23

4.3 Dados hipotéticos de SNPs de $\mathbf{n}=\mathbf{6}$ indivíduos do banco de dados. FID = Identificação da família, IID = Identificação do indivíduo, PAT = Identificação do pai, MAT $=$ Identificação da mãe, SEX $=$ Sexo, rs8192678 = SNP no gene MCT-1, rs1049434 = SNP no gene PPARGC1A, rs1815739 = SNP no gene ACTN3.

4.4 Dados hipotéticos de CNVs de $\mathbf{n}=\mathbf{6}$ indivíduos do banco de dados. FID = Identificação da família, IID = Identificação do indivíduo, PAT = Identificação do pai, MAT $=$ Identificação da mãe, SEX $=$ Sexo, celfile $=$ Arquivo celfile dos dados de SNP-Array, CNV = Identificação do CNV estimado através de dados de SNPs, Tamanho $=$ Tamanho do CNV $(\mathrm{em}$ bp $)$, Estado $=$ Estado utilizado na Cadeia de Markov correspondente ao número de cópias, Cópias = Número de cópias do CNV. . 24

4.5 Frequências absolutas para homens, mulheres e total de invivíduos em 0 e no intervalo 1-7 dias da semana para cada perfil de atividade física, com suas respectivas razões de chance. . . . . . . . . . . . . 26

4.6 Estatísticas descritivas das variáveis e covariáveis avaliadas no presente estudo para uma amostra de 760 indivíduos. . . . . . . . . . . . . . . . . . . 30

4.7 Estimativas de correlação entre covariáveis para indivíduos não independentes. $\rho T$, $\rho g$, e $\rho$ e correspondem às estimativas de correlação total, genética e ambiental, respectivamente. . . . . . . . . . . . . . . . . . . . 32

4.8 p-valores das covariáveis significativas para cada fenótipo no ajuste do modelo poligênico . . . . . . . . . . . . . . . . . . . 33 
4.9 Seleção de covariáveis e estimativas de herdabilidades para os fenótipos de atividade física coletados pelo IPAQ-SF. SexI $=$ Idade, $_{\text {idade }}^{2}$, sexo e seus efeitos de interação, IMC = Índice de Massa Corpórea, Cint $=$ Circunferência da cintura, Pesc $=$ Circunferência do pescoço. ${ }^{*}=$ p-valor da $\mathrm{h}^{2}<0,05 . \diamond=$ p-valor da covariável $<0,05 . \otimes=$ Modelo mal ajustado devido a curtose residual elevada. . . . 34

4.10 Herdabilidade estratificada pelo sexo para Mulheres (M) e Homens (H). mod1 corresponde ao modelo sem estratificação, mod2 ao com heterogeneidade em pelo menos um dos componentes de variância, mod3 ao com heterogeneidade apenas no componente ambiental e mod4 ao com apenas no genético. $\diamond$ Modelo sem estratificação. * p-valor do LRT das comparações mod1-2, 1-3 e 1-4 < 0,05, presentes nas

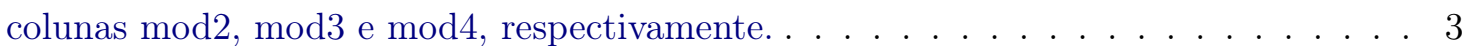

4.11 Resultados finais dos ajustes e seleção de modelos específicos aos fenótipos de atividade física e sedentarismo. $\mathbf{h}^{2} \mathbf{m}=$ mulheres, $\mathbf{h}^{2} \mathbf{h}=$ homens, $\sigma=$ raiz quadrada do componente de variância. . . . . . . . . . . . . . . . . 37

4.12 Variação da herdabilidade após inclusão das covariáveis IMC e Fumo em

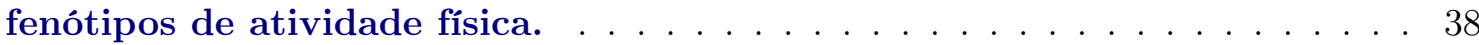

4.13 Os 20 SNPs com os menores p-valores nos testes de associação com invAFT 43

4.14 Os 20 SNPs com os menores p-valores nos testes de associação com invWK 43

4.15 Os 20 SNPs com os menores p-valores nos testes de associação com invMVPA 44

4.16 Os 20 SNPs com os menores p-valores nos testes de associação com invSB 44

4.17 Os $20 \mathrm{CNVs}$ (covariável categórica) com os menores $p$-valores nos testes de associação com invAFT MET . . . . . . . . . . . . . . . . . . 47

4.18 Os 20 CNVs (covariável categórica) com os menores $p$-valores nos testes de associação com invWK MET. . . . . . . . . . . . . . . . . . . . 48

4.19 Os 20 CNVs (covariável categórica) com os menores $p$-valores nos testes de associação com invMVPA MET.

4.20 Os 20 CNVs (covariável categórica) com os menores $p$-valores nos testes de associação com invSB.

4.21 Os 20 CNVs (covariável dicotômica) com os menores $p$-valores nos testes de associação com invAFT MET.

4.22 Os 20 CNVs (covariável dicotômica) com os menores $p$-valores nos testes de associação com invWK MET.

4.23 Os 20 CNVs (covariável dicotômica) com os menores $p$-valores nos testes de associação com invMVPA MET.

4.24 Os 20 CNVs (covariável dicotômica) com os menores $p$-valores nos testes de associação com invSB.

B.1 Seleção inicial forward. Herdabilidades com modelos em comum para os fenótipos de atividade física coletados pelo IPAQ-SF. ${ }^{*}=$ p-valor da $h^{2}<0,05 \ldots \ldots \ldots . .662$

C.1 Dicionário de Variáveis . . . . . . . . . . . . . . . . . . . . 63

E.1 Os $20 \mathrm{CNVs}$ (covariável categórica) com os menores $p$-valores nos testes de associação com log AFT MET. 
E.2 Os 20 CNVs (covariável categórica) com os menores $p$-valores nos testes de associação com log WK MET. . . . . . . . . . . . . . . . 68

E.3 Os 20 CNVs (covariável categórica) com os menores $p$-valores nos testes

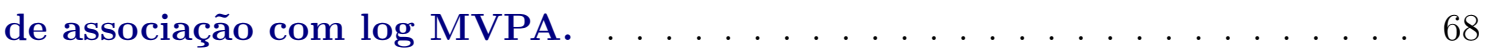

E.4 Os 20 CNVs (covariável categórica) com os menores $p$-valores nos testes de associação com log SB . . . . . . . . . . . . . . . . . . . . . 69

E.5 Os 20 SNPs com os menores p-valores nos testes de associação com lo-

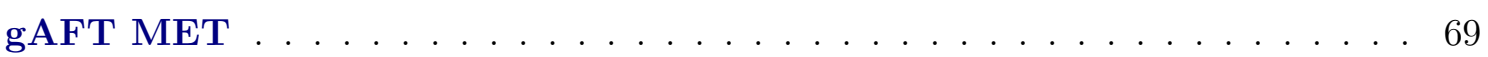

E.6 Os 20 SNPs com os menores p-valores nos testes de associação com logWK

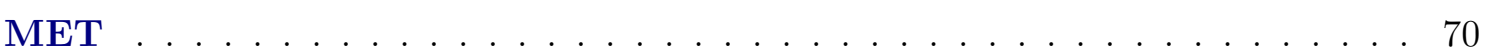

E.7 Os 20 SNPs com os menores p-valores nos testes de associação com logMVPA

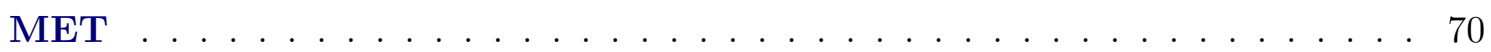

E.8 Os 20 SNPs com os menores p-valores nos testes de associação com logSB 71

F.1 SNPs candidatos associados a invSB sob o critério de $10^{-5} \ldots \ldots \ldots$. . . . . . 72 


\section{Capítulo 1}

\section{Introdução}

Tendo como marco o sequenciamento do genoma humano em 2001, o advento das tecnologias de sequenciamento de DNA e sua revolução nas ciências da Computação, Biologia Molecular e Estatística estabeleceu a Era das Ômicas, na qual são geradas rotineiramente uma quantidade imensa e sem precedentes de informacões genômicas, transcriptômicas e proteômicas, entre outras [Venter et al., 2001]. Por conta disso, atualmente a Genética se estende anos-luz para além dos trabalhos clássicos de Mendel, cujo estudo se restringia a padrões de herança e fenótipos determinados por um único gene, derrubando antigos conceitos (como o 'para cada gene existe uma proteína') e construindo novas teorias [Nelson e Cox, 2017]. O patamar ao qual pesquisas nessas áreas chegaram é tão elevado, que hoje é possível, dentre as mais diversas aplicações, editar e clonar genes de forma altamente rápida e precisa, realizar o diagnóstico pré-natal de anormalidades e desordens genéticas, e fazer o mapeamento gênico de inúmeros fenótipos e doenças complexas [Kim et al., 2017, Ran et al., 2013]. Os intensos avanços tecnológicos de obtenção, processamento e análise de dados ômicos têm contribuído para uma melhor compreensão de dezenas de doenças como Alzheimer, alergias, anemia falciforme, anormalidades cromossômicas, dentre inúmeras outras, ajudando, consequentemente, em seu diagnóstico, tratamento e prevenção [Dai et al., 2018, de Klein et al., 1982, Schechter, 2008, Tamari et al., 2013].

A concepção de que doenças e fenótipos complexos não são influenciados apenas por um único gene, mas sim por uma rede altamente estruturada envolvendo múltiplos genes e fatores ambientais é fundamental para compreender como esses fenótipos e doenças se desenvolvem, se estabelecem e afetam a saúde humana. Para lidar com esses questionamentos, a Genética tem expandido seu foco para uma abordagem mais ampla e integrada: desde os Estudos de Associação Genômica Ampla (GWAS, do inglês Genome Wide Association Studies), passando pelos sequenciamentos de nova 
geração e atingindo o estado da arte com os estudos multiômicos. No caso particular dos GWAS, os estudos atuais objetivam esclarecer a contribuição de diferentes tipos de variações moleculares sobre os fenótipos complexos, analisando a associação entre centenas a milhões de variantes genéticas e essas características [Hirschhorn e Daly, 2005, McCarthy et al., 2008]. Nesses estudos, a definição dos fenótipos tem sido considerada de forma bastante ampla, envolvendo desde variáveis como altura, peso, glicemia, até variáveis obtidas a partir de exames de imagens (como ressonância magnética, ultrassonografia, tomografia computadorizada, etc.) e dados de questionários (como construção de escalas de dor, qualidade de vida, depressão, desempenho físico, etc.), dentre outros, e mesmo fenótipos multivariados [Gourraud et al., 2013, Halper-Stromberg et al., 2017]. Em relação às unidades básicas de variabilidade genética, as mais comumente analisadas nessas investigações são os polimorfismos de nucleotídeo único (SNPs, do inglês Single Nucleotide Polymorphism), que são alterações em um único par de bases no DNA presentes em pelo menos $1 \%$ da população [Foulkes, 2009]. Os marcadores SNPs foram precedidos pelos microssatélites Ball et al. [2010], que são mais raros e bem maiores em pares de bases. Atualmente, os SNPs, que em geral têm efeitos pequenos, vêm sendo analisados conjuntamente (formando haplótipos), bem como em conjunto com outros tipos de marcadores como as variações no número de cópias de fragmentos de DNA (CNVs, do inglês Copy Number Variation), para explicar toda a informação herdável de um fenótipo.

Os SNPs estão envolvidos no surgimento de muitas doenças assim como em fenótipos gerais como altura, cor de cabelo e olhos, pigmentação da pele, plumagem, tipo de hemoglobina, entre outros [de Araújo Lima et al., 2015, Schechter, 2008]. Uma vez que eles contribuem para parte da variação fenotípica entre indivíduos e populações e que têm sido implicados na determinação dos mais variados fenótipos complexos, é possível que essas variantes genéticas estejam relacionadas com o engajamento em atividade física $(\mathrm{AF})$ e com a performance atlética. Nas últimas três décadas, as pesquisas com indivíduos sedentários e atletas de diferentes modalidades têm indicado associações desses polimorfismos com resistência cardiovascular, força, transporte de lactato, dentre outros fenótipos de papel importante nessas atividades [Almeida et al., 2012, Cupeiro et al., 2012, Papadimitriou et al., 2016, Popadic Gacesa et al., 2012]. O gene ACTN3 codifica uma proteína muscular , $\alpha$ - actinina 3, que promove a estabilidade da faixa $\mathrm{Z}$ das fibras musculares, sendo, consequentemente, relevante em atividades físicas que demandam movimentos explosivos e de curta duração. No polimorfismo mais comumente descrito para esse gene, a mudança em uma base nitrogenada $\mathrm{C}$ para $\mathrm{T}$ gera a substituição do aminoácido arginina para um códon de parada prematuro na posição 577, impedindo a produção do polipeptídeo [Maffulli et al., 2013]. Como consequência desse polimorfismo, ocorre redução da força de preensão palmar, peso muscular e corporal, diminuição no 
diâmetro das fibras musculares tipo 2B e mudança na predominância metabólica em modelos murinos, equanto em humanos observa-se a redução da força de preensão manual e velocidade na prova de corrida de 200m [MacArthur et al., 2008, Papadimitriou et al., 2016, Willems et al., 2017]. Além disso, o mapeamento de genes envolvidos na atividade física indica que indivíduos com o genótipo XX do gene ACTN3 possuem uma resistência ou endurance maior e portanto uma performance melhor em esportes aeróbicos como corrida de longa distância, ao contrário dos detentores do fenótipo RR, que apresentam uma maior explosão de força em esportes de alta intensidade, como corridas de curta distância [Maffulli et al., 2013]. Em contra partida, a ocorrência de indivíduos com uma cópia do alelo R é mais elevada em fisiculturistas de elite, levantadores de peso e em atletas de força no nível universitário que no grupo sedentário, o que demonstra o papel desse alelo no fenótipo de força [Roth et al., 2008]. Recentemente, assim como nesse estudo, uma maior prevalência do genótipo com alelos $\mathrm{R}$ foi encontrada em jogadores de futebol profissionais [Galeandro et al., 2017].

A variabilidade de características relacionadas à atividade física e, portanto, envolvidas no movimento humano, é de fundamental importância para a adaptação ao ambiente. Isso pode ser facilmente percebido através de nossa ancestralidade, voltando às origens do bipedalismo. Para que possamos permanecer numa posição vertical e lidar com as perturbações biomecânicas sobre nossos corpos, temos que adaptar nosso centro de equilíbrio constantemente por meio de mudanças na ativação neuromuscular [Nashner, 1976, Xiao e Fu, 2016]. Além disso, através de processos evolutivos, nossos primeiros ancestrais desenvolveram estratégias de caça e fuga de seus predadores. Tais habilidades requerem não apenas a ativação de músculos específicos com a quantidade adequada de força, mas também um refinamento cognitivo aliado a adaptações cardiovasculares, bioenergéticas e termoregulatórias de forma a executar essas tarefas de maneira eficiente [Chagdes et al., 2013, Dumas et al., 2007].

A importância da atividade física para nossa espécie não reside apenas em sua história evolutiva, mas também no efeito protetor contra muitos problemas de saúde. Por exemplo, Ahmad et al. [2013], em uma meta-análise com indivíduos de ancestralidade européia, mostraram que níveis de atividade física exercem um efeito protetor contra obesidade em coortes norte americanas. A existência de um componente genético subjacente que estimule o engajar e a performance física responsável por esse efeito protetor é uma hipótese que desperta bastante curiosidade e que está ainda em aberto. Considerando que a variação genética em múltiplas etnias e países se manifesta em suas diferenças fenotípicas e que o Brasil consiste numa população altamente miscigenada, compreender as influências genéticas em fenótipos relacionados à atividade física na população brasileira ajudará na prevenção e tratamento de muitas doenças e injúrias, além de possibilitar uma me- 
lhor e mais eficaz identificação e orientação de talentos em modalidades esportivas. Apesar de os SNPs estarem fortemente envolvidos na manifestação de diferenças fenotípicas e serem bastante estudados na literatura, pouco tem sido feito para avaliar o papel de outras variantes genéticas nessa variabilidade. Estudos recentes indicam que grande parte dessas diferenças fenotípicas pode ser explicada por variações no número de cópias de porções de comprimento variado da sequência de DNA, os CNVs [Iafrate et al., 2004]. De acordo com a base de dados de Variantes Estruturais, entre 2009 e 2015, o número de CNVs a ela adicionados aumentou 14 vezes e seu crescimento apresenta uma tendência exponencial [MacDonald et al., 2014]. Apesar do número de CNV identificados até 2018 compreender apenas 1\% da quantidade de SNPs, tais variantes estruturais cobrem uma extensa parte do genoma humano, aproximadamente 30\% [Zhang et al., 2009]( NCBI, 2018). A importância dos CNVs para a espécie humana se estende além de sua cobertura genômica: eles desempenham um papel primordial na história evolutiva do Homo sapiens. Comparando o genoma de 10 espécies de primatas divergentes ao longo de 60 milhões de anos de evolução, DUMAS et al. (2007) identificaram assinaturas moleculares humanas associadas à capacidade termorregulatória e utilização de energia, as quais foram primordiais para a resistência durante a corrida. Além disso, os CNVs têm sido associados com diversos outros fenótipos e doenças complexas, como as patogenias neurodegenerativas esclerose lateral amiotrófica (ELA) e atrofia muscular espinhal, as quais afetam também o sistema muscular [Butchbach, 2016, Wain et al., 2009]. Apesar do papel altamente relevante dos CNVs nos aspectos acima citados e suas potenciais aplicações no bem-estar, na medicina e prática esportivas, pouquíssimo tem sido feito para investigar a influência e relevância dos CNVs na variabilidade de características relacionadas ao esporte e à atividade física. Uma vez que o Brasil é um país de referência em alguns esportes e que a prática de atividade física tem sido cada vez mais estimulada em academias, eventos 'fitness' e por iniciativas governamentais, estudar o papel dessas variantes genéticas nesses fenótipos se configura de extrema valia [Amorim et al., 2013, da Saúde. Secretaria de Políticas de Saúde, 2002].

No cenário brasileiro, alguns esforços já vêm sendo empregados para se identificar marcadores relacionados à atividade física, com enfoque em atividade esportiva. O projeto Atletas do Futuro, por exemplo, iniciado em 2011, desenvolveu um painel de 4 marcadores de polimorfismos nos genes ACTN3, ECA, BRDK2 e AGT, cuja relação com atividade física tem sido amplamente evidenciada na literatura [Maffulli et al., 2013, Papadimitriou et al., 2016, Willems et al., 2017]. Recentemente, o grupo Atletas do Futuro investigou a relação desses polimorfismos na posição em quadra de jogadores que disputaram o campeonato brasileiro de basketball e encontrou associação para alguns dos genótipos e o perfil de atividade física nas posições em jogo [Lima et al., 2015]. Adicionalmente, 
esse grupo de pesquisadores têm avaliado outras modalidades esportivas como o judô, para a qual foi encontrada associação entre ACTN3 e o perfil de competição (elite, internacional, nacional) e o futebol, nos times do Palmeiras e Santos, para o qual foi encontrada associação entre ACTN3, o perfil de competição e testes de performance (resultados ainda não reportados na literatura). Atualmente potenciais novos marcadores estão sendo também avaliados.

Além do trabalho desenvolvido pelo grupo acima mencionado, existe um projeto colaborativo brasileiro no qual o presente estudo se insere, Corações de Baependi, um estudo epidemiológico de estrutura familiar realizado no município de Baependi, MG. Essa pequena comunidade tradicional localizada numa área de proteção ambiental, no sul do estado, é altamente miscigenada e sofreu pouquíssima migração, o que a torna apropriada para o estudo de padrões de herança na população brasileira [de Oliveira et al., 2008, Egan et al., 2016]. Esse estudo, que possui caráter longitudinal, começou entre Dezembro de 2005 e Janeiro de 2006 e já passa pelo terceiro corte transversal (2006, 2012 e 2018), ou seja, encontra-se no terceiro momento ou onda de coleta.

Quanto à ampla gama de variáveis coletadas na amostra de famílias de Baependi, encontram-se disponíveis dados de genoma e transcriptoma, características demográficas, psicossociais, comportamentais, cardiovasculares, antropométricas e, no contexto do presente estudo, medidas de níveis de atividade física. De acordo com estimativas iniciais feitas por Horimoto et al. [2011] com base nos dados da primeira onda do Projeto Corações de Baependi, existe um componente genético considerável nos fenótipos relacionados à atividade física. Este estudo encontrou estimativas da herdabilidade de fenótipos associados à atividade física na população brasileira variando de $9 \%$ a $35 \%$, em concordância com outros estudos, e evidência significante de heterogeneidade dos componentes de variância de acordo com o sexo do indivíduo. Estes resultados abrem portas para os seguintes questionamentos e investigações: 1- Quais específicas variantes genéticas explicam essa herdabilidade e estão associadas a esses fenótipos? 2- Quais são os papéis biológicos dessas variantes e como elas influenciam na variação fenotípica dos indivíduos de Baependi e, por consequência, na população brasileira? 3- É possível aplicar esse conhecimento de forma personalizada (Educação Física e Esportiva de Precisão) visando a preparar rotinas de treinamento mais apropriadas para a manutenção da saúde e bem-estar dos indivíduos, bem como para o direcionamento mais adequado de jovens a atividades esportivas? Nesse contexto, considerando que o Projeto Corações de Baependi é um estudo brasileiro pioneiro a considerar a estrutura familiar com uma riqueza de informações moleculares e fenotípicas única, nosso objetivo neste trabalho é investigar o papel de variantes genéticas, em particular SNPs e CNVs, na manifestação de comportamentos sedentários e no engajar em atividade física leve, moderada e intensa, verificando a possível existência de hete- 
rogeneidades relativamente ao sexo do indivíduo, assim como de outras covariáveis como a idade, índice de massa corpórea e escore de depressão.

\subsection{Objetivos}

\subsubsection{Geral}

O objetivo principal deste estudo é estimar o quanto da variabilidade de comportamentos sedentários e do engajar em atividade física leve, moderada e intensa é decorrente de efeitos genéticos bem como identificar variantes genéticas, SNPs e CNVs, com influência nesses fenótipos com base nos dados do Projeto Corações de Baependi, MG.

\subsubsection{Específicos}

- Obter estimativas da herdabilidade de fenótipos associados à atividade física: determinar o quanto da variabilidade dessas características é explicada por componentes genéticos.

- Avaliar a heterogeneidade dos componentes de variância genéticos e ambientais nas estimativas de herdabilidade especificamente devido ao sexo dos indivíduos.

- Mapear geneticamente esses fenótipos por meio de GWAS, identificando quais SNPs e CNVs estão a eles associados.

- Identificar os possíveis mecanismos moleculares subjacentes pelos quais essas variantes influenciam fenótipos relacionados à atividade física. 


\section{Capítulo 2}

\section{Atividade Física e Variantes Genéticas}

Como mencionado previamente na Introdução (1), a importância do movimento humano e sua plasticidade ou adaptação ao ambiente pode ser evidenciada primeiramente por meio de nossa ancestralidade, voltando às origens do bipedalismo. A manutenção de uma postura ereta, a qual requer que o corpo seja capaz de lidar com diferentes perturbações biomecânicas, necessita de adaptações constantes no nosso centro de equilíbrio por meio de mudanças na ativação neuromuscular [Nashner, 1976, Xiao e Fu, 2016]. Além disso, nossos primeiros ancestrais desenvolveram estratégias de caça e fuga de seus predadores ao longo de sua história evolutiva. Tais habilidades requerem não apenas o recrutamento de músculos específicos com a quantidade adequada de força, mas também um refinamento cognitivo aliado a adaptações cardiovasculares, bioenergéticas e termorregulatórias de forma a desempenhar essas tarefas eficientemente [Chagdes et al., 2013, Dumas et al., 2007].

Além de sua relevância na história evolutiva de nossa espécie, a atividade física (AF) é capaz de reduzir múltiplas morbidades e proteger contra diversos problemas de saúde, sendo essencial para a manutenção da qualidade de vida. No que se refere às doenças cardiovasculares, que são umas das principais causas de morte no mundo, diversos benefícios têm sido apontados. Em um estudo feito numa pequena amostra da população norueguesa, que sofreu parada cardíaca pósinfarto, Wisløff et al. [2007] submeteram esses pacientes a um programa de exercícios aeróbicos, mostrando 35\% de melhoria na função sistólica, 32\% de aumento no volume máximo de consumo de oxigênio $\left(\mathrm{VO}^{2}\right)$ e uma redução no diâmetro ventricular esquerdo. O impacto positivo desse tipo de exercício é evidenciado também numa melhoria nos perfis lipídicos, constatado pela redução no IMC e aumento nos níveis de HDL-C [Halbert et al., 1999]. Sattelmair et al. [2011], numa metanálise de 33 estudos conduzidos entre 1995 e 2011, identificaram um risco 14\% menor de doenças cardíacas coronarianas em indivíduos praticantes de $150 \mathrm{~min} /$ semana de atividade física de lazer moderada- 
intensa. Essa redução foi ainda mais acentuada em praticantes de $300 \mathrm{~min} /$ semana. Vale salientar que os benefícios da atividade física tem sido também demonstrados em modelos animais, como em ratos idosos, nos quais observou-se melhoria no inotropismo do miocárdio ${ }^{1}$, prevenção de fibrose e alteração na expressão de proteínas manuseadoras de cálcio, o qual é primordial para os mecanismos de contração muscular [Yoshizaki et al., 2017].

Ainda no contexto de doenças cardíacas e fatores de risco a ela associados, Ahmad et al. [2013], em uma meta-análise com indivíduos de ancestralidade européia, mostraram que níveis de atividade física exercem um efeito protetor contra obesidade em coortes norte americanas. De acordo com a OMS, a obesidade, a qual acometeu aproximadamente 13\% da população mundial em 2016, é um dos principais fatores de risco para o diabetes, doenças cardiovasculares, alguns tipos de câncer bem como desordens músculo-esqueléticas [WHO, 2018]. Além disso, em um estudo prospectivo feito no Reino Unido, Celis-Morales et al. [2018] mostraram que, quanto menor a força de preensão manual, maior a incidência e mortalidade por doenças cardiovasculares, indicando que essa medida pode ser inserida como mais uma forma de avaliação do risco para essas enfermidades. Surpreendentemente, esses mesmos autores identificaram também maior incidência e mortalidade por todos os tipos de câncer e alguns subtipos, incluindo colorretal, pulmão e mama. Em concordância com esses pesquisadores, existem vários outros trabalhos mostrando também risco reduzido de câncer endometrial, de mama e cólon, dentre outros tumores, decorrente da prática de atividade física [Behrens et al., 2018, Friedenreich et al., 2010].

Quanto ao câncer de mama em específico, o qual é o tipo de tumor mais comum diagnosticado em mulheres, existe um forte conjunto de evidências mostrando que o exercício físico tanto reduz o risco de desenvolvimento tumoral como melhora a prognose da doença. Buss e Dachs [2018] propuseram alguns mecanismos moleculares para explicar os efeitos fisiológicos benéficos do exercício no câncer de mama, os quais envolvem principalmente fatores de crescimento como IGF-1, adipocinas como a leptina, dentre outras quimiocinas. Uma vez liberadas durante a prática do exercício físico, especialmente pelos miócitos ${ }^{2}$, essas moléculas exercem efeitos moduladores, evitando assim a proliferação desenfreada das células do tecido mamário. Mecanismos semelhantes provavelmente atuam de forma parecida na prevenção e melhora de outros tipos tumorais, embora os aspectos específicos a cada tumor e seus subtipos ainda precisem de muita pesquisa e elucidação.

Os efeitos benéficos da atividade física estendem-se também para a manutenção e melhora

\footnotetext{
${ }^{1}$ Vulgo 'contratilidade miocardial', o inotropismo pode ser acessado por meio da medição de parâmetros miocardiais dos músculos papilares, presentes no ventrículo esquerdo [Yoshizaki et al., 2017].

${ }^{2}$ Os miócitos, também chamados genericamente de células musculares ou fibras musculares, são as unidades de contração do tecido muscular esquelético [Junqueira et al., 2013].
} 
do bem-estar e saúde mentais. Por conta da liberação de endorfinas, a atividade física promove sensações de prazer sendo portanto indicada para a redução do estresse e combate à depressão [Chekroud et al., 2018]. Além disso, em faixas etárias mais avançadas, alguns estudos tem mostrado que AF pode reduzir o risco de desenvolvimento de demência, bem como de outras desordens cognitivas, como a doença de Parkinson [Fenesi et al., 2017]. Em relação a essa doença, foi demonstrada tanto preservação como melhoria na função cognitiva global, na velocidade de processamento, flexibilidade mental e atenção sustentada decorrente de diversos programas de exercício, tais como esteira e aulas de tango [da Silva et al., 2018]. Os efeitos positivos da atividade física sobre o sistema nervoso são mediados, pelo menos em parte, por alterações estruturais e moleculares nos neurônios e outras células nervosas. Van Praag et al. [1999], por exemplo, mostraram aumento na neurogênese em estruturas cerebrais relacionadas à memória e aprendizado, como o giro denteado no hipocampo. Mais recentemente, Lourenco et al. [2019] reportaram que os efeitos benéficos da atividade física sobre a plasticidade sináptica são mediados pela Irisina, uma miocina cuja liberação é induzida pelo exercício, a qual tem sido implicada no retardo do desenvolvimento do Alzheimer. As implicações desse estudo são extremamente relevantes, pois poderiam ajudar na prevenção e tratamento dessa doença tão comum em indivíduos de idade mais avançada.

Nesse contexto, à medida que a população passa pelo processo de envelhecimento e se aproxima da terceira idade, tende também a ficar mais sedentária e a sofrer diversos efeitos do processo natural de envelhecimento, o que compromete sua qualidade de vida. O exercício físico, de forma geral, é capaz de contrabalancear esses efeitos, conservando a longevidade em múltiplos aspectos. Por exemplo, de acordo com da Silva et al. [2018], a redução da densidade mineral dos ossos e enfraquecimento dos músculos para-espinhais é comum em adultos mais velhos, e tende a levar a quedas com consequentes fraturas osteoporóticas. Exercícios de fortalecimento e resistência com enfoque nos extensores da coluna podem portanto ajudar no controle da osteoporose, especialmente em mulheres pós-menopausa [da Silva et al., 2018, Sinaki, 2012]. Ainda, a atividade física é altamente recomendada para os idosos por melhorar também sua funcionalidade e tolerância ao exercício, além de qualidade de vida [Floegel e Perez, 2016].

Considerando todos os benefícios na prevenção, controle e tratamento de doenças e manutenção da qualidade de vida provenientes da atividade física, identificar os componentes genéticos subjacentes que possam estimular o engajar e a performance física, responsáveis por essa vasta gama de efeitos protetores é de suma importância. Não surpreendentemente, esforços para desvendar a interface entre a genética e a atividade física geral e esportiva têm florescido nos últimos 20 anos.

No contexto mais específico de atividade física como lazer e esporte, um grande número de pes- 
quisas tanto com indíviduos sedentários como com atletas de diferentes modalidades esportivas têm indicado associações de diversas variantes genéticas com fenótipos relacionados à atividade física, como resistência cardiovascular e força muscular [Almeida et al., 2012, Papadimitriou et al., 2016, Popadic Gacesa et al., 2012]. Por exemplo, a deleção de um fragmento de 9bp no gene B2BRK, que codifica um potente vasodilatador, está associada com um aumento na hipertrofia do músculo tríceps braquial, bastante recrutado em exercícios de levantamento de peso como o supino, movimentos de remada e ações do cotidiano como fechar janelas, dentre outras [Popadic Gacesa et al., 2012].

Outros dois genes importantes apontados pela literatura são os da ECA e AGT, os quais codificam as proteínas enzima conversora de angiotensina e angiotensinogênio, respectivamente. Essas proteínas são essenciais para a regulação da pressão sanguínea, a qual é sabidamente alterada e modulada durante o exercício. Poucos anos após seu descobrimento em 1990, a inserção de 287 pb no íntron 16 do gene codificador da ECA foi o primeiro polimorfismo associado à atividade física [Montgomery et al., 1997, Rigat et al., 1990]. Em um trabalho pioneiro, Montgomery et al. [1997] estudaram a relação entre esse polimorfismo e a hipertrofia cardíaca induzida por um programa de treinamento físico de 10 semanas, tendo observado que indivíduos com dupla deleção do fragmento de 287 pb (genótipo DD) apresentavam ventrículos esquerdos maiores que os de genótipo II. Esse crescimento ventricular é explicado pelo aumento dos níveis plasmáticos de ECA circulante como consequência dessa deleção.

Assim como a ECA, o AGT faz parte do sistema Renina-angiotensina-aldosterona, um conjunto de mecanismos primordial não só para a regulação da pressão sanguínea mas como do balanço de água e sais minerais. O AGT, produzido no fígado, é clivado pela enzima Renina na ligação peptídica entre os resíduos de leucina e valina do AGT, liberando o decapeptídeo Angiotensina I, que por sua vez é convertido em Angiotensina II pela ECA [De Mello Costa e Slocombe, 2012]. Alguns polimorfismos de perda de sentido (missense), principalmente o rs699 e rs4762, também foram identificados no gene codificador do AGT e têm sido alvo de investigações no contexto do diabetes, pressão sanguínea, sobrepeso, dentre outros fatores de risco cardiometabólicos comumente associados ao exercício físico[Makuc et al., 2017, Muñoz et al., 2017, Rauramaa et al., 2002].

Diferentemente das inserções e deleções presentes na anteriormente citada ECA, os polimorfismos no AGT são variantes comuns conhecidas como polimorfismos de nucleotídeo único (SNPs), os quais têm sido também bastante associados com fenótipos de atividade física. O gene ACTN3 por exemplo, cuja relevância nesses fenótipos tem sido amplamente demonstrada, codifica a proteína $\alpha$-actinina 3, que se liga aos filamentos de actina e promove a estabilidade da faixa $\mathrm{Z}$ das 
fibras musculares, sendo assim importante em exercícios que demandam movimentos explosivos e de curta duração. No polimorfismo R577X desse gene, a mudança em uma base nitrogenada C para T gera a substituição do aminoácido arginina para um códon de parada prematuro na posição 577, impedindo que a proteína seja produzida [MacArthur et al., 2008, Maffulli et al., 2013].

As consequências desse polimorfismo se manifestam das mais diversas formas: em modelos murínicos, redução na força de preensão palmar, peso muscular e corporal, diminuição no diâmetro das fibras musculares tipo $2 \mathrm{X}^{3}$ e mudança na predominância metabólica, em humanos, redução na força de preensão manual e velocidade na prova de corrida de 200m [MacArthur et al., 2008, Papadimitriou et al., 2016, Willems et al., 2017]. Apesar das alterações metabólicas e histológicas decorrentes do SNP R577X e da frequência de indivíduos com uma cópia do alelo R ser mais elevada em fisiculturistas de elite, levantadores de peso e atletas de força a nível universitário, o papel desse gene em esportes de resistência não está estabelecido, levantando questões quanto ao modelo de expressão desse gene bem como à possível interação desse gene com outros polimorfismos [Papadimitriou et al., 2018, Roth et al., 2008].

Devido à grande diminuição no custo financeiro das técnicas de genotipagem por microarranjo e mais atualmente, de sequenciamento do genoma inteiro, os estudos mais simples de associação entre um ou alguns poucos marcadores (estudos genes-candidato) e fenótipos relacionados à atividade física migraram para uma nova fase. Hoje em dia grande parte das investigações se inserem no contexto dos Estudos de Associação Genômica de Ampla Cobertura (GWAS). Esses estudos tem como objetivo analisar sequências de DNA ao longo de todo o genoma, buscando encontrar variantes genéticas que possam ser utilizadas como marcadores de doenças ou características não patogênicas, em, geralmente, um grande número de indivíduos [Bush e Moore, 2012]. Os GWAS são atualmente o estado da arte e desempenham um papel primordial, trazendo luz à arquitetura genética de diversas doenças bem como de diversos fenótipos. O primeiro GWAS a ser publicado, em 2002, ainda que com um $\mathrm{N}$ amostral inicial e uma cobertura genômica reduzida, identificou diversos SNPs funcionais associados à susceptibilidade ao infarto do miocárdio [Ikegawa, 2012, Ozaki et al., 2002]. Apenas três anos mais tarde, o fator do complemento $\mathrm{H}$ foi identificado como o principal fator de risco na degeneração macular relacionada à idade, impactando a prevenção e tratamento dessa doença [Haines et al., 2005]. Logo depois, o estudo Corações de Framingham foi pioneiro em realizar um GWAS que identificou diversos SNPs envolvidos na resposta à corrida em esteira, ou seja, à atividade física [Vasan et al., 2007]. Desde então, dezenas de SNPs têm sido associados a fenótipos

\footnotetext{
${ }^{3} \mathrm{~A}$ partir de 1994, as anteriormente chamadas fibras tipo 2B passaram a ser denominadas 2X, por conta da presença da cadeia pesada da miosina $\mathrm{X}$ em humanos, a qual difere da B em camundongos. Entretanto, alguns trabalhos ainda utilizam o nome 2B ao se referir à 2X [Smerdu et al., 1994].
} 
relacionados tanto à atividade física de forma geral quanto à performance esportiva [Doherty et al., 2018, EBI, 2019].

A utilização dos GWAS para elucidar a relação gene-atividade física é também vantajosa por permitir a inclusão de outros tipos de variantes genéticas. Os CNVs( do inglês Copy Number Variation) são variações no número de cópias de segmentos do DNA de tamanho variado e podem ser inferidos por meio da utilização de algoritmos sofisticados, que processam os dados de SNPs [Wang et al., 2007]. Há algumas evidências de que estas variantes estruturais também possuem relação com fenótipos relacionados à atividade física, como demonstrado por Dumas et al. [2007], que encontraram um número elevado de cópias do gene $A Q P$ r, apontado como primordial para o surgimento da corrida de resistência no Homo sapiens. Recentemente, essas variantes têm sido ainda incluídas nos GWAS, fornecendo resultados intrigantes e inovadores. Em relação ao sistema neuromuscular, foi demonstrado o envolvimento de CNVs nos genes SNM1 e SNM2 com a Atrofia Muscular Espinhal, uma das principais causas genéticas de mortalidade infantil ao redor do mundo [Butchbach, 2016]. No que concerne a outras caracteristicas, estudos mostram o envolvimento de CNVs no fenótipo altura, como demonstrado em Macé et al. [2017] bem como num trabalho prévio de nosso grupo [Ciconelle, 2018]. Além disso, CNVs têm sido encontrados em genes de predisposição ao câncer de uma forma geral, bem como em alguns específicos como o hepatocelular e o de próstata [Innes et al., 2018, Sophonnithiprasert et al., 2019, Wu et al., 2018]. Por último, essas variantes tem sido também implicadas em doenças do sistema nervoso como Esclerose Lateral Amiotrófica (ELA), a esquizofrenia e desordem do espectro autista [Chen et al., 2017, Sekar et al., 2016, Wain et al., 2009].

Mesmo com a inclusão crescente dessas variantes nos GWAS, com o aumento de evidências associando-as a fenótipos gerais e condições patológicas e o interesse cada vez maior em se encontrar marcadores associados à atividade física para prevenção de lesões e melhora de performance atlética, pouquíssimo se tem feito para elucidar o papel dos CNVs nesses fenótipos particulares.

Assim, inserido no projeto Corações de Baependi - MG, o presente trabalho se destaca por seu pioneirismo em investigar, além dos SNPs, a associação dos CNVs e fenótipos de atividade física numa amostra da população brasileira, ao mesmo tempo em que considera a estratificação populacional em famílias, ou seja, utiliza as relações de parentesco entre os indivíduos nos modelos genéticos avaliados. 


\section{Capítulo 3}

\section{Material e Métodos}

\subsection{Dados de SNPs e CNVs}

No Projeto Corações de Baependi, as informações referentes aos SNPs foram adquiridas pelo Affymetrix Genome-Wide Human SNP Array 6.0, conhecido como Plataforma Affymetrics TM 6, a qual utiliza 1,8 milhões de marcadores genéticos que incluem SNPs e CNV probes [Affymetrix, 2017]. Essa plataforma utilizou o genoma de referência GRch37p.13, conhecido também como hg19. Quando do processamento, limpeza e análises de controle de qualidade dos dados da primeira onda de coleta do estudo, o número final de marcadores é de 843.039 SNPs genotipados para cerca de 1.700 indivíduos de 92 famílias [Ciconelle, 2018]. Entretanto, atualmente, considerando a segunda onda do estudo, dispõe-se de dados genotípicos de 2300 indivíduos. Em particular, os SNPs estão categorizados como 0 (= aa, homozigoto para o alelo mais comum), 1 (= Aa, heterozigoto) e 2 (= AA, homozigoto para o alelo menos frequente - MAF: minimum allele frequency). Considerando o alto nível de miscigenação que é esperado dos dados genômicos da população brasileira, foi realizada uma análise de componentes principais (ajustada para a estrutura de famílias) para obtenção de escores de ancestralidade global dos indivíduos de Baependi [De Andrade et al., 2015]. Estes componentes principais (em geral, os dois ou três primeiros) são usados para caracterizar a estrutura da população e devem ser usados nas análises de associação (GWAS) para controlar o efeito de confundimento (falsos positivos ou negativos) devido à estrutura da população [Bush e Moore, 2012].

Adicionalmente, através do processamento de 946.000 probes dessa plataforma, dados de 8.794 CNVs estão disponíveis para os indivíduos amostrados de Baependi [Ciconelle, 2018]. A chamada de CNVs a partir dos dados de SNPs foi realizada por meio do software APT e PennCNV, sendo, este último, uma ferramenta de software livre que implementa um modelo de cadeias ocultas de 
Markov (HMM) (do inglês Hidden Markov Model), seguindo o pipeline representado na Figura 3.1.

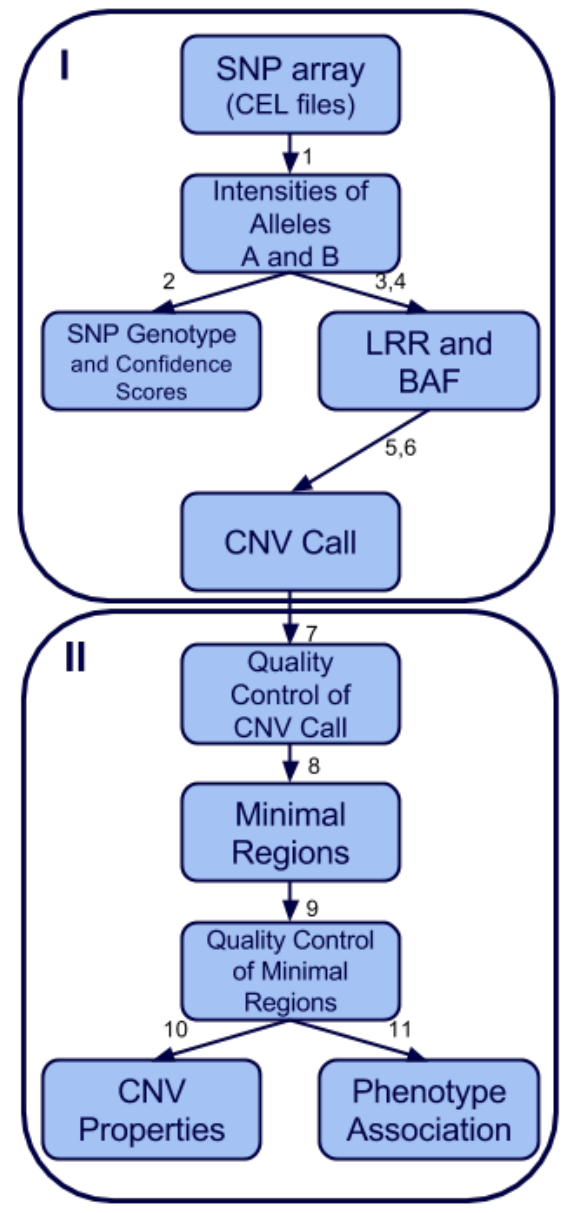

Figura 3.1: Pipeline do processamento de probes para chamada de CNVs. Retirado de Ciconelle [2018].

O uso do algoritmo PennCNV tem se mostrado especialmente apropriado quando utilizado em dados de famílias, uma vez que a utilização de informações familiares permite a resolução aumentada dessas variantes genéticas, ou seja, a identificação de CNVs de tamanhos menores (WANG et al., 2007). A categorização dos CNVs por esse algoritmo corresponde a cinco categorias dadas por: -2 (perdeu duas cópias do alelo), -1 (perdeu uma cópia do alelo), 0 (normal), 1 (ganhou uma cópia do alelo) e 2 (ganhou duas cópias do alelo). Nas análises de associação do presente estudo a serem descritas na seção 3.6, esses níveis foram recodificados para 0,1,2, 3 e 4, sendo 2 a categoria de referência utilizada. Adicionalmente, considerou-se a parametrização binária ou dicotômica em que o CNV é codificado apenas como normal (0) ou alterado (1), independentemente de ter ocorrido deleção/perda ou inserção/ganho. 


\subsection{O Projeto Corações de Baependi}

O Projeto Corações de Baependi, cujo planejamento amostral baseou-se nos dados do censo do IBGE de 2000, teve sua origem entre Dezembro de 2005 e Janeiro de 2006 numa pequena comunidade tradicional localizada na Área de Proteção Ambiental da Serra da Mantiqueira, no município de Baependi, ao sul de Minas Gerais (MG) (Figura 3.2). De acordo com dados do último censo do IBGE em 2010, o município de Baependi possui uma área de $750.554 \mathrm{~km}^{2}$ e uma população de 18.307 pessoas. Segundo as estimativas desse órgão, atualmente houve um pequeno crescimento para aproximadamente 19.094 habitantes. Por se localizar numa zona mais rural, a população baependiana tem hábitos mais campesinos, tendo o catolicismo como religião predominante. Suas principais atividades econômicas são a agricultura, especialmente no que se refere ao cultivo de café, a pecuária bovina, artesanato e turismo [de Andrade, 2011, IBGE, 2010].

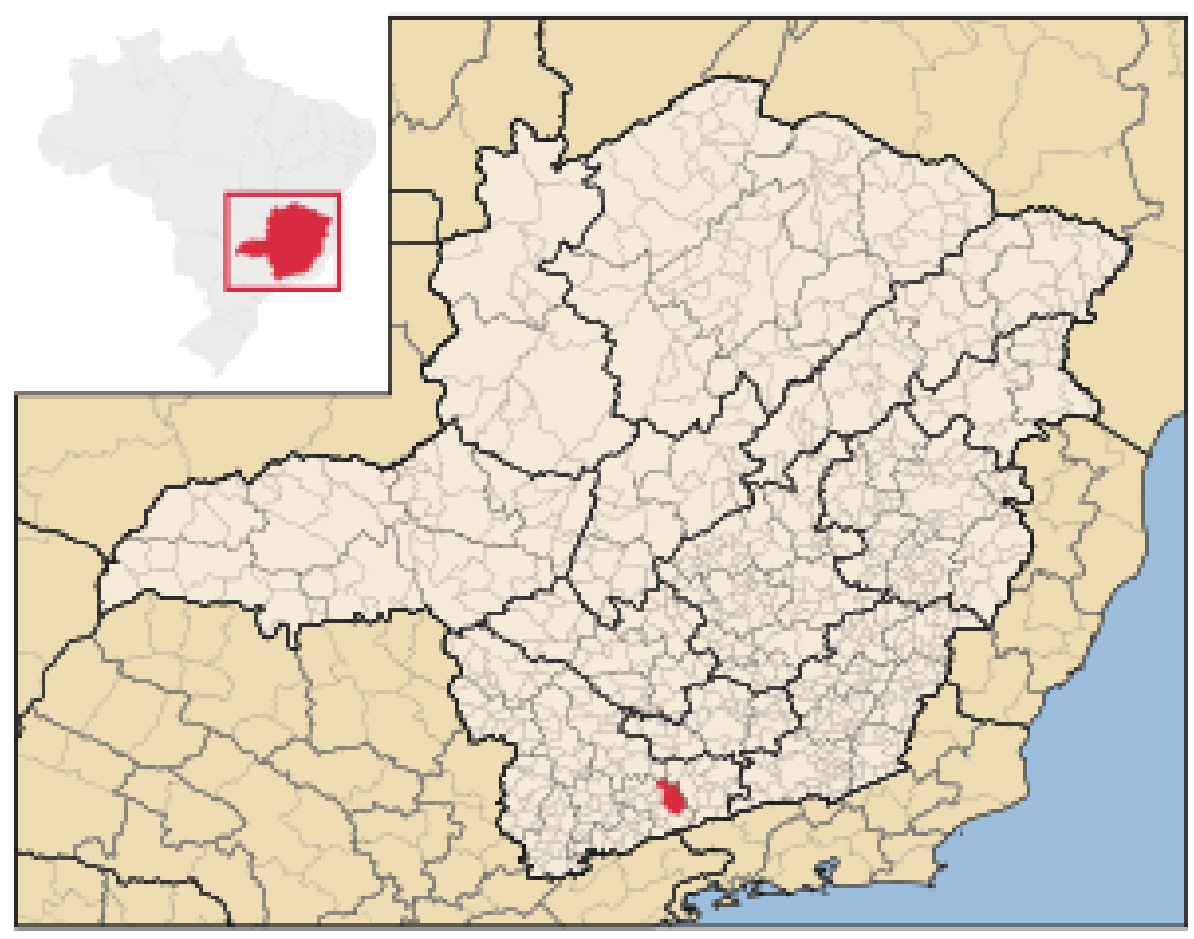

Figura 3.2: Mapa do município de Baependi-MG. Retirado de https://pt.wikipedia.org/wiki/Baependi/media/Ficheiro:MinasGerais_Municip_Baependi.svg

Antes do recrutamento dos indivíduos, o Projeto Corações de Baependi foi divulgado pelas autoridades provinciais, religiosas e municipais, em canais de TV e jornais locais, por rádio, médicos e ligação telefônica. Inicialmente o projeto focou em coletar informações referentes à saúde cardiovascular dos habitantes junto a dados genômicos, de forma a compreender a influência genética em tais fenótipos, para melhorar as estratégias de prevenção e combate a doenças cardiovasculares. Posteriormente, ele se estendeu bastante, passando a incluir dados de transcriptoma, variáveis nutricionais, psicossociais, antropométricas, de atividade física, dentre outras variáveis, coletadas 
principalmente por meio de questionários [Egan et al., 2016].

Uma vez que Corações de Baependi é um estudo observacional de estrutura familiar com um desenho longitudinal contendo dados fenotípicos e moleculares, nosso objetivo foi estimar a variação genética (herdabilidade) em fenótipos de atividade física e encontrar associações de variantes genéticas com esses traços coletados no segundo corte transversal. As informações de SNPs dos indivíduos participantes do projeto foram adquiridas pela Affymetrics TM 6.0, a qual utiliza aproximadamente 1,8 milhões de marcadores genéticos. Por estar no terceiro corte transversal, o projeto dispõe de informações genotípicas para aproximadamente 2300 indivíduos, entretanto, apenas 760 desses indivíduos, estruturados em 81 famílias, foram entrevistados para coleta das informações fenotípicas de interesse, a serem descritas na próxima seção. Assim, as análises de mapeamento gênico a serem descritas posteriormente foram feitas para esse conjunto de 760 indivíduos.

Através do processamento dos SNPs, dados de aproximadamente $8.794 \mathrm{CNVs}$, foram estimados em um dos trabalhos anteriores de nosso grupo e analisados quanto à sua associação com fenótipos como a altura [Ciconelle, 2018]. Utilizando dos marcadores SNPs e CNVs, estendemos o trabalho para o mapeamento de fenótipos da atividade física, delineados a seguir.

\subsection{Fenótipos da Atividade Física}

As informações de comportamento referente à atividade física foram coletadas através do Questionário Internacional de Atividade Física - versão curta (IPAQ-SF) (Apêndice A). Este instrumento foi reconhecido e validado em diversos países por meio da utilização de métricas de repetibilidade e comparação com outros intrumentos como o acelerômetro, sendo, portanto, bastante utilizado ao se estudar esses fenótipos [Bauman et al., 2009, Craig et al., 2003]. O perfil de atividade física foi delineado usando 3 dimensões: atividade física leve (caminhadas para o trabalho, casa, lazer ou como forma de exercício), moderada (atividades como natação, dança, ginástica aeróbica leve, serviços domésticos em casa, jardim, etc) e vigorosa (corrida, ginástica aeróbica, futebol, basquete, etc). Além disso, tempo diário sabático e semanal gasto em posições sentadas (comportamento sedentário), bem como tempo gasto semanalmente em atividade física foram avaliados no Projeto Corações de Baependi, sendo este último delineado em quatro fenótipos: AFT (atividade física total), WK (atividade física leve), MPA (atividade física moderada), VPA (atividade física vigorosa).

Seguindo as Recomendações de Análise e Processamento de Dados do IPAQ-SF, considerou-se como outliers os casos em que a soma total de WK, MPA e VPA excediam 960 minutos (16 horas), excluindo esses dados da análise. Ainda, variáveis que excediam 180 minutos dentro desses três 
perfis foram recodificadas para 180 minutos para permitir o máximo de 21 horas de atividade na semana. Afim de mensurar esses níveis de atividade física de forma mais concordante com o gasto de energia e, consequentemente, com sua relevância biológica, seguindo recomendações internacionais, utilizou-se valores de referência conhecidos como equivalentes metabólicos de tarefa $(\mathrm{MET})^{1}$ (do inglês, Metabolic Equivalent Task), específicos para cada um dos fenótipos delineados: MET = 3,3 para WK, 4 para MPA e 8 para VPA. Somando-se esses três fenótipos ponderados por METs, obtivemos então o tempo total de atividade física ponderada por MET, o fenótipo AFT MET, o qual é uma combinação linear dos demais. Dessa maneira, obtivemos variáveis quantitativas que são mais representativas do gasto energético/esforço empregado pelos indivíduos, o que permite uma estimativa mais fidedigna dos componentes genéticos subjacentes aos fenótipos. No caso particular do fenótipo comportamento sedentário (SB), não se utilizou conversão por MET, em conformidade com as recomendações do questionário.

\subsection{Modelos Estatísticos}

Considerando dados de famílias, os modelos empregados neste trabalho para as estimativas de herdabilidade de fenótipos quantitativos e associação com marcadores moleculares seguem os modelos lineares mistos, os quais têm sido amplamente aplicados na medicina, pecuária, oncologia, dentre outras áreas [Almasy e Blangero, 2010, 1998, Chu e Huang, 2017, de Andrade et al., 1999, 2002, Kachman e Stroup, 1994].

Esses modelos são bastante flexíveis na modelagem de dados tanto da média como dos componentes de (co)variância de variáveis normais sob delineamentos com indivíduos relacionados e têm sido usados em estudos de herdabilidade de fenótipos quantitativos e de mapeamento de genes, mostrando resultados promissores [de Oliveira et al., 2008, Diego et al., 2015, Kris M et al., 2013].

Pertencente à classe dos modelos lineares mistos, o modelo mais recomendado e utilizado para explicar a herança de fenótipos foi inicialmente proposto por Fisher em 1918, denominado modelo de componentes de variância e sendo mais tarde chamado modelo linear misto poligênico. Esse modelo assume que as características fenotípicas são influenciadas por, potencialmente, um número grande de loci no genoma, assumindo-se que eles exercem seus efeitos no fenótipo de forma aditiva, ou seja, de forma independente. Considere $y_{i}$ a variável fenotípica medida no $i$-ésimo indivíduo da $f$-ésima família com $i=1, \ldots, \mathrm{n}, f=1, \ldots, \mathrm{F}$, em que o conjunto de indivíduos são agrupados em F famílias de $n_{f}$ parentes. Sob o modelo linear misto poligênico, $y_{i}$ é expresso como (por exemplo,

\footnotetext{
${ }^{1} 1 \mathrm{MET}$ corresponde a $3 \mathrm{~mL} / \mathrm{kg} / \mathrm{min}$ de $O^{2}$ consumido em repouso.
} 
Giolo et al. [2010]):

$$
y_{i f}=\mu+X_{i f}^{\prime} \beta+g_{i f}+\epsilon_{i f}
$$

em que $\mu$ é a média do traço, $X_{i f}$ é o vetor com os valores das covariáveis e $\beta$ é o vetor de coeficientes de regressão para cada covariável. Os demais componentes, $g_{i f}$ e $\epsilon_{i f}$, são os efeitos aleatórios genéticos residuais devido ao termo poligênico e o componente aleatório de erro, respectivamente. Assume-se que $g_{i f}$ e $\epsilon_{i f}$ são não-correlacionados e possuem distribuição normal com média 0 e variância $\sigma_{g}^{2}$ e $\sigma_{e}^{2}$, respectivamente. Caso haja interesse, poderia-se ainda adicionar a esse modelo outros componentes aleatórios, tais como o household effect, que corresponde aos efeitos (compartilhados) dos indivíduos morarem na mesma residência.

\subsection{Herdabilidade de Fenótipos da Atividade Física}

Para se entender a influência genética na variação de fenótipos da atividade física como definidos anteriormente, usaremos a abordagem de componentes de variância, via o ajuste de modelos lineares mistos, implementada no pacote SOLAR-Eclipse 8.3.1. Assumindo que a característica de interesse segue uma distribuição normal, podendo ser descrita por meio de sua média e componentes de variância (como na equação 3.1), a proporção da variância fenotípica explicada por fatores genéticos é denominada herdabilidade, a qual corresponde ao coeficiente de correlação intraclasse [Almasy e Blangero, 2010].

A estimativa da herdabilidade é baseada em um modelo linear misto poligênico (equação 3.1), que permite decompor a variância fenotípica global em componentes genéticos e ambientais, por exemplo, como segue:

$$
\Omega=2 \Phi \sigma_{g}^{2}+I_{n} \sigma_{e}^{2}
$$

em que $\Omega$ corresponde à matriz nxn de covariância total entre os indivíduos da amostra, $\Phi$ é a matriz de parentesco (kinship) que modela a covariância dos efeitos gênicos aditivos entre parentes e $I_{n}$ é uma matriz identidade de ordem n que representa a matriz estrutural da variância dos fatores ambientais residuais. O motivo primordial que justifica a utilização da matriz $\Phi$ é a necessidade de considerar as relações de parentesco dos indivíduos na variância do fenótipo, o que pode ser feito modelando a estrutura de covariância entre os indivíduos pertencentes à mesma família utilizando coeficientes de parentesco que são proporcionais ao grau de relacionamento dos membros familiares. Caso eles fossem todos independentes, o modelo se reduziria a apenas $I \sigma_{e}^{2}$. Assim, a covariância 
para os indivíduos $y_{i f}$ e $y_{i^{\prime} f^{\prime}}$ é dada por Giolo et al. [2010]:

$$
\operatorname{Cov}\left(y_{i}, y_{i^{\prime}}\right)=\left\{\begin{array}{cc}
\sigma_{g}^{2}+\sigma_{e}^{2} & \text { para } i=i^{\prime} \\
2 \phi_{i i^{\prime}} \sigma_{g}^{2} & \text { para } i \neq i^{\prime} \text { e relacionados } \\
0 & \text { para } i \neq i^{\prime} \text { e não relacionados }
\end{array}\right.
$$

Usando esse modelo, a herdabilidade é definida pela fórmula:

$$
h^{2}=\sigma_{g}^{2} / \sigma_{p}^{2}
$$

em que $h^{2}$ corresponde à herdabilidade, $\sigma_{g}^{2}$ à variância atribuída aos efeitos gênicos aditivos e $\sigma_{p}^{2}$ à variância fenotípica total, tal que, sob o modelo 3.1, $\sigma_{p}^{2}=\sigma_{g}^{2}+\sigma_{e}^{2}$. Estimativas da herdabilidade podem ser obtidas por Máxima Verossimilhança Restrita e a significância da herdabilidade pela estatística da Razão de Verossimilhanças (LRT) ${ }^{2}$. [Blangero et al., 2013].

O efeito das covariáveis sexo, idade, idade ${ }^{2} 3$ e sua interação (sexo*idade), assim como das covariáveis depressão, fumo, índice de massa corpórea (IMC) e circunferências da cintura, quadril e pescoço, foi investigado no ajuste do modelo e estimativas de herdabilidade. Além disso, verificou-se se a inclusão de covariáveis contribui ou não para a significância da herdabilidade. Pôde-se assim, discriminar entre covariáveis que mais explicam o componente poligênico ou o ambiental.

Por fim, a estratificação da herdabilidade pelo sexo foi avaliada, de forma a investigar se há heterogeneidade nos componentes de variância genéticos poligênicos e ambientais, como em Giolo et al. [2010] e Horimoto et al. [2011]. Assim, sob o modelo linear misto poligênico 3.1, pode-se acrescentar efeitos genéticos e ambientais específicos ao sexo, de forma que a covariância entre traços para os individuos $y_{i}$ e $y_{i^{\prime}}$ é expressa como:

$$
\operatorname{Cov}\left(y_{i}, y_{i^{\prime}}\right)=\left\{\begin{array}{cc}
\sigma_{g^{2}, \text { mulher }}+\sigma_{e^{2}, \text { mulher }} & \text { para } i=i^{\prime} \text { e mulher } \\
\sigma_{g^{2}, \text { homem }}+\sigma_{e^{2}, \text { homem }} & \text { para } i=i^{\prime} \text { e homem } \\
2 \phi_{i i^{\prime}} \sigma_{g^{2}, \text { mulher }} & \text { para } i \neq i^{\prime}, \text { relacionados e mulheres } \\
2 \phi_{i i^{\prime}} \sigma_{g^{2}, \text { homem }} & \text { para } i \neq i^{\prime}, \text { relacionados e homems } \\
2 \phi_{i i^{\prime}} \sigma_{g^{2}, \text { mulher,homem }} & \text { para } i \neq i^{\prime}, \text { relacionados e de sexos diferentes } \\
0 & \text { para } i \neq i^{\prime} \text { e não relacionados }
\end{array}\right.
$$

\footnotetext{
${ }^{2}$ Essa estatística é assintóticamente distribuída como uma mistura de $1 / 2 \chi_{0}^{2}$ e $1 / 2 \chi_{1}^{2}$ [Self e Liang, 1987]
}

${ }^{3}$ Ao se elevar a idade ao quadrado diminui-se problemas de fuga da linearidade em análises de correlação 
A estratificação por sexo já foi utilizada também com os dados de Baependi e se justifica pelo fato de homens e mulheres diferirem, dentre muitos aspectos, quanto ao cariótipo, expressão gênica, características psicossociais e comportamentais, bem como respostas fisiológicas ao exercício físico [Hallal et al., 2012, Hands e Parker, 2016]. Para tal, comparamos 4 modelos: 1- sem heterogeneidade quanto ao sexo (ambos $\sigma_{g}^{2}$ e $\sigma_{e}^{2}$ são iguais para homens e mulheres), 2- heterogeneidade em pelo menos um dos componentes, 3 - heterogeneidade somente no componente genético, 4- heterogeneidade somente no ambiental. As comparações foram executadas por meio do LRT.

Esses ajustes de modelos, com ou sem estratificação, foram feitos utilizando o pacote SOLAREclipse 8.3.1.

\subsection{Associação de SNPs e CNVs com Fenótipos da Atividade Física}

Assim como para estimação de herdabilidade, os estudos de associação ou mapeamento gênico (GWAS) se baseiam num modelo linear misto poligênico, que pode ser representado de forma simples como:

$$
y_{i f}=\mu+X_{i f}^{\prime} \beta+X_{G i f} \beta_{G}+g_{i f}+\epsilon_{i f}
$$

em que, $X_{\text {Gif }}$ é a variável (ou vetor) com informações do marcador de interesse (genótipo do SNP ou a categoria do CNV) para o $i$-ésimo indivíduo da $f$-ésima família, e $\beta_{G}$ corresponde ao parâmetro com os correspondentes coeficientes de regressão associados. Os demais termos do modelo estão definidos como em 3.1. Esse modelo pode ser ajustado para análises de associação uni e multi-locos considerando dados de SNP, de CNVs, bem como, caso seja de interesse no mapeamento, de ambos marcadores simultaneamente e interações entre eles.

Os testes de significância para a seleção dos SNPs e CNVs $\left(\mathrm{H}: \beta_{G}=0\right)$ devem adotar correções nos valores-p para os múltiplos testes, de forma a evitar um número elevado de falsos positivos. Dentre as possíveis maneiras, optamos por adotar a Correção de Bonferroni, a qual divide o $\alpha$, em geral de 0,05, pelo número de testes utilizados na análise [Bush e Moore, 2012]. Como o número de CNVs em nosso banco é 8.794, o nível de significância adotado foi $0,05 / 8.794=5,68 \times 10^{-6}$. Quanto aos SNPs, adotou-se o valor de 5,92 $\times 10^{-8}$, já que o número destes marcadores é 843.039. Adicionalmente a essa correção, fez-se uso de um critério mais flexível (ponto de corte de $10^{-5}$ ) para uma análise exploratória de marcadores candidatos associados a esses fenótipos como recomendado por [Duggal et al., 2008]. Além disso, reportou-se também os 20 menores $p$-valores para os CNVs e SNPs.

Para investigar a existência de associação entre os SNPs, CNVs e os fenótipos relacionados à ati- 
vidade física, AFT, WK, MPA, VPA, e sedentarismo, utilizamos ainda derivações mais complexas desse modelo poligênico, as quais incluiram, além dos SNPs e CNVs, idade, sexo e as demais covariáveis selecionadas nos ajustes de modelo específicos a cada fenótipo. Ainda, incluiu-se coeficientes de ancestralidade (pca1 e pca2) obtidos pela análise de componentes principais em [De Andrade et al., 2015], os quais funcionam como uma medida de correção importante em estudos de associação com estrutura familiar. Por conta da normalidade das variáveis resposta ser uma das premissas do modelo linear misto poligênico, devendo ser atendida para uma estimação fidedigna dos coeficientes $\beta$ e p-valores [Almasy e Blangero, 2010], utilizamos transformações dessas variáveis de acordo com os resultados dos ajustes dos modelos, as quais estão descritas no capítulo 4.3.

O ajuste dos modelos incluindo os SNPs e CNVs foi realizado utilizando as funções lmekin e makekinship das bibliotecas coxme e kinship2, do R [Therneau e Sinnwell, 2015, Therneau e Therneau, 2015], respectivamente. Uma vez que, no caso de SNPs, trabalhamos com um gigantesco conjunto de dados, cujas colunas estão na ordem de centenas de milhares, optamos por dividir o conjunto de dados em subconjuntos de 5000 marcadores e utilizar uma paralelização no GWAS desses polimorfismos. Essa paralelização foi feita em dez processadores num computador Desktop de 34GB de memória. Essa estratégia adicionada do recurso computacional utilizado se mostrou bastante eficaz em análises prévias feitas pelo nosso grupo por reduzir imensamente o tempo computacional empregado. 


\section{Capítulo 4}

\section{Resultados e Discussão}

\subsection{Banco de Dados}

Uma das características principais do Projeto Corações de Baependi é sua estrutura de dados: os indivíduos são recrutados e avaliados segundo suas relações de parentesco, sendo assim estruturados em famílias. Uma ilustração simples dessa organização é apresentada no heredograma da Figura 4.1, cuja codificação em 5 colunas no banco de dados está na Tabela 4.1.

Com relação às variáveis coletadas nas unidades amostrais, o banco de dados utilizado pode ser descrito separadamente para os fenótipos observados e coletados de cada indivíduo, para as informações genotípicas de SNPs e de CNVs, ou de forma conjunta, com essas informações integradas em uma única matriz de dados. Os formatos de banco de dados com as 5 colunas de identificação principal dos indivíduos e das famílias, utilizado globalmente em estudos de família, além de colunas com alguns dos fenótipos de atividade física, SNPs e CNVs de alguns indivíduos podem ser visualizados nas Tabelas 4.2, 4.3 e 4.4, respectivamente.

Tabela 4.1: Indivíduos pertencentes à familia hipotética 1 e suas relações de parentesco. FID = Identificação da família do indivíduo, IID = Identificação do indivíduo, PAT = Identificação do pai do indivíduo, MAT = Identificação da mãe do indivíduo, SEX = Sexo do indivíduo.

\begin{tabular}{cccccc}
\hline \hline & FID & IID & PAT & MAT & SEX \\
\hline 1 & 1 & 1 & 0 & 0 & 2 \\
2 & 1 & 2 & 0 & 0 & 1 \\
3 & 1 & 3 & 0 & 0 & 1 \\
4 & 1 & 4 & 2 & 1 & 2 \\
5 & 1 & 5 & 2 & 1 & 1 \\
6 & 1 & 6 & 2 & 1 & 2 \\
7 & 1 & 7 & 0 & 0 & 1 \\
8 & 1 & 8 & 3 & 4 & 2 \\
9 & 1 & 9 & 7 & 6 & 1 \\
\hline
\end{tabular}




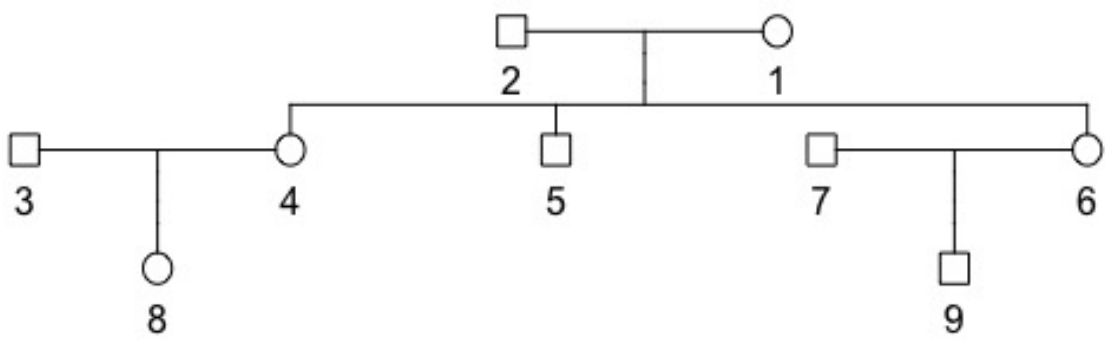

Figura 4.1: Heredograma da família hipotética 1 mostrando as relações de parentesco entre seus membros. Quadrados indicam indivíduos do sexo masculino e círculos indicam os do sexo feminino

Tabela 4.2: Dados fenotípicos de $n=6$ indivíduos do banco de dados utilizado. FID = Identificação da família, IID = Identificação do indivíduo, PAT = Identificação do pai, MAT = Identificação da mãe, SEX = sexo, AFT_MET = Atividade Física Total em METs* min/sem, SB = Tempo gasto em posição sentada (sedentarismo) em min/sem, IMC = Índice de Massa Corpórea, Depressão = escore de intensidade de depressão do questionário Beck.

\begin{tabular}{cccccccccc}
\hline \hline & FID & IID & PAT & MAT & SEX & AFT_MET & SB & IMC & Depressão \\
\hline 1 & 2 & 2.101 & 0 & 0 & 1 & 396 & 2.220 & & 2 \\
2 & 2 & 2.201 & 0 & 0 & 2 & 462 & 1.140 & 25.7 & 31 \\
3 & 160 & 2.202 & 51.051 & 51.953 & 2 & & & 28.8 & 9 \\
4 & 2 & 2.302 & 2.101 & 2,201 & 1 & 3.600 & 420 & 28.9 & 4 \\
5 & 2 & 2.303 & 2.101 & 2.201 & 2 & & & & \\
6 & 4 & 4.101 & 4,501 & 4.502 & 2 & & & & \\
\hline
\end{tabular}

Tabela 4.3: Dados hipotéticos de SNPs de $n=6$ indivíduos do banco de dados. FID = Identificação da família, IID = Identificação do indivíduo, PAT = Identificação do pai, MAT = Identificação da mãe, $S E X=$ Sexo, rs8192678 $=$ SNP no gene MCT-1, rs1049434 = SNP no gene PPARGC1A, rs1815739= SNP no gene ACTN3.

\begin{tabular}{cccccccc}
\hline \hline FID & IID & PAT & MAT & SEX & rs8192678 & rs1049434 & rs1815739 \\
\hline 1 & 1 & 0 & 0 & 2 & 1 & 2 & 2 \\
1 & 1 & 0 & 0 & 1 & 1 & 2 & 0 \\
1 & 1 & 0 & 0 & 1 & 2 & 0 & 1 \\
1 & 1 & 2 & 1 & 2 & 0 & 1 & 0 \\
1 & 1 & 2 & 1 & 1 & 1 & 1 & 0 \\
1 & 1 & 2 & 1 & 2 & 1 & 0 & 1 \\
\hline
\end{tabular}


Tabela 4.4: Dados hipotéticos de CNVs de $n=6$ individuos do banco de dados. FID = Identificação da família, IID = Identificação do indivíduo, PAT =Identificação do pai, MAT = Identificação da mãe, SEX $=$ Sexo, celfile = Arquivo celfile dos dados de SNP-Array, CNV = Identificação do CNV estimado através de dados de SNPs, Tamanho = Tamanho do CNV (em bp), Estado = Estado utilizado na Cadeia de Markov correspondente ao número de cópias, Cópias = Número de cópias do CNV.

\begin{tabular}{cccccccccccc}
\hline \hline & \multirow{2}{*}{ FID } & IID & PAT & MAT & SEX & celfile & CNV & Chr & Tamanho & Estado & Cópias \\
\hline 1 & 110 & 110.601 & 51.483 & 110.502 & 2 & 1 & 2 & 6 & 47.700 & 5 & 3 \\
2 & 110 & 110.601 & 51.483 & 110.502 & 2 & 1 & 2 & 14 & 223.190 & 5 & 3 \\
3 & 110 & 110.601 & 51.483 & 110.502 & 2 & 1 & 2 & 7 & 18.361 & 5 & 3 \\
4 & 110 & 110.601 & 51.483 & 110.502 & 2 & 1 & 2 & 4 & 8.083 & 1 & 0 \\
5 & 110 & 110.601 & 51.483 & 110.502 & 2 & 1 & 2 & 9 & 387.407 & 2 & 1 \\
6 & 110 & 110.601 & 51.483 & 110.502 & 2 & 1 & 2 & 9 & 132.540 & 5 & 3 \\
\hline
\end{tabular}

\subsection{Análise Descritiva}

Dos indivíduos que reportaram praticar pelo menos algum tipo de atividade física no IPAQSF, 307 (40\%) são homens e 451 (60\%) mulheres, com uma média de idade de 48 e 50 anos, respectivamente. Dentre as 81 famílias, o número médio de indivíduos por família foi 11,23 com desvio padrão de 12,81 .

Comparando-se a frequência de indivíduos que praticavam atividade física leve (WK) ao longo dos 7 dias da semana, observa-se que 55,3\% pratica atividade em pelo menos 1 dia, principalmente em 5 dias ou em 3 dias na semana (Figura 4.2). Daqueles que praticam 3 e 5 vezes na semana, a maioria é mulher. Contudo, há também predominância de mulheres no grupo que não pratica atividade leve em nenhum dia na semana. Em 0 dias há predominância de mulheres relativamente aos homens, mas para 7 dias na semana esse padrão inverte, com mais homens praticando.

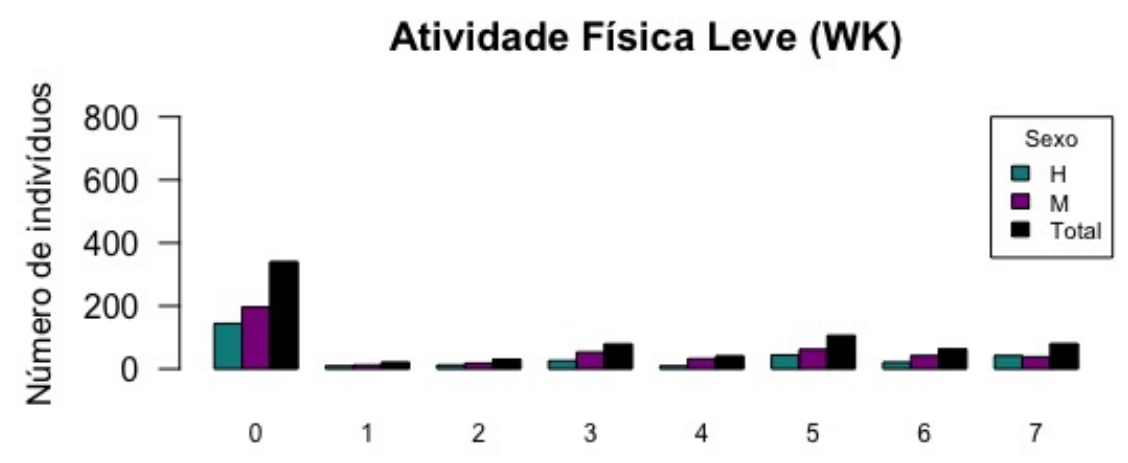

Número de dias da semana

Figura 4.2: Distribuição do número de dias da semana nos quais homens, mulheres e total de indivíduos praticam atividade física leve.

Por sua vez, a frequência de indivíduos do perfil moderado (MPA) praticantes de atividade em 


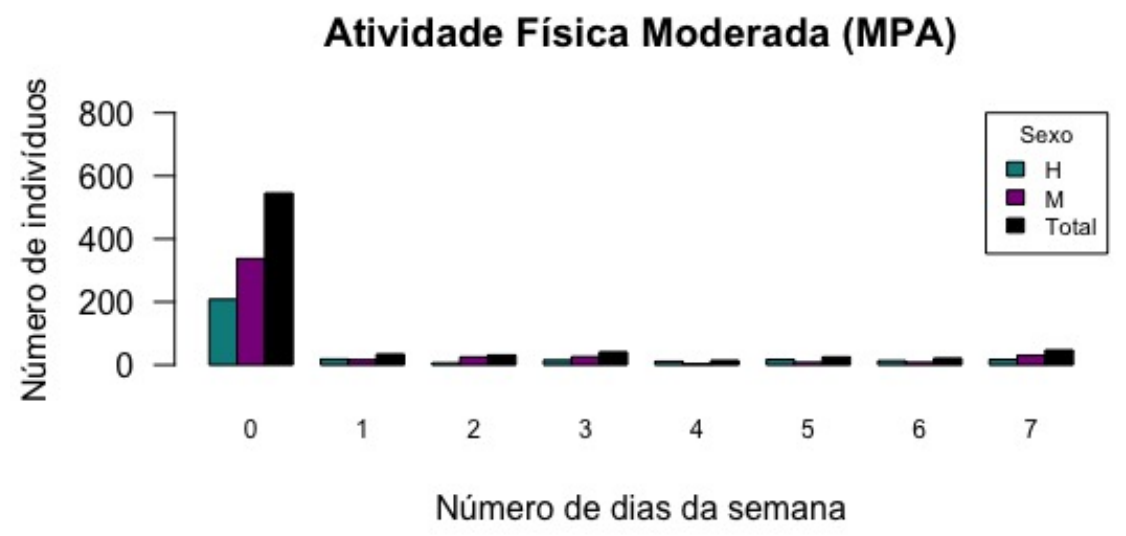

Figura 4.3: Distribuição do número de dias da semana nos quais homens, mulheres e total de indivíduos praticam atividade física moderada.

pelo menos 1 dia da semana foi de apenas 28,1\%. Todavia, a prática dos demais foi distribuída de forma bastante homogênea nos vários dias da semana (Figura 4.3). A aderência baixa desses indivíduos a atividades físicas moderadas é bastante razoável, uma vez que essas atividades demandam bastante do corpo.

Semelhantemente a MPA, o número de indivíduos de Baependi engajados em atividade física vigorosa em pelo menos um dia na semana foi bastante reduzido $(8,93 \%)$, o que reflete ainda mais a alta demanda dessas práticas bem como uma possível consequência do perfil etário da população, o qual, por ser elevado (média de 48 e 50 anos para homens e mulheres, respectivamente), dificulta ainda mais a execução de atividades muito dispendiosas fisicamente (Figura 4.4). Assim, a aderência de atividade física total, que corresponde à média das aderências nos 3 perfis avaliados foi 33,78.

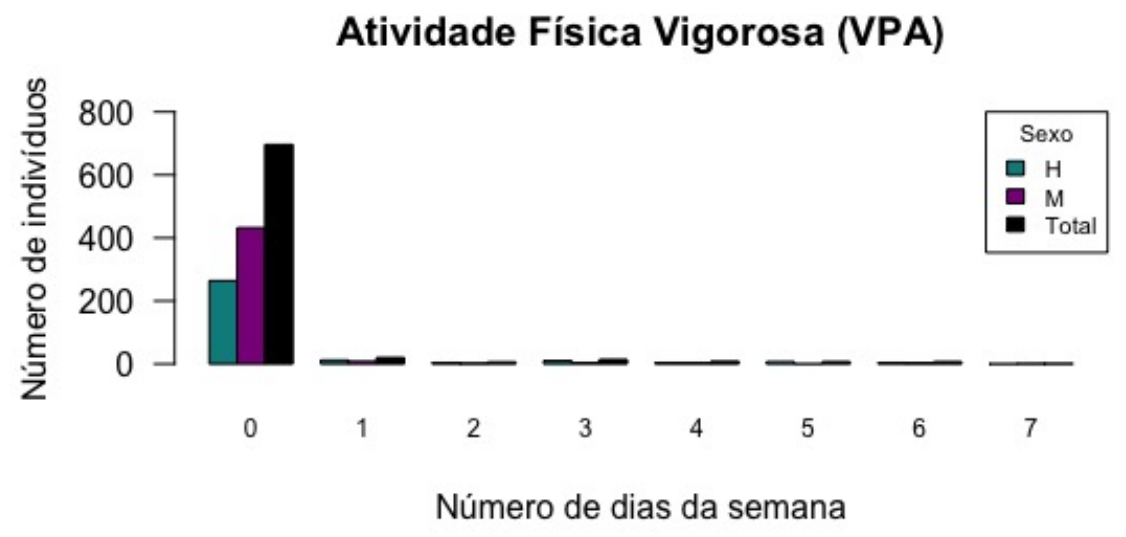

Figura 4.4: Distribuição do número de dias da semana nos quais homens, mulheres e total de indivíduos praticam atividade física vigorosa.

As frequências de indivíduos que praticam atividade física em 0 e no intervalo 1-7 dias para 
homens, mulheres e total de indivíduos estão apresentadas em tabelas de contingência (Tabela 4.5). A Razão de Chances (Odds Ratio), que corresponde à proporção entre as chances de uma mulher praticar atividade física e a de homens praticarem foi calculada para os diferentes perfis de atividade física. Os valores $1,158,0,738$ e 0,328, mostram que as chances de uma mulher praticar atividade física em pelo menos um dia na semana quando comparada à de homens são 1,158, 0,738 e 0,328 para os perfis leve, moderado e vigoroso, respectivamente.

Tabela 4.5: Frequências absolutas para homens, mulheres e total de invividuos em 0 e no intervalo 1-7 dias da semana para cada perfil de atividade física, com suas respectivas razões de chance.

\begin{tabular}{|c|c|c|c|c|c|c|c|c|c|c|c|}
\hline $\begin{array}{c}\text { WK } \\
\text { Sexo/Número de Dias na Semana }\end{array}$ & 0 & $1-7$ & Total & $\begin{array}{c}\text { MPA } \\
\text { Sexo/Número de Dias na Semana }\end{array}$ & 0 & $1-7$ & Total & $\begin{array}{c}\text { VPA } \\
\text { Sexo/Número de Dias na Semana }\end{array}$ & 0 & $1-7$ & Total \\
\hline $\mathrm{F}$ & 196 & 257 & 453 & $\mathrm{~F}$ & 337 & 116 & 453 & $\mathrm{~F}$ & 432 & 22 & 454 \\
\hline M & 144 & 163 & 307 & M & 208 & 97 & 305 & M & 264 & 41 & 305 \\
\hline Total & 340 & 420 & 760 & Total & 545 & 213 & 758 & Total & 696 & 63 & 759 \\
\hline Odds ratio & 1,158 & & & Odds ratio & 0,738 & & & Odds ratio & 0,328 & & \\
\hline
\end{tabular}

Num estudo global que avaliou a prevalência de atividade e inatividade física em adolescentes e adultos de 122 países utilizando o IPAQ e o GPAQ (Questionário Global de Atividade Física), foi observado uma prevalência maior que $50 \%$ em adultos homens e menor que $50 \%$ em mulheres na população brasileira [Hallal et al., 2012].

Numa outra investigação que utilizou os mesmos fenótipos aqui avaliados usando uma versão adaptada do IPAQ-SF para a população nigeriana, foi encontrada uma prevalência maior $(68,6 \%)$ de adultos classificados como suficientemente ativos seguindo recomendações da Organização Mundial de Saúde (OMS) [Oyeyemi et al., 2013]. Entretanto, não houve diferença significante entre as prevalências de homens e mulheres nessa população. Ainda, em um compêndio de dados de prevalência de 38 países mulçumanos, Kahan [2015] encontrou um valor médio de 67,7\% mas com bastante variação entre os países $(13,2-95,3 \%)$.

Em relação ao tempo diário dispendido em atividade física estratificado por sexo nos diferentes perfis, observou-se uma dispersão dos dados maior para MPA e VPA, especialmente nas mulheres (Figura 4.5). Além disso, houve um aumento na mediana dos homens entre o perfil moderado e vigoroso, o que não ocorreu para mulheres. Essa distinção entre os sexos se assemelha à encontrada por Horimoto et al. [2011], refletindo a facilidade e consequente propensão que homens têm a desempenhar atividades físicas mais extenuantes.

Por meio da análise desses resultados de prevalência e comparação do tempo diário gasto em atividades leves, moderadas e vigorosas, há fortes indicações de que: 1) Apesar das diferenças na metodologia dos estudos e nas características sociodemográficas das populações estudadas dificultarem a comparação entre os diferentes estudos, a prevalência de atividade física é específica para 


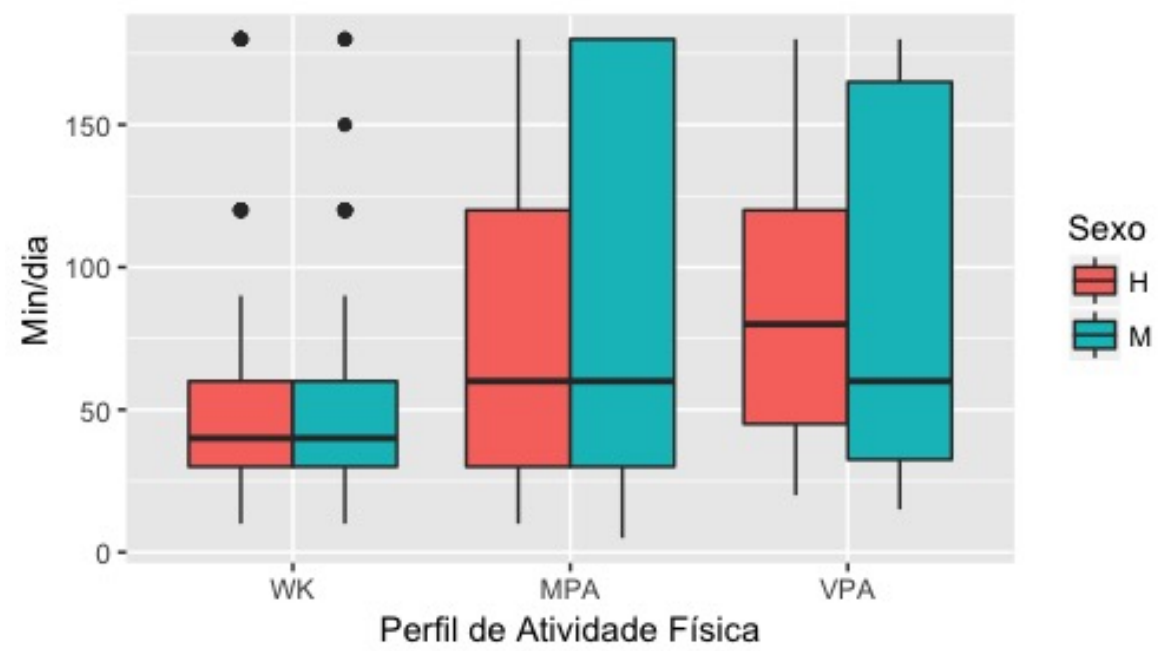

Figura 4.5: Boxplots das distribuições do tempo diário de atividade física nos perfis WK (atividade em caminhada), MPA (atividade moderada) e VPA (atividade vigorosa) estratificado por sexo.

cada população e, no caso, da de Baependi, está de acordo com os registros prévios para a população brasileira. 2) Apesar de terem sido usados instrumentos de mensuração diferentes, a distinção entre os sexos quanto à prática de atividade física na população de Baependi se manteve na segunda onda do estudo quando comparada à primeira [Hallal et al., 2012, Horimoto et al., 2011].

A relação entre as variáveis de gasto energético por minuto semanalmente e a idade dos indivíduos foi também avaliada. Como observado previamente na Figura 4.5 e novamente na Figura 4.6, houve uma tendência de homens fazerem mais atividade física que mulheres como indicado pelos maiores valores de AFT MET*min/sem, o que está de acordo com o perfil da população de Baependi, na qual os homens desempenham mais atividades rurais. Apesar de outros trabalhos terem usado amostras de populações com perfis diferentes do estudo aqui realizado, Hallal et al. [2012] também apontaram essa tendência. Além disso, não se detectou qualquer correlação linear entre esse fenótipo e idade tanto para homens quanto para mulheres (coeficientes de correlação linear próximos a zero). A mesma ausência de correlação foi observada nos perfis leve, moderado e vigoroso.

Quanto às distribuições de frequência dos fenótipos WK, MPA, VPA e AFT transformados por MET, os boxplots estratificados por sexo ilustram a ocorrência marcante de observações outliers, além de uma predominância de atividade física nos perfis leve e moderado (Figura 4.7).

A maior parte do gasto semanal médio despendido em atividade física foi feito nos perfis Atividade Física Moderada (MPA) e Atividade Física Leve (WK), sendo assim estes o principais contribuintes para Atividade Física Total (AFT), resultante da soma dos demais (Figura 4.8). Quanto ao fenótipo de sedentarismo (SB), o tempo médio em min/semana foi muito maior que o dos de 


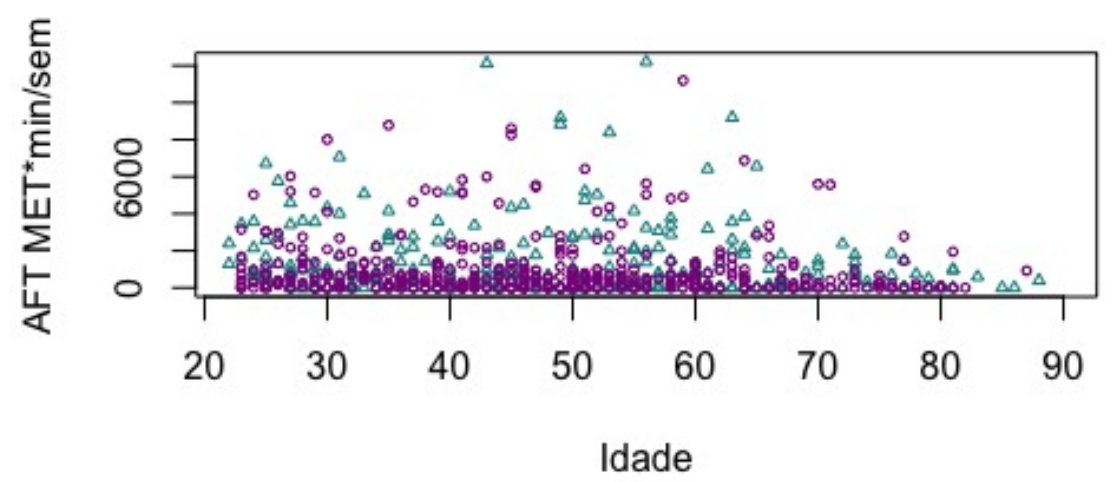

Figura 4.6: Gráfico de dispersão de Atividade Física Total em MET*min/sem em função da idade para homens e mulheres. Triângulos e círculos correspondem a homens e mulheres, respectivamente.

atividade física (Figura 4.5), mas não houve diferença entre homens e mulheres (Figura 4.9). Esses resultados demonstram que os homens e mulheres de Baependi gastam igualmente mais tempo em posições sentadas.

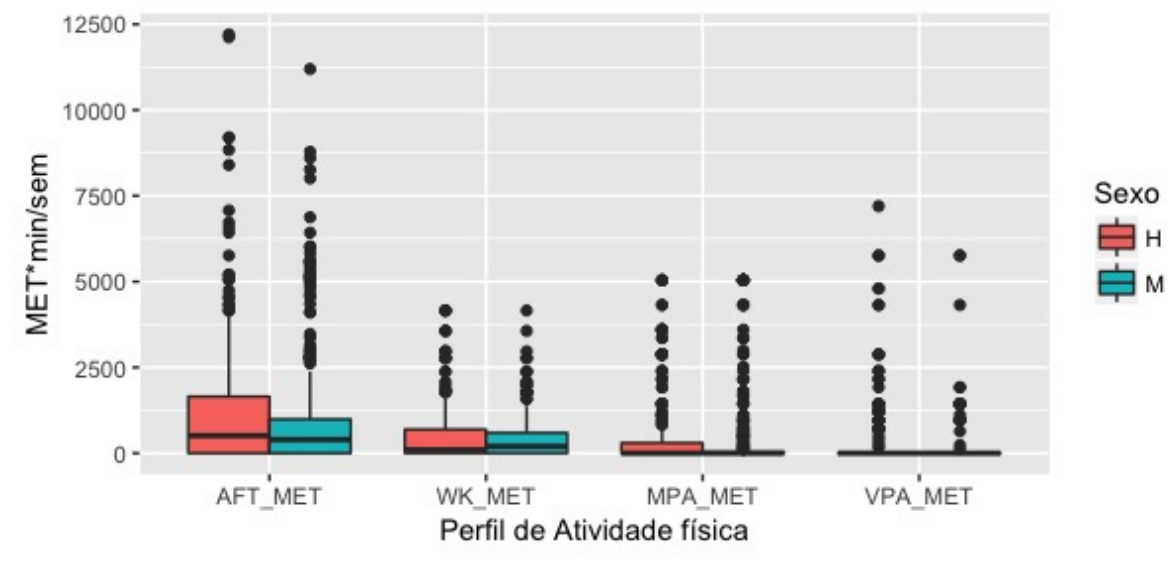

Figura 4.7: Boxplots das distribuições de Atividade Física nos perfis AFT (atividade física total), WK (atividade em caminhada), MPA (atividade moderada) e VPA (atividade vigorosa) estratificado por sexo, medida em equivalentes metabólicos de tarefa (MET) $x$ min /semana.

Devido ao caráter assimétrico e às recomendações do próprio questionário IPAQ-SF, a descrição dos dados deve ser baseada não apenas em sua média (Figuras 4.8 e 4.9) e desvios padrão, mas também incluindo seus quartis (Q1, Q2=mediana e Q3) e intervalos interquartis. Na Tabela 4.6 podem ser vistas as estatísticas descritivas (média e desvio padrão) para todas as variáveis quantitativas avaliadas. Os significados das legendas indicadas nas tabelas e figuras são apresentados no dicionário de variáveis no apêndice C. 


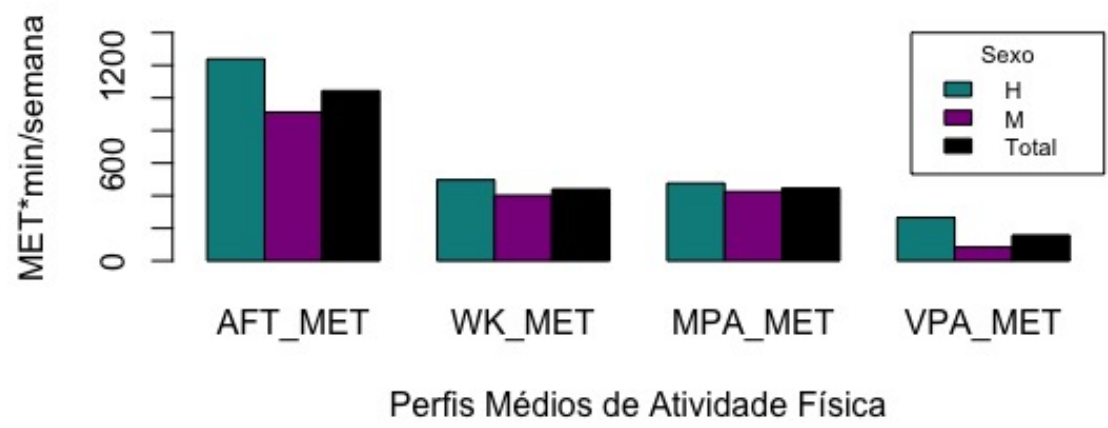

Figura 4.8: Atividade Física estratificado por sexo nos perfis médios AFT (atividade física total), WK (atividade em caminhada), MPA (atividade moderada) e VPA (atividade vigorosa), medida em equivalentes metabólicos de tarefa (MET) $x$ min /semana em 760 indivíduos.

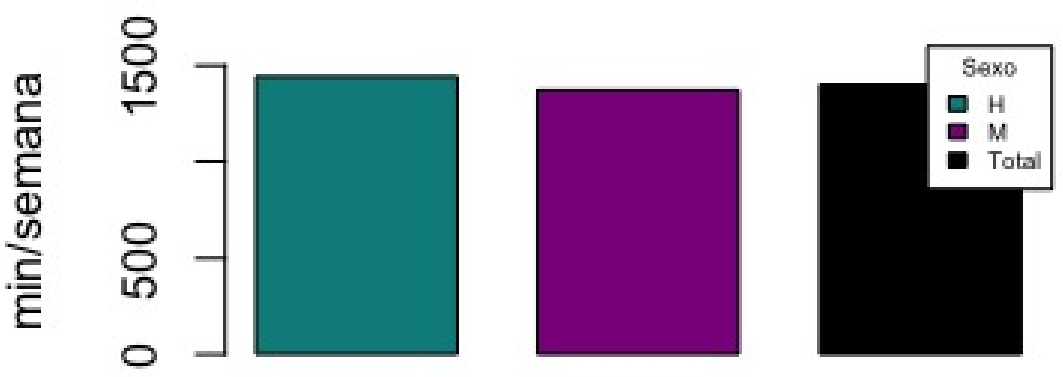

Perfil Médio de Sedentarismo

Figura 4.9: Tempo médio em min/semana gasto em posições sentadas para homens, mulheres e total de indivíduos. 
Tabela 4.6: Estatísticas descritivas das variáveis e covariáveis avaliadas no presente estudo para uma amostra de 760 indivíduos.

\begin{tabular}{ccccccc}
\hline \hline & $\bar{X}$ Total & sd Total & $\bar{X} \mathrm{H}$ & sd H & $\bar{X}$ M & sd M \\
\hline IPAQ_1_A(dias) & 2,56 & 2,65 & 2,56 & 2,76 & 2,56 & 2,58 \\
IPAQ_2_A(dias) & 1,12 & 2,14 & 1,30 & 2,25 & 1,00 & 2,05 \\
IPAQ_3_A(dias) & 0,25 & 0,97 & 0,40 & 1,21 & 0,14 & 0,76 \\
IPAQ_1_B(h/min) & 50,11 & 35,99 & 55,52 & 44,07 & 46,69 & 29,33 \\
IPAQ_2_B(h/min) & 88,82 & 63,63 & 85,81 & 61,70 & 91,39 & 65,39 \\
IPAQ_3_B(h/min) & 85,79 & 52,83 & 83,41 & 46,62 & 90,22 & 63,77 \\
AFT MET(MET*min/sem) & $1.043,38$ & $1.712,70$ & $1.233,55$ & $1.896,94$ & 913,94 & $1.564,03$ \\
WK MET(MET*min/sem) & 439,74 & 677,05 & 496,61 & 811,16 & 401,20 & 566,21 \\
MPA MET(MET*min/sem) & 445,33 & $1.117,61$ & 473,09 & $1.062,17$ & 426,43 & $1.154,60$ \\
VPA MET(MET*min/sem) & 156,94 & 702,38 & 263,84 & 914,57 & 84,33 & 498,57 \\
SB(min/sem) & $1.401,54$ & 949,96 & $1.443,18$ & 998,28 & $1.373,32$ & 915,83 \\
C CINTURA(cm) & 92,23 & 11,59 & 91,59 & 10,86 & 92,64 & 12,04 \\
C QUADRIL(cm) & 98,20 & 9,18 & 95,66 & 7,32 & 99,89 & 9,88 \\
C PESCOCO(cm) & 35,65 & 3,54 & 38,10 & 2,94 & 34,04 & 2,93 \\
IMC(kg/cm $\left.{ }^{2}\right)$ & 26,20 & 4,99 & 25,24 & 4,18 & 26,84 & 5,37 \\
Fumo(cigarros/sem) & 13,25 & 11,65 & 15,24 & 12,80 & 11,00 & 9,76 \\
Depressão & 11,14 & 9,01 & 7,83 & 6,44 & 13,40 & 9,80 \\
\hline
\end{tabular}

\subsection{Seleção de Modelos e Herdabilidade}

Após a transformação dos dados referentes a MET x minuto/semana dispendidos em atividade física nos perfis leve (WK), moderado (MPA) e intenso (VPA), e sua junção em um único fenótipo (AFT), a herdabilidade $\left(\mathrm{h}^{2}\right)$ desses traços foi estimada adotando-se um modelo linear misto poligênico, utilizando inicialmente, como covariáveis, o sexo, idade, idade ${ }^{2}$ e efeitos de interação entre sexo e idade simultaneamente, as quais constituem o conjunto de covariáveis recomendado nessas análises [Cox et al., 2012, Diego et al., 2015, Giolo et al., 2010, Horimoto et al., 2011, Seabra et al., 2014].

Para comparação e seleção do modelo mais adequado, inicialmente decidimos estimar a herdabilidade utilizando o banco de dados de aproximadamente 760 indivíduos descrito anteriormente. Partindo do modelo com sexo, idade, idade $^{2}$ e efeitos de interação, utilizamos uma abordagem forward na qual as covariáveis IMC, circunferência da cintura, quadril, pescoço, fumo e depressão foram sendo adicionadas uma a uma (Apêndice B.1). Essas covariáveis, uma vez disponíveis no banco de dados do Projeto Corações de Baependi, foram escolhidas pela literatura indicar um envolvimento direto com atividade física ou com fenótipos a ela relacionados.

Esse primeiro processo de seleção de modelo mostrou um padrão muito interessante. À medida em que as covariáveis iam sendo adicionadas ao modelo inicial, a significância do sexo, idade e suas 
derivações tendia a desaparecer, de forma que, para a maior parte dos fenótipos de atividade física, não havia qualquer significância de covariáveis no modelo mais complexo. Contudo, vale notar o impacto na estimativa da herdabilidade Igualmente, ao se ajustar um modelo incluindo todas as covariáveis, somente idade e sexo apresentaram significância para AFT, o que nem sequer aconteceu para outros fenótipos.

Por conta desse padrão e da distribuição dos fenótipos ter apresentado curtose residual bastante elevada, optamos por:

- Utilizar um banco de dados maior com informações fenotípicas de aproximadamente 2300 indivíduos (Capítulo 3), para estimativas mais fidedignas e melhoradas dos parâmetros.

- Realizar uma transformação (inversa normal) dos dados, a qual reduz a assimetria dos dados e aproxima sua distribuição à da normal.

- Ajustar modelos específicos para cada fenótipo, ou seja, avaliando a inclusão e a significância de cada covariável quando adicionadas ao modelo basal, como mostrado nas Tabelas 4.8 e 4.9.

A transformação inversa normal faz parte de uma abordagem de transformação conhecida como transformação empírica quantílica normal (ENQT, do inglês Empirical Normal Quantile Transformation), a qual ordena os valores da variável, os escalona e os transforma de forma que sigam uma distribuição normal. Essa transformação baseia-se na equação 4.1, como descrita em Beasley et al. [2009].

$$
Y_{i}^{t}=\phi^{-1}\left(\frac{r_{i}-c}{N-2 c+1}\right)
$$

em que $Y_{i}^{t}$ corresponde ao novo valor da variável transformada para o $i$-ésimo indivíduo, $r_{i}$ ao rank do $i$-ésimo caso de $N$ observações, $\phi^{-1}$ denota a função probit da Normal Padrão e $c$ a um parâmetro comumente fixado a $3 / 8$.

Simulações demonstraram que essa transformação é bastante eficiente computacionalmente e superior a métodos tradicionais no quesito poder estatístico, uma vez que controla o erro do tipo I [Peng et al., 2007]. Essa solução tem sido comumente empregada em estudos de associação e de herdabilidade [Arya et al., 2018, Chu et al., 2017, Yang et al., 2012], tendo sido utilizada anteriormente nos mesmos fenótipos aqui avaliados [Diego et al., 2015], e foi implementada no pacote SOLAR Eclipse 8.3.1 com o comando define $<$ defname $>=$ inormal_$_{-}<$phenotype $>$. No contexto presente, essa solução reduziu a curtose para o critério aceitável $(<0.8)$ para AFT, WK, SB, mas, na maioria dos ajustes, não foi suficiente para MPA e, em nenhum dos casos, para VPA. Por conta disso, utilizamos uma solução adicional mais robusta para essa variável, tdist, a qual assume uma 
distribuição t de Student para os dados e também está disponível no pacote SOLAR Eclipse 8.3.1. Mesmo com a utilizacão da distribuição t, não foi possível fazer o ajuste de nenhum modelo para o fenótipo VPA. Isso decorre da distribuição desse traço ser bastante inflacionada no zero, o que impede a convergência do algoritmo e, consequentemente, resulta na impossibilidade de estimar os parâmetros do modelo linear misto poligênico aqui utilizado.

Para solucionar esse problema, combinamos os fenótipos moderado e vigoroso em um único fenótipo, moderado-vigoroso (MVPA), como em Klimentidis et al. [2018]. A concatenação dessas duas variáveis em MVPA permitiu que os modelos se ajustassem bem, já que que desta vez a distribuição fenotípica foi bem menos inflacionada no zero.

Considerando a possível existência de correlação entre as covariáveis depressão, fumo, circunferências do pescoço, quadril, cintura e IMC, ou seja, de que haja problemas de colinearidade, realizamos uma série de testes de correlação de Pearson.

Como observado na Tabela 4.7, as covariáveis IMC e circunferências apresentaram elevados coeficientes de correlação ambiental altos, o que mostra que elas fornecem informações semelhantes se incluídas no mesmo modelo. Isto não acontece tão notoriamente para depressão e fumo, o que significa que, caso significantes, essas duas covariáveis devem ser incluídas concomitamente no modelo. Assim, o próximo passo da seleção foi: para cada fenótipo, dentre as covariáveis cuja significância individual foi encontrada e que apresentavam um coeficiente de correlação entre si alto, incluiuse no modelo final para estratificação da herdabilidade aquelas que a literatura indica como mais relevantes para o estudo da atividade física. Por exemplo, para AFT, as covariáveis identificadas como significantes (Tabela 4.8 e Tabela 4.9) foram IMC e todas as circunferências. Já que essas covariáveis tiveram correlação entre si altas, para esse caso, incluiu-se no modelo apenas o IMC, o qual é o principal indicado como associado à atividade física e à manutenção do bem estar físico, tanto pela literatura como pela prática clínica [Klimentidis et al., 2018, Schutte et al., 2016b].

Tabela 4.7: Estimativas de correlação entre covariáveis para indivíduos não independentes. $\rho T$, $\rho g$, e $\rho$ e correspondem às estimativas de correlação total, genética e ambiental, respectivamente.

\begin{tabular}{llllllll}
\hline Testes de correlação & $\rho T$ & $\rho g$ & $\rho e$ & Testes de correlação & $\rho T$ & $\rho g$ & $\rho e$ \\
\hline Cintura-Quadril & 0,77 & 0,89 & 0,68 & Quadril-Depressão & 0,07 & 0,24 & 0,02 \\
Cintura-Pescoço & 0,48 & 0,85 & 0,38 & Pescoço-IMC & 0,74 & 0,93 & 0,69 \\
Cintura-IMC & 0,73 & 0,85 & 0,67 & Pescoço-Fumo & 0,45 & $-0,36$ & 0,80 \\
Cintura-Fumo & 0,06 & 0,49 & 0,07 & Pescoço-Depressão & 0,20 & 0,04 & 0,22 \\
Cintura-Depressão & 0,04 & 0,3 & $-0,03$ & IMC-Fumo & 0,34 & $-0,23$ & 0,69 \\
Quadril-Pescoço & 0,30 & 0,82 & 0,08 & IMC-Depressão & 0,30 & $-0,06$ & 0,39 \\
Quadril-IMC & 0,68 & 0,88 & 0,55 & Fumo-Depressão & 0,27 & $-0,04$ & 0,39 \\
Quadril-Fumo & $-0,04$ & 0,03 & $-0,11$ & & & & \\
\hline
\end{tabular}


Tabela 4.8: p-valores das covariáveis significativas para cada fenótipo no ajuste do modelo poligênico

AFT WK MVPA SB

\begin{tabular}{ll|ll|ll|ll} 
Covariáveis & p-valor & Covariáveis & p-valor & Covariáveis & p-valor & Covariáveis & p-valor \\
\hline Cintura & $1.20 \mathrm{E}-04$ & Cintura & $4.10 \mathrm{E}-04$ & Cintura & $1.06 \mathrm{E}-02$ & Cintura & $5.70 \mathrm{E}-05$ \\
IMC & $1.80 \mathrm{E}-03$ & IMC & $7.70 \mathrm{E}-04$ & IMC & $4.63 \mathrm{E}-02$ & IMC & $2.90 \mathrm{E}-04$ \\
Quadril & $3.90 \mathrm{E}-03$ & Quadril & $1.50 \mathrm{E}-04$ & Quadril & $>0,05$ & Quadril & $2.00 \mathrm{E}-06$ \\
Pescoço & $5.90 \mathrm{E}-05$ & Pescoço & $4.50 \mathrm{E}-05$ & Pescoço & $2.63 \mathrm{E}-03$ & Pescoço & $6.10 \mathrm{E}-06$ \\
Fumo & $>0,05$ & Fumo & $>0,05$ & Fumo & $>0,05$ & Fumo & $1.35 \mathrm{E}-02$ \\
Depressão & $>0,05$ & Depressão & $>0,05$ & Depressão & $>0,05$ & Depressão & $>0,05$
\end{tabular}

As estimativas de herdabilidade $\left(h^{2}\right)$ para os cinco fenótipos em diferentes modelos, antes da selecão final, são apresentadas na Tabela 4.9 e tiveram valores considerados baixos a moderados. A comparação desses resultados com os demais encontrados na literatura torna-se um desafio, uma vez que existe heterogeneidade quanto ao tamanho amostral, perfil da população estudada, delineamento do estudo, uso de diferentes questionários e métodos de coleta e análise de dados. Na investigação de Diego et al. [2015] em uma amostra da população portuguesa, com exceção do fenótipo MVPA, o qual não foi avaliado, foram encontrados valores de $\mathrm{h}^{2}$ variando entre 28 a $45 \%$. Diferentemente do referido trabalho, o qual encontrou uma maior $\mathrm{h}^{2}$ no fenótipo WK $(45,6 \%)$ a $\mathrm{h}^{2}$ na amostra de Baependi foi de 10,4 a 10,9\%, o que mostra que a variação na prática de atividade leve numa amostra da população brasileira tem um componente genético herdável com efeitos aditivos menor que na da portuguesa. Em outras palavras, para WK, a influência de componentes ambientais na variância quando comparada aos genéticos é maior na amostra de Baependi que na da população portuguesa (ver equação 3.4). Quanto aos demais fenótipos, AFT e SB, as estimativas aqui encontradas foram menores mas não tão distantes das reportadas na amostra da população portuguesa. Essa discrepância nas estimativas, especialmente para WK, não surpreende, uma vez que reflete diferenças nos perfis de ambas as populações, já que estas tendem a ser afetadas por fatores socio-culturais e geopolíticos diversos e específicos ao local de amostragem, os quais certamente influenciam na variabilidade da prática de atividade física. Além disso, o background genético dessas populações é certamente diferente por refletir diferentes graus de miscigenação e ancestralidade.

Um segundo aspecto a ser considerado é que as estimativas de herdabilidades dependem de como a variável resposta, no presente caso, atividade física, é definida e mensurada. No presente estudo, utilizou-se variáveis derivadas de questionário, o IPAQ-SF. Apesar desse intrumento ser amplamente utilizado e de que alguns estudos mostram sua validação por meio de medidas de reprodutibilidade quando comparadas a outros questionários, também autoadiministrados, sua eficácia em mensurar 
Tabela 4.9: Seleção de covariáveis e estimativas de herdabilidades para os fenótipos de atividade fisica coletados pelo IPAQ-SF. SexI = Idade, idade ${ }^{2}$, sexo e seus efeitos de interação, IMC = Índice de Massa Corpórea, Cint = Circunferência da cintura, Pesc $=$ Circunferência do pescoço. ${ }^{*}=p$-valor da $h^{2}<0,05 . \diamond=p$-valor da covariável $<0,05 . \otimes=$ Modelo mal ajustado devido a curtose residual elevada.

\begin{tabular}{cccccc}
\hline \hline & $\mathrm{h}^{2}$ AFT MET & $\mathrm{h}^{2}$ WK MET & $\mathrm{h}^{2}$ MPA MET & $\mathrm{h}^{2}$ MVPA MET & $\mathrm{h}^{2} \mathrm{SB}$ \\
\hline Sem cov & $0,215 *$ & $0,112 *$ & $0,257 *$ & $0,224 *$ & $0,186 *$ \\
SexoI & $0,210 * \diamond$ & $0,112 *$ & $0,245 * \diamond$ & $0,217 * \diamond$ & $0,234 * \diamond$ \\
SexoI+Cint & $0,213 * \diamond$ & $0,106 * \diamond$ & $0,268 * \diamond \otimes$ & $0,224 * \diamond$ & $0,247 * \diamond$ \\
SexoI+IMC & $0,221 * \diamond$ & $0,109 * \diamond$ & $0,247 * \diamond \otimes$ & $0,226 * \diamond$ & $0,249 * \diamond$ \\
SexoI+Quad & $0,214 * \diamond$ & $0,107 * \diamond$ & $0,248 * \diamond \otimes$ & $0,217 *$ & $0,235 * \diamond$ \\
SexoI+Depressão & $0,236 *$ & $0,112 *$ & $0,251 *$ & $0,232 *$ & $0,226 *$ \\
SexoI+Fumo & $0,209 *$ & $0,112 *$ & $0,238 * \diamond \otimes$ & $0,217 *$ & $0,245 * \diamond$ \\
SexoI+Pesc & $0,216 * \diamond$ & $0,104 * \diamond$ & $0,267 * \diamond \otimes$ & $0,224 * \diamond$ & $0,247 * \diamond$ \\
\hline
\end{tabular}

atividade física é ainda bastante questionável [Craig et al., 2003]. Ekelund et al. [2006], por exemplo, compararam a quantidade de AF medida objetivamente por um acelerômetro e autorreportada pelo IPAQ-SF. Ainda que a especificidade do IPAQ-SF tenha sido relativamente alta (77\%), sua sensibilidade (verdadeiro positivo) foi bem baixa (45\%), o que evidencia que esse intrumento tende a subestimar a prática de AF. Por outro lado, Folley et al. [2018] destacam que em determinadas situações, relacionadas à estratificação da amostra utilizada, pode haver a superestimação da quantidade de AF reportada, o que ressalta a importância de se avaliar outras medidas de AF ou mesmo de se ajustar as utilizadas no IPAQ por outras variáveis.

Quanto à estratificação pelo sexo do indivíduo avaliada no presente trabalho, foi encontrada heterogeneidade para os componentes de variância, exceto no fenótipo SB. A Tabela 4.10 mostra os valores de $\mathrm{h}^{2}$ para cada um dos modelos de estratificação, sem a comparação entre eles pela LRT. Por sua vez, a Tabela 4.11 inclui os valores finais de $\mathrm{h}^{2}$ obtidos após a comparação e seleção dos modelos de estratificação. Semelhantemente aos resultados aqui apresentados, embora Horimoto et al. [2011] tenham empregado um questionário diferente, baseado no WHO-MONICA, não foi encontrada heterogeneidade nos componentes de variância nem diferença entre os sexos nas estimativas de $\mathrm{h}^{2}$ para sedentarismo. Entretanto, esses autores obtiveram sucesso ao reportar diferenças para alguns fenótipos de AF, como atividade física semanal e diária em indivíduos não sedentários.

É importante salientar que, em relação à estratificação pelo sexo nos componentes de variância, a indagação ou problema em questão consiste em: existe um efeito de interação entre gene e sexo (GSI) no fenótipo de interesse? Diversos trabalhos têm buscado responder a esse questionamento, enfrentando a dificuldade inicial de definir o conceito de GSI, cuja interpretação e relação com os componentes de variância não são de todo claras e objetivas [Diego et al., 2015]. Entretanto, 
as estimativas de $\mathrm{h}^{2}$ em sexos diferentes fornecem informações muito importantes, por meio de 3 possíveis cenários (Tabela 4.10):

- Existe diferença no componente de variância genético entre homens e mulheres, mas não no ambiental.

- Existe diferença no componente de variância ambiental entre homens e mulheres, mas não no genético.

- Existe diferença entre os sexos em ambos os componentes.

No caso do primeiro cenário, a igualdade no componente ambiental implica que o conjunto de fatores aleatórios associados com aspectos culturais, sociais e econômicos não diverge entre os sexos. Para muitas situações, esse cenário é muito provavelmente falacioso, uma vez que as diferenças entre os sexos são notáveis em culturas e populações diferentes, tanto em conjunturas históricas mais antigas quanto na atual.

Já no segundo, não há diferença na influência dos fatores genéticos aditivos sobre variação fenotípica, mas uma grande heterogeneidade nos fatores ambientais, ou seja, os aspectos socioculturais divergem entre homens e mulheres. Esse cenário é mais plausível sob a perspectiva sociocomportamental humana, entretanto, não abre espaço para as diferenças nos aspectos biológicos, tão claramente pontuadas na literatura [Hands e Parker, 2016].

Por sua vez, o terceiro cenário está de acordo com as diferenças entre os sexos tanto em fatores genéticos como ambientais, tendo uma maior probabilidade de acontecer em situações reais. Nesse contexto, considerando que a $\mathrm{h}^{2}$ é uma proporção, pode ser que a diferença no numerador, correspondente ao componente genético, se equilibre com a do denominador, que tem também o componente ambiental (Equação 3.4), fazendo com que as $\mathrm{h}^{2}$ de homens e mulheres sejam iguais. Tal situação tem implicações importantes para a mensuração de GSI, pois, nesse caso, $\mathrm{h}^{2}$ iguais não implicam em falta de GSI. Segundo esse racional, a avaliação de cada um dos componentes de variância $\left(\sigma_{g}^{2}\right.$ e $\left.\sigma_{e}^{2}\right)$ per si nos diferentes sexos é muito mais informativa.

Como esperado, as presentes análises se enquadraram de uma forma geral no terceiro cenário acima apresentado (Tabelas 4.10 e 4.11). Com exceção de SB, tanto o componente genético como o ambiental foi diferente em ambos os sexos. As herdabilidades foram maiores nos homens que nas mulheres para o fenótipo MVPA MET, cuja $\mathrm{h}^{2}$ em um dos modelos com estratificação foi 44,5\% e 13,4\% para o sexo masculino e o feminino, respectivamente (Tabela 4.10). Quanto a WK MET, observou-se o padrão oposto (Tabela 4.11). A maior $\mathrm{h}^{2}$ encontrada em homens para os fenótipos 
AFT MET e MVPA MET indica que a influência de fatores genéticos aditivos em suas variâncias é maior em homens que em mulheres, o que pode resultar tanto de GSI per si diferentes entre os sexos como de conjuntos de fatores genéticos diferentes influenciando esses fenótipos.

Quanto aos componentes de variância, foram obtidas estimativas maiores para o ambiental de homens nos fenótipos AFT MET, WK MET e MVPA MET, o que indica que fatores socioculturais atuam de forma mais intensa na variação do tempo dispendido em atividade física ponderado por MET em indivíduos do sexo masculino. Esse resultado corrobora com os achados de Horimoto et al. [2011], que reportaram um componente ambiental maior em homens num fenótipo de atividade física diária, mensurado por outro questionário. Já para o componente de variância genético, os homens apresentaram valores consideravelmente maiores, exceto no caso de WK. Assim, há igualdade no componente de variância genético da prática de atividade física leve em mulheres e homens, ou seja, para esse fenótipo, não há diferença no efeito dos fatores genéticos que segregam ao longo das gerações em indivíduos do sexo masculino comparados ao dos fatores que segregam em indivíduos do sexo feminino. No caso de AFT e MVPA, a maior variância no componente genético de homens indica que os fatores genéticos que segregam nesses indivíduos são mais heterogêneos. Dessa forma, esses resultados podem, ao menos em parte, explicar a tendência de homens precisarem praticar atividades físicas mais intensas que mulheres para conseguirem os mesmos benefícios de saúde, pois possivelmente os efeitos genéticos sobre o fenótipo seriam mais heterogêneos [Hands e Parker, 2016]. Isso fundamenta e estimula os estudos de mapeamento gênico, que podem apontar quais elementos ou variantes genéticas estão envolvidas com essas diferenças.

Não obstante, a interpretação dos resultados de $\mathrm{h}^{2}$ estratificada pelo sexo é ainda bem desafiante, uma vez que é difícil hipotetizar quais fatores exatos estão atuando diferentemente nos sexos e o quão influenciam na prática de atividade física e no sedentarismo. Um questionamento importante, ainda por ser investigado, é: como a heterogeneidade nos componentes de variância se relaciona com as atividades específicas a cada um dos sexos?

Ao contrário dos resultados aqui apresentados, nas estimativas feitas pelo grupo de Diego et al. [2015], não foi encontrada diferença na herdabilidade entre os sexos em nenhum dos fenótipos de atividade física, apenas num de sedentarismo (tempo gasto assistindo TV), o qual não foi avaliado no presente estudo. Como a abordagem de estratificação empregada por esse grupo foi diferente, torna-se difícil realizar uma comparação adequada desses resultados. Dessa forma, é importante, em análises futuras, utilizar as duas abordagens para comparar essas estimativas, verificando se os resultados se replicam.

Diversos outros trabalhos têm evidenciado a presença de fortes componentes genéticos em traços 
Tabela 4.10: Herdabilidade estratificada pelo sexo para Mulheres (M) e Homens (H). mod1 corresponde ao modelo sem estratificação, mod2 ao com heterogeneidade em pelo menos um dos componentes de variância, mod3 ao com heterogeneidade apenas no componente ambiental e mod4 ao com apenas no genético. $\diamond$ Modelo sem estratificação. ${ }^{*} p$-valor do LRT das comparações mod1-2, 1-3 e 1-4 <0,05, presentes nas colunas mod2, mod3 e mod4, respectivamente.

\begin{tabular}{cccccccc}
\hline \hline & $\bmod 1 \diamond$ & $\bmod 2 \mathrm{M}$ & $\bmod 2 \mathrm{H}$ & $\bmod 3 \mathrm{M}$ & $\bmod 3 \mathrm{H}$ & $\bmod 4 \mathrm{M}$ & $\bmod 4 \mathrm{H}$ \\
\hline AFT MET & 0,221 & $0,142 *$ & $0,349 *$ & $0,235 *$ & $0,182 *$ & $0,145 *$ & $0,357 *$ \\
WK MET & 0,109 & $0,127 *$ & $0,089 *$ & $0,119 *$ & $0,091 *$ & $0,042 *$ & $0,248 *$ \\
MVPA MET & 0,226 & $0,168 *$ & $0,320 *$ & $0,242 *$ & $0,158 *$ & $0,134 *$ & $0,445 *$ \\
SB & 0,276 & 0,219 & 0,350 & 0,276 & 0,288 & 0,293 & 0,266 \\
\hline
\end{tabular}

Tabela 4.11: Resultados finais dos ajustes e seleção de modelos específicos aos fenótipos de atividade fisica e sedentarismo. $h^{2} m=$ mulheres, $h^{2} h=$ homens, $\sigma=$ raiz quadrada do componente de variância.

\begin{tabular}{|c|c|c|c|c|c|c|c|c|c|}
\hline \multirow[t]{3}{*}{ Fenótipos } & \multirow{3}{*}{$\begin{array}{l}\text { Covariáveis no modelo } \\
\text { selecionado }\end{array}$} & \multirow[t]{3}{*}{ Modelo Selecionado } & \multirow{3}{*}{$\begin{array}{l}\text { Modelo sem } \\
\text { estratificação } \\
\mathrm{h}^{2}\end{array}$} & \multicolumn{6}{|c|}{ Modelo com estratificação } \\
\hline & & & & \multicolumn{6}{|c|}{ Genético e/ou ambiental } \\
\hline & & & & $\mathrm{h}_{m}^{2}$ & $\mathrm{~h}_{h}^{2}$ & $\sigma_{g} m$ & $\sigma_{e} m$ & $\sigma_{g} h$ & $\sigma_{e} h$ \\
\hline AFT MET & SexI + IMC & Ambos & 0,221 & 0,148 & 0,349 & 0,328 & 0,787 & 0,581 & 0,794 \\
\hline WK MET & SexI + IMC & Ambos & 0,109 & 0,127 & 0,089 & 0,299 & 0,785 & 0,292 & 0,933 \\
\hline MVPA MET & SexI + IMC & Ambos & 0,226 & 0,169 & 0,320 & 0,283 & 0,629 & 0,493 & 0,719 \\
\hline SB & SexI + IMC + Fumo & Sem estratificação & 0,276 & 0,219 & 0,350 & 0.453 & 0,855 & 0,569 & 0,776 \\
\hline
\end{tabular}

quantitativos relacionados à atividade física. A herdabilidade do IMC e circunferência da cintura, por exemplo, duas das covariáveis por nós utilizadas, foi de $51 \%$ e $40,1 \%$, respectivamente, sob o mesmo modelo basal, numa amostra da população de Baependi referente à primeira onda de coleta [de Oliveira et al., 2008] . Em um estudo com gêmeos holandeses, a h ${ }^{2}$ do volume máximo de oxigênio consumido em $\mathrm{ml} / \mathrm{min}\left(\mathrm{VO}_{\max }^{2}\right)$ foi $60 \%$ [Schutte et al., 2016a]. Analisando-se outros fenótipos, Schutte et al. [2016b] encontraram valores médios ponderados de $\mathrm{h}^{2}$ de 62,63 e $50 \%$ para pulo vertical, força de preensão manual e flexibilidade, respectivamente, numa metanálise de 15 estudos com gêmeos.

Assim, para estimativas fidedignas e comparáveis da herdabilidade de fenótipos relacionados à atividade física, é importante se definir esses traços o mais clara e objetivamente possível. Bush e Moore [2012], por exemplo, ressaltam a importância de se estabelecer um critério rigoroso e padronizado de definição de fenótipos para o sucesso dos estudos genéticos, como foi o caso do bem sucedido mapeamento gênico da esclerose múltipla [Polman et al., 2005].

Além das estimativas de herdabilidade per si, é importante se avaliar sua variação $\left(\Delta h^{2}=\left(h_{y}^{2}\right)\right.$ cov) $-h_{y}^{2}$ ) decorrente da inclusão de covariáveis como o IMC e Fumo, como forma de caracterizar uma eventual correlação entre a variável resposta e covariáveis. Como observado na Tabela 4.12, a inclusão dessas covariáveis em seus respectivos modelos ajustados e selecionados para os fenótipos de atividade física alterou a estimativa de $\mathrm{h}^{2}$ minimamente. Exceto para WK, houve um ligeiro aumento 
Tabela 4.12: Variação da herdabilidade após inclusão das covariáveis IMC e Fumo em fenótipos de atividade física.

\begin{tabular}{lllll} 
& $\Delta \mathrm{h}^{2}$ AFT MET & $\Delta \mathrm{h}^{2}$ WK MET & $\Delta \mathrm{h}^{2}$ MVPA MET & $\Delta \mathrm{h}^{2} \mathrm{SB}$ \\
\hline IMC & 0,011 & $-0,0031$ & 0,009 & 0,015 \\
Fumo & - & - & - & 0,011 \\
IMC+Fumo & - & - & - & 0,042 \\
\hline
\end{tabular}

nas estimativas de $\mathrm{h}^{2}$ colocando o IMC como covariável, o que significa que sua inclusão diminui o componente de variância ambiental em relação ao genético, ou seja, explica mais o componente residual do modelo. Caso tivesse sido encontrada uma diminuição na herdabilidade após a inclusão dessas covariáveis, poderia-se inferir que estas estavam presentes no componente aleatório genético do modelo, já que este teria diminuido (ver equação 3.4). Nesse cenário, haveria uma correlação entre os fatores genéticos associados tanto à atividade física como ao IMC, sendo possivelmente os mesmos. Entretanto, já que que essas variações na $\mathrm{h}^{2}$ foram muito pequenas, a possibilidade de que o mapeamento gênico identifique variantes genéticas que estejam associadas a ambos fenótipos de atividade física e IMC parece ser remota. Além disso, foi observado um aumento de $4 \%$ na estimativa de $\mathrm{h}^{2}$ para SB quando da adição de ambos IMC e Fumo, o que indica que a inclusão do tabagismo diminui o resíduo do modelo, ressaltando a importância da inclusão dessa covariável nas análises desse fenótipo.

Por último, é importante salientar que a interpretação das estimativas de herdabilidades devem ser cautelosas. O termo "herdabilidade"teve sua primeira utilização na obra Animal Breeding Plans, como uma medida quantitativa que representasse como a variação fenotípica se relaciona matematicamente à variação genética em uma população [Lush et al., 1943]. Assim, como discutido em Moore e Shenk [2017], a herdabilidade não deve ser interpretada como uma medida da real influência de genes no desenvolvimento de qualquer fenótipo, muito menos extrapolada para o nível do indíviduo, já que a mesma descreve a variação numa população e não um efeito na média fenotípica.

A necessidade de uma interpretação cautelosa da herdabilidade foi também bastante discutida por Lewontin [1974], o qual aponta a premissa de independência entre $\sigma_{g}^{2}$ e $\sigma_{e}^{2}$, ou seja, de que não existem efeitos de interação gene-ambiente, como o principal viés presente no modelo genético aditivo. Considerando a complexidade de muitos dos fenótipos na espécie humana, o que inclui a atividade física, é necessario considerar um modelo mais complexo para avaliação desses fenótipos quanto à estimativa de herdabilidade, que permita interpretações mais corretas e condizentes com os contextos biológicos, como a abordagem de estratificação pelo sexo que adotamos. 


\subsection{GWAS - Associação de SNPs e CNVs com fenótipos de ativi- dade física}

O mapeamento gênico foi realizado seguindo o modelo linear misto descrito na equação 3.6, em que y corresponde à variável resposta de atividade física. Como covariáveis, utilizamos as selecionadas na seção 4.3, que são específicas a cada fenótipo, além dos marcadores SNPs e CNVs. Para estes últimos, em particular, duas possíveis alternativas de inclusão desses efeitos fixos no modelo foram avaliadas:

- CNV como variável categórica, cujas categorias ou níveis 0, 1, 2, 3 e 4 correspondem a dupla deleção, deleção única, número de cópias normal, uma duplicação, e duas ou mais duplicações, respectivamente.

- CNV como variável dicotômica, em que 0 caracteriza o indivíduo com duas cópias e 1 o indivíduo com alguma alteração.

Construímos os gráficos Manhattan (do inglês Manhattan Plot), que mostram os picos de associação ao longo dos 22 pares de autossomos, com o objetivo de vizualizar os marcadores cuja associação com os fenótipos de atividade física tenha sido estatisticamente significante sob o nível de significância de $5,68 \times 10^{-6}$ e 5,92 $\times 10^{-8}$ nas análises de CNVs e SNPs, respectivamente. Esses valores foram adotados após a correção de Bonferroni. Os gráficos Manhattan são ubiquamente utilizados nessas análises de mapeamento por permitirem a fácil identificação dos marcadores associados.

\subsubsection{GWAS com SNPs}

Os gráficos Manhattan mostrando a associação dos SNPs nos modelos para os fenótipos transformados pela inversa normal e as tabelas com 20 menores p-valores são apresentados nas figuras $4.10,4.11,4.12$ e 4.13 e tabelas 4.13, 4.14, 4.15 e 4.16, respectivamente. Como observado pela linha de corte correspondente ao nível de significância de $5,92 \times 10^{-8}$ corrigido pelo método de Bonferroni, nenhum pico de associação significante foi encontrado para os fenótipos WK MET, MVPA MET e SB. Entretanto, para o fenótipo AFT MET, houve um SNP localizado exatamente na linha de corte. Esse marcador denominado rs1441720 está presente no cromossomo 4 e não possui função e localização gênica descrita na base dados SCAN [SCAN, 2019].

A pesquisa de anotação usando tanto a base de dados supracitada como a do NCBI para esse polimorfismo apontou que o mesmo está flanqueado por 2 genes, NPY5R e TKTL2. O gene NPY5R 
codifica para o receptor do neuropeptídeo Y e peptídeo YY, estando envolvido na regulação da ingestão de alimentos, desordens alimentares e obesidade, mas sem implicações conhecidas diretas com atividade física [NCBI, 2019]. Por sua vez, o gene TKTL2 foi recentemente identificado como codificador de uma genuína transketolase, a qual se sabe estar inserida nas vias metabólicas das pentoses fosfato e glicolítica, que por sua vez são recrutadas durante o exercício ou em resposta ao mesmo [Deshpande et al., 2019].

Por outro lado, a utilização de um critério mais flexível, $10^{-5}$, permitiu a visualização de 28,18 , 35 e 13 potenciais candidatos associados aos fenótipos de AFT, WK, MVPA e SB, respectivamente, distribuídos principalmente nos cromossomos 4, 5, 6, 8 e 14?. Dos candidatos apontados para o fenótipo AFT, 16 encontram-se em regiões intrônicas, enquanto os demais não possuem região propriamente identificada. Em particular, um desses polimorfismos (rs7679206), encontra-se no gene NPY5R, o qual flanqueia o rs1441720 discutido anteriormente e apontado como significativo pela correção de Bonferroni. Isso indica que possivelmente esses dois marcadores encontram-se em desequilíbrio de ligação e dá suporte à hipótese de que o gene NPY5R possa estar envolvido biologicamente com a prática de atividade física total. Dentre os demais genes nos quais encontrouse marcadores candidatos, observou-se alguns envolvidos no funcionamento de células nervosas como o CDH8 e NXPH1.

Quanto ao fenótipo WK, a maior parte dos SNPs encontram-se em regiões intrônicas, exceto o rs10163109, caracterizado por uma substituição sinônima na região codificante do gene MYO5C. Apesar desse gene codificar para uma miosina, esta proteína em particular, pertencente a uma classe não tradicional de miosinas, não possui funções na contratilidade das fibras musculares, mas sim no tráfego de organelas, sendo majoritariamente expressa em células epiteliais [Jacobs et al., 2009]. Dos polimorfismos encontrados em regiões intrônicas, merece destaque o rs10759021, presente no gene PTPRD, que codifica para uma proteína fosfatase que tem sido implicada no crescimento de neuritos in vitro e, mais recentemente, associados com os emaranhados neurofibrilares na doença de Alzheimer [Chibnik et al., 2018, Gonzalez-Brito e Bixby, 2006].

Para o fenótipo MVPA, a maior parte dos SNPs candidatos não possui localização gênica ou intergênica descrita. Alguns polimorfismos foram encontrados em íntrons, dentre os quais dois localizam-se no gene PRKCH, que codifica para uma proteína da família das proteína quinase C (PKC). Interessantemente, o rs17098579 presente nesse gene foi também apontado na análise para o fenótipos AFT, mas não possui nenhuma implicação em fenótipos de atividade física em outros trabalhos até a presente data. Além disso, foram encontrados três polimorfismos presentes nos genes ADAMTS3, EXT1 e GNA14, que têm sido relacionados à estrutura e funcionalidade de 
cartilagens articulares [Blazek et al., 2016, Ren et al., 2018, Wuyts et al., 2013]. Recentemente, por meio de uma análise de redes de interação gênica usando dados de microarranjo, Ren et al. [2018] identificaram o gene GNA14 como um dos participantes no processo patológico do estiramento do manguito rotador, um músculo importante para a estabilização do ombro.

Para SB, alguns SNPs candidatos foram também encontrados em regiões próximas às extremidades 3'e 5'de alguns genes, como o OTOP3, que codifica para um canal iônico próton-seletivo na membrana plasmática, o ZNF266. Além disso, foram encontrados dois SNPs em regiões intrônicas no gene KCNIP (que codifica uma proteína pertencente à família de sensores neuronais de cálcio).

A presença de alguns SNPs candidatos no cromossomo 6 corrobora com os resultados de Klimentidis et al. [2018], os quais encontraram alguns marcadores no cromossomo associados com MVPA. A elucidação dos possíveis papéis biológicos dessas variantes candidatas está ainda por ser investigada e se configura de grande importância para o melhor entendimento da arquitetura genética por trás desses fenótipos.

Assim como para as variáveis transformadas pela inversa normal, as transformadas pelo log não apresentaram associação significativa em nenhum SNP (Figuras D.1. D.2, D.3 e D.4 e tabelas E.5, E.6, E.7 e E.8). Além disso, não houve nenhum pico próximo ao limiar de significância, o que mostra que esta transformação não foi adequada no sentido de apontar marcadores SNPs associados com os fenótipos de atividade física e sedentarismo.

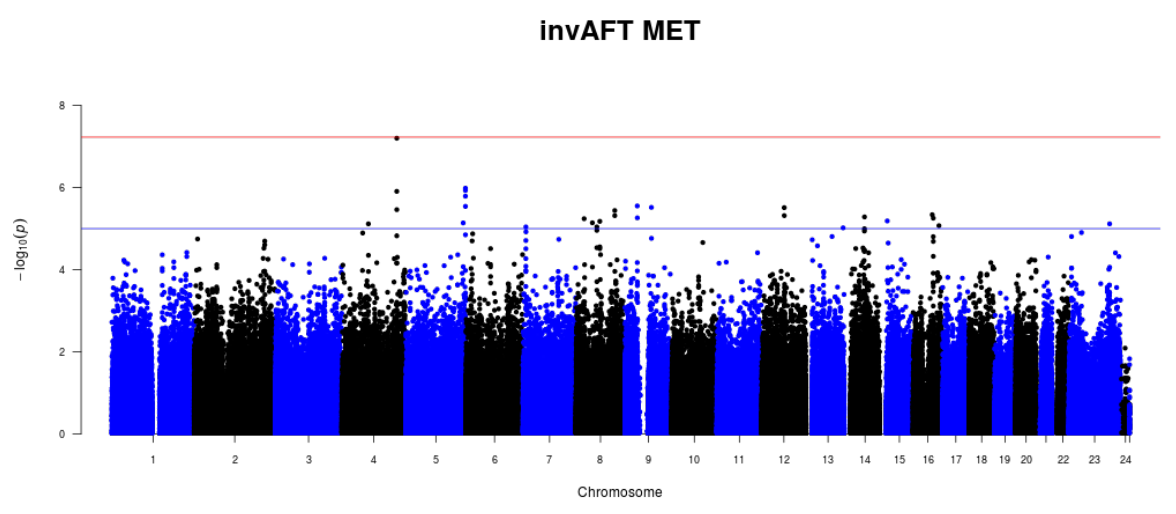

Figura 4.10: Gráfico Manhattan de associação de SNPs com atividade física total (inv AFT). O eixo y indica o $-\log _{10}(p)$ valor dos testes de associação para cada SNP. Por sua vez, o eixo $x$ indica em $p b$ dos SNPs ao longo dos 22 autossomos e cromossomos sexuais, indicados como 23 e 24. 


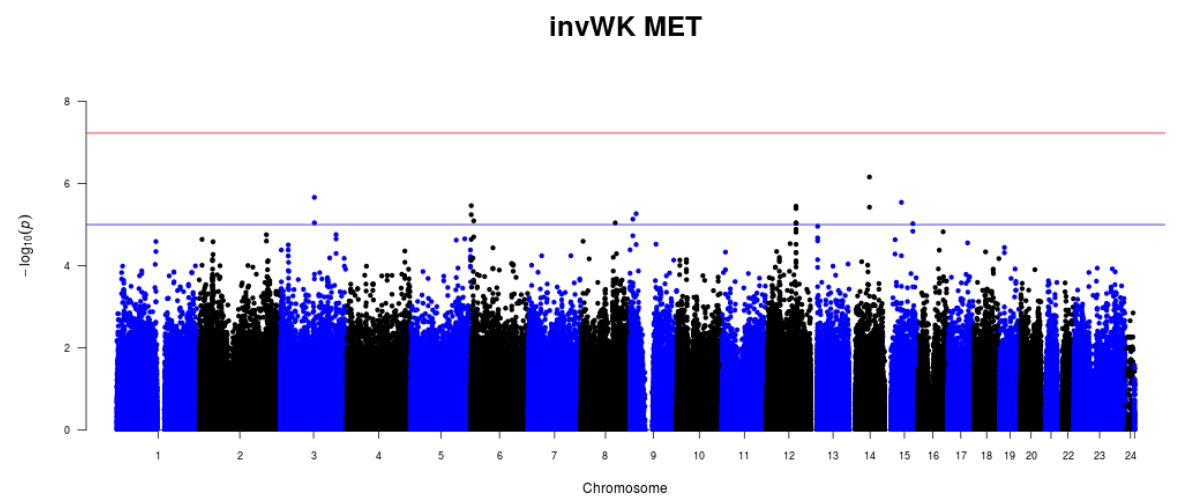

Figura 4.11: Gráfico Manhattan de associação de SNPs com atividade física leve (inv WK). O eixo y indica $o-\log _{10}(p)$ valor dos testes de associação para cada SNP. Por sua vez, o eixo $x$ indica em pb dos SNPs ao longo dos 22 autossomos e cromossomos sexuais, indicados como 23 e 24.

invMVPA MET

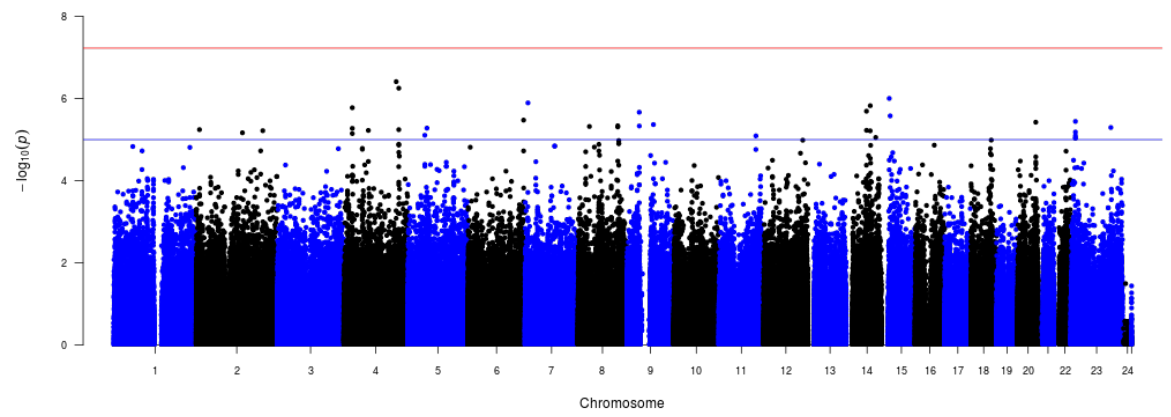

Figura 4.12: Gráfico Manhattan de associação de SNPs com atividade física leve (inv MVPA). O eixo y indica o $-\log _{10}(p)$ valor dos testes de associação para cada SNP. Por sua vez, o eixo $x$ indica em $p b$ dos SNPs ao longo dos 22 autossomos e cromossomos sexuais, indicados como 23 e 24.

invSB

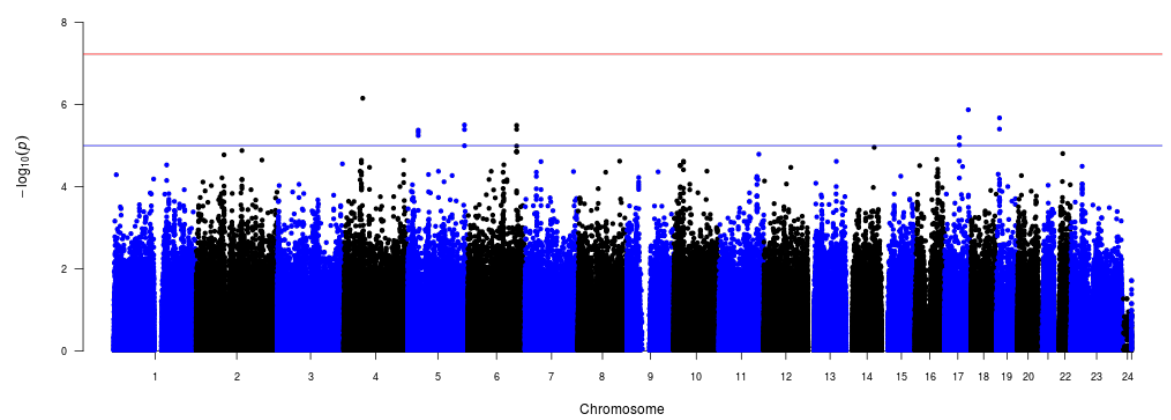

Figura 4.13: Gráfico Manhattan de associação de SNPs com atividade física leve (inv SB). O eixo y indica $o-\log _{10}(p)$ valor dos testes de associação para cada SNP. Por sua vez, o eixo $x$ indica em $p b$ dos SNPs ao longo dos 22 autossomos e cromossomos sexuais, indicados como 23 e 24. 
Tabela 4.13: Os 20 SNPs com os menores p-valores nos testes de associação com invAFT

\begin{tabular}{|c|c|c|c|c|c|}
\hline SNP & Cromossomo & $\mathrm{pb}$ & Alelo & Coeficiente beta & $\mathrm{P}$-valor \\
\hline rs1441720 & 4 & $164,577,424$ & $\mathrm{~T}$ & -0.341 & $6.31194 \mathrm{e}-08$ \\
\hline rs4701132 & 5 & $178,917,876$ & $\mathrm{~A}$ & -0.278 & $1.03887 \mathrm{e}-06$ \\
\hline rs4701130 & 5 & $178,915,022$ & $\mathrm{C}$ & -0.260 & $1.17511 \mathrm{e}-06$ \\
\hline rs7679206 & 4 & $164,488,684$ & $\mathrm{~T}$ & -0.274 & $1.23993 \mathrm{e}-06$ \\
\hline rs4701131 & 5 & $178,915,052$ & $\mathrm{G}$ & -0.255 & $1.62156 \mathrm{e}-06$ \\
\hline rs4483247 & 9 & $37,035,825$ & $\mathrm{C}$ & 0.370 & $2.80584 \mathrm{e}-06$ \\
\hline rs6895677 & 5 & $178,949,270$ & $\mathrm{~A}$ & -0.282 & $2.86852 \mathrm{e}-06$ \\
\hline rs17063753 & 9 & $79,375,723$ & $\mathrm{~A}$ & 0.733 & $3.04278 \mathrm{e}-06$ \\
\hline rs2439755 & 12 & $67,276,385$ & $\mathrm{~A}$ & 0.259 & $3.08425 \mathrm{e}-06$ \\
\hline rs4691921 & 4 & $164,581,586$ & $\mathrm{G}$ & -0.313 & $3.45449 \mathrm{e}-06$ \\
\hline rs2884249 & 8 & $115,860,432$ & $\mathrm{~T}$ & 0.280 & $3.63299 \mathrm{e}-06$ \\
\hline rs 8045775 & 16 & $57,425,356$ & $\mathrm{C}$ & 0.247 & $4.58612 \mathrm{e}-06$ \\
\hline rs1966751 & 12 & $67,271,472$ & $\mathrm{G}$ & 0.249 & $4.82454 \mathrm{e}-06$ \\
\hline rs7843119 & 8 & $115,858,530$ & $\mathrm{~T}$ & 0.299 & $4.83586 \mathrm{e}-06$ \\
\hline rs17098579 & 14 & $61,035,362$ & G & 0.815 & 5.18801e-06 \\
\hline rs12376809 & 9 & $37,115,911$ & $\mathrm{~T}$ & 0.355 & $5.46695 \mathrm{e}-06$ \\
\hline rs4784168 & 16 & $60,480,156$ & $\mathrm{G}$ & 0.255 & $5.5605 \mathrm{e}-06$ \\
\hline rs870033 & 8 & $24,163,410$ & $\mathrm{~A}$ & -0.303 & $5.73866 \mathrm{e}-06$ \\
\hline rs6576404 & 15 & $22,883,811$ & $\mathrm{~A}$ & 0.834 & $6.50533 \mathrm{e}-06$ \\
\hline rs10112802 & 8 & $71,130,733$ & $\mathrm{G}$ & 0.236 & $6.64414 \mathrm{e}-06$ \\
\hline
\end{tabular}

Tabela 4.14: $O s$ 20 SNPs com os menores p-valores nos testes de associação com invWK

\begin{tabular}{cccccc}
\hline \hline SNP & Cromossomo & pb & Alelo & Coeficiente beta & P-valor \\
\hline rs1536014 & 14 & $60,950,281$ & $\mathrm{C}$ & 0.347 & $6.94177 \mathrm{e}-07$ \\
rs2197897 & 3 & $102,254,217$ & $\mathrm{~T}$ & 0.257 & $2.17186 \mathrm{e}-06$ \\
rs10163109 & 15 & $50,326,965$ & $\mathrm{G}$ & 0.602 & $2.87595 \mathrm{e}-06$ \\
rs1933646 & 6 & 700,033 & $\mathrm{~T}$ & 0.506 & $3.4604 \mathrm{e}-06$ \\
rs2407206 & 12 & $87,467,454$ & $\mathrm{C}$ & 0.272 & $3.57172 \mathrm{e}-06$ \\
rs11852192 & 14 & $60,957,230$ & $\mathrm{~A}$ & 0.325 & $3.75972 \mathrm{e}-06$ \\
rs1352947 & 12 & $87,484,858$ & $\mathrm{G}$ & 0.288 & $4.05972 \mathrm{e}-06$ \\
rs13287455 & 9 & $18,626,050$ & $\mathrm{~T}$ & 0.671 & $5.43814 \mathrm{e}-06$ \\
rs2804756 & 6 & 698,586 & $\mathrm{~A}$ & 0.497 & $5.73644 \mathrm{e}-06$ \\
rs10759021 & 9 & $8,931,696$ & $\mathrm{G}$ & 0.240 & $7.34752 \mathrm{e}-06$ \\
rs9502693 & 6 & $8,161,900$ & $\mathrm{G}$ & 0.234 & $8.09297 \mathrm{e}-06$ \\
rs1900910 & 3 & $102,266,522$ & $\mathrm{~A}$ & 0.234 & $9.01213 \mathrm{e}-06$ \\
rs4734023 & 8 & $102,375,801$ & $\mathrm{~T}$ & -0.231 & $9.07166 \mathrm{e}-06$ \\
rs3782180 & 12 & $87,477,530$ & $\mathrm{C}$ & 0.259 & $9.14843 \mathrm{e}-06$ \\
rs3782179 & 12 & $87,477,457$ & $\mathrm{G}$ & 0.259 & $9.23399 \mathrm{e}-06$ \\
rs4474514 & 12 & $87,478,090$ & $\mathrm{G}$ & 0.259 & $9.23399 \mathrm{e}-06$ \\
rs11104952 & 12 & $87,480,531$ & $\mathrm{~A}$ & 0.259 & $9.23399 \mathrm{e}-06$ \\
rs8042880 & 15 & $84,532,368$ & $\mathrm{~T}$ & -0.225 & $9.47615 \mathrm{e}-06$ \\
rs4770010 & 13 & $19,840,037$ & $\mathrm{~A}$ & 0.228 & $1.09793 \mathrm{e}-05$ \\
rs1472899 & 12 & $87,475,616$ & $\mathrm{C}$ & 0.254 & $1.30468 \mathrm{e}-05$ \\
\hline
\end{tabular}


Tabela 4.15: Os 20 SNPs com os menores p-valores nos testes de associação com invMVPA

\begin{tabular}{cccccc}
\hline \hline SNP & Cromossomo & pb & Alelo & Coeficiente beta & P-valor \\
\hline rs7667749 & 4 & $156,750,782$ & $\mathrm{G}$ & 0.910 & $3.87598 \mathrm{e}-07$ \\
rs1441720 & 4 & $164,577,424$ & $\mathrm{~T}$ & -0.277 & $5.60722 \mathrm{e}-07$ \\
rs6576404 & 15 & $22,883,811$ & $\mathrm{~A}$ & 0.787 & $9.93735 \mathrm{e}-07$ \\
rs17427703 & 7 & $8,806,235$ & $\mathrm{C}$ & 0.642 & $1.27566 \mathrm{e}-06$ \\
rs8008338 & 14 & $72,312,223$ & $\mathrm{C}$ & 0.511 & $1.49245 \mathrm{e}-06$ \\
rs10517083 & 4 & $25,317,039$ & $\mathrm{~T}$ & -0.226 & $1.67447 \mathrm{e}-06$ \\
rs17098666 & 14 & $61,053,256$ & $\mathrm{~A}$ & 0.775 & $2.03322 \mathrm{e}-06$ \\
rs4483247 & 9 & $37,035,825$ & $\mathrm{C}$ & 0.327 & $2.15197 \mathrm{e}-06$ \\
rs745331 & 15 & $25,602,742$ & $\mathrm{C}$ & 0.244 & $2.64369 \mathrm{e}-06$ \\
rs3127351 & 6 & $166,517,803$ & $\mathrm{G}$ & 0.794 & $3.34977 \mathrm{e}-06$ \\
rs5934153 & 23 & $14,073,370$ & $\mathrm{G}$ & -0.227 & $3.60331 \mathrm{e}-06$ \\
rs6064348 & 20 & $54,199,726$ & $\mathrm{~T}$ & 0.235 & $3.76904 \mathrm{e}-06$ \\
rs17063753 & 9 & $79,375,723$ & $\mathrm{~A}$ & 0.631 & $4.30372 \mathrm{e}-06$ \\
rs7835395 & 8 & $118,930,184$ & $\mathrm{~T}$ & 0.360 & $4.60951 \mathrm{e}-06$ \\
rs12376809 & 9 & $37,115,911$ & $\mathrm{~T}$ & 0.311 & $4.66122 \mathrm{e}-06$ \\
rs10110998 & 8 & $34,064,076$ & $\mathrm{C}$ & 0.388 & $4.78892 \mathrm{e}-06$ \\
rs10111990 & 8 & $118,929,145$ & $\mathrm{~A}$ & 0.359 & $4.90913 \mathrm{e}-06$ \\
rs5957522 & 23 & $120,046,463$ & $\mathrm{~T}$ & 0.382 & $5.07538 \mathrm{e}-06$ \\
rs16887978 & 5 & $57,593,578$ & $\mathrm{G}$ & 0.618 & $5.26554 \mathrm{e}-06$ \\
rs10018315 & 4 & $25,314,542$ & $\mathrm{G}$ & -0.217 & $5.3058 \mathrm{e}-06$ \\
\hline
\end{tabular}

Tabela 4.16: Os 20 SNPs com os menores p-valores nos testes de associação com invSB

\begin{tabular}{cccccc}
\hline \hline SNP & Cromossomo & pb & Alelo & Coeficiente beta & P-valor \\
\hline rs4865055 & 4 & $56,681,169$ & $\mathrm{C}$ & -0.398 & $7.02396 \mathrm{e}-07$ \\
rs1994718 & 17 & $70,457,440$ & $\mathrm{C}$ & -0.306 & $1.34271 \mathrm{e}-06$ \\
rs1433060 & 19 & $9,407,329$ & $\mathrm{~A}$ & -0.508 & $2.11417 \mathrm{e}-06$ \\
rs10076795 & 5 & $170,013,947$ & $\mathrm{C}$ & -0.505 & $3.1454 \mathrm{e}-06$ \\
rs500566 & 6 & $145,644,112$ & $\mathrm{G}$ & 0.417 & $3.21432 \mathrm{e}-06$ \\
rs8104971 & 19 & $9,241,978$ & $\mathrm{C}$ & -0.366 & $3.9446 \mathrm{e}-06$ \\
rs494020 & 6 & $145,644,809$ & $\mathrm{C}$ & 0.450 & $4.0148 \mathrm{e}-06$ \\
rs10039227 & 5 & $170,023,873$ & $\mathrm{C}$ & -0.494 & $4.05277 \mathrm{e}-06$ \\
rs6869981 & 5 & $31,602,404$ & $\mathrm{C}$ & -0.316 & $4.20248 \mathrm{e}-06$ \\
rs6891195 & 5 & $31,602,359$ & $\mathrm{C}$ & -0.315 & $4.75187 \mathrm{e}-06$ \\
rs1046625 & 5 & $31,595,233$ & $\mathrm{C}$ & -0.308 & $5.68176 \mathrm{e}-06$ \\
rs11079826 & 17 & $43,952,047$ & $\mathrm{C}$ & 0.270 & $6.31928 \mathrm{e}-06$ \\
rs11651168 & 17 & $43,952,192$ & $\mathrm{G}$ & -0.265 & $9.62054 \mathrm{e}-06$ \\
rs10065535 & 5 & $170,025,434$ & $\mathrm{~T}$ & -0.496 & $1.00724 \mathrm{e}-05$ \\
rs544793 & 6 & $145,645,323$ & $\mathrm{~T}$ & 0.389 & $1.0272 \mathrm{e}-05$ \\
rs11159676 & 14 & $84,214,187$ & $\mathrm{~T}$ & -0.423 & $1.10334 \mathrm{e}-05$ \\
rs12612658 & 2 & $136,931,217$ & $\mathrm{G}$ & -0.279 & $1.31996 \mathrm{e}-05$ \\
rs482410 & 6 & $145,647,522$ & $\mathrm{~A}$ & 0.382 & $1.39629 \mathrm{e}-05$ \\
rs579234 & 6 & $145,649,569$ & $\mathrm{~A}$ & 0.386 & $1.41766 \mathrm{e}-05$ \\
rs581234 & 6 & $145,649,820$ & $\mathrm{C}$ & 0.386 & $1.41766 \mathrm{e}-05$ \\
\hline
\end{tabular}




\subsubsection{GWAS com CNVs como covariáveis categóricas}

Os gráficos Manhattan mostrando a associação dos CNVs inseridos como covariáveis categóricas, com os p-valores para cada CNV nos modelos para os fenótipos transformados pela inversa normal, bem como as tabelas com 20 menores p-valores, são apresentados nas figuras 4.14, 4.15, 4.16 e 4.17, e tabelas $4.17,4.18,4.20$ e 4.19 .

Assumindo-se o nível de significância de $5,68 \times 10^{-6}$, não foi encontrada associação significante para os fenótipos transformados pela inversa normal, exceto para WK MET. Em particular, pôde-se observar 3 CNVs cujos p-valores alcançaram o limiar estabelecido pelo nível de significância adotado, além de outro CNV logo abaixo (Figura 4.15 e Tabela 4.18). Essas variantes estão dispostas em uma sequência contínua que se estende da posição 95.013 .278 à 95.022 .270 no cromossomo 6, e correspondem a dupla delecões. Pela consulta à base de dados de anotação de SNPs e CNVs (SCAN, do inglês SNP and CNV Annotation Database), essa sequência possui 34 SNPs ([SCAN, 2019]), os quais não possuem quaiquer funções biológicas descritas. Por conta disso, essa base de dados sugere que esses SNPs estão possivelmente presentes em regiões intergênicas.

Por outro lado, ao se adotar um critério mais flexível $\left(10^{-3}\right)$, pôde-se observar um número maior de marcadores CNV candidatos (27), os quais se localizam principalmente nos cromossomos 3, 6 e em menor grau, no 7. Devido à proximidade entre si dessas variantes estruturais, dentro de um dado cromossomo, é possível que elas estejam em desequilíbrio de ligação (LD). Interessantemente, em um GWAS para MVPA, Klimentidis et al. [2018] encontraram vários picos significantes de associação distribuídos nos cromossomos 6 e 7. Entretanto, após a pesquisa de anotação pelo SCAN, observou-se que os marcadores presentes nos CNVs aqui apontados, incluindo os presentes nesses cromossomos, encontram-se massivamente em regiões intrônicas de genes de funções biológicas ainda desconhecidas.

Uma vez que não foi encontrado associação estatisticamente significante sob a correção de Bonferroni para a maior parte dos fenótipos, decidimos testar se esses resultados seriam os mesmos para variáveis transformadas por métodos mais tradicionais, como a transformação logarítmica. Assim, fez-se o mapeamento para esses fenótipos, cujos manhattans e tabelas estão apresentados no apêndice D. Dentre essas variáveis, apenas MVPA MET apresentou picos de associação significantes. Para esse fenótipo, encontrou-se 2 CNVs no cromossomo 1 presentes em 3 cópias dispostos em sequência, iniciando na posição 72.522.437 e terminando na 72.528.701. Essa região possui 41 SNPs, os quais estão presentes num íntron do gene LOC100132353. Entretanto,os registros do NCBI para esse gene foram apagados pois o modelo no qual foi baseado não foi predito numa anotação 
posterior. Além disso, nenhum desses SNPs foi em algum momento apontado como significante para MVPA MET em outros GWAS e não foi encontrado SNPs significantes em outros GWAS presentes no cromossomo 1 [SCAN, 2019].

invAFT MET (CNV como covariável categórica)

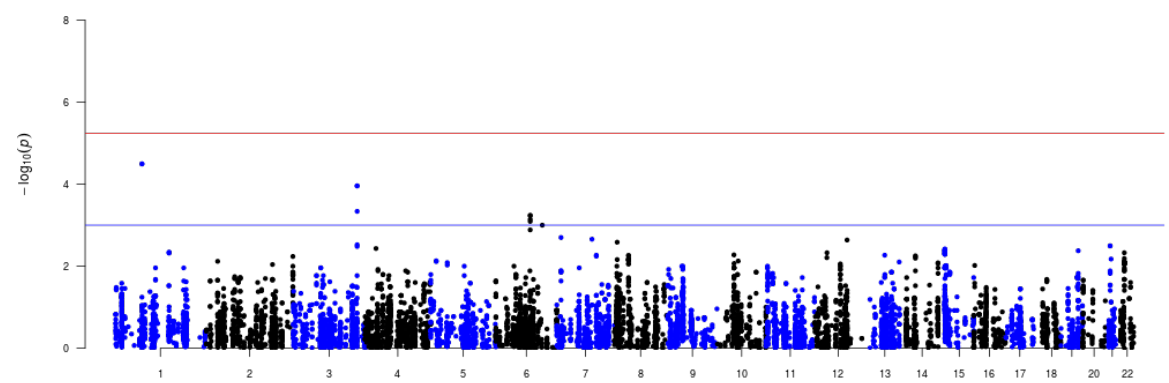

Figura 4.14: Gráfico Manhattan de associação de CNVs com atividade física total (invAFT MET). O eixo y indica o $-\log _{10}(p)$ valor dos testes de associação para cada $C N V$. Por sua vez, o eixo $x$ indica a posição central em pb dos CNVs ao longo dos 22 autossomos.

invWK MET (CNV como covariável categórica)

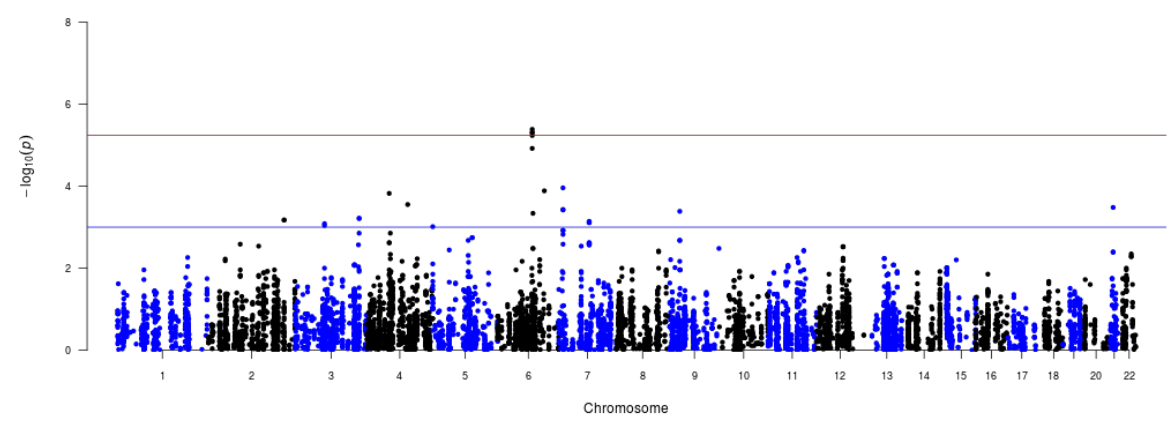

Figura 4.15: Gráfico Manhattan de associação de CNVs com atividade física total (invWK MET). O eixo y indica o $-\log _{10}(p)$ valor dos testes de associação para cada $C N V$. Por sua vez, o eixo $x$ indica a posição central em pb dos CNVs ao longo dos 22 autossomos.

invMVPA MET (CNV como covariável categórica)

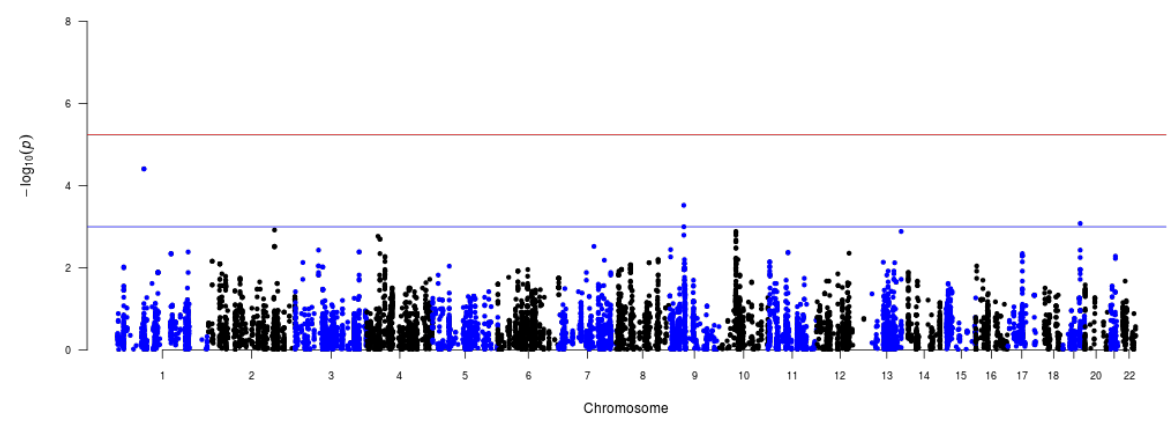

Figura 4.16: Gráfico Manhattan de associação de CNVs com atividade física total (invMVPA MET). O eixo y indica o $-\log _{10}(p)$ valor dos testes de associação para cada $C N V$. Por sua vez, o eixo $x$ indica a posição central em pb dos CNVs ao longo dos 22 autossomos. 
invSB (CNV como covariável categórica)

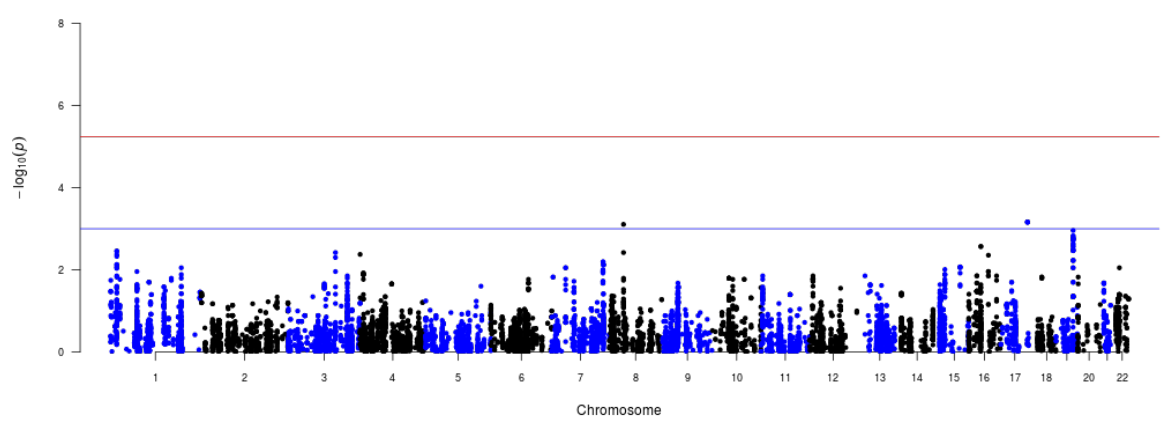

Figura 4.17: Gráfico Manhattan de associação de CNVs com sedentarismo (inv SB). O eixo y indica o $-\log _{10}(p)$ valor dos testes de associação para cada CNV. Por sua vez, o eixo $x$ indica a posição central em pb dos CNVs ao longo dos 22 autossomos.

Tabela 4.17: Os 20 CNVs (covariável categórica) com os menores p-valores nos testes de associação com invAFT MET.

\begin{tabular}{cccccc}
\hline \hline Cromossomo & Começo & Fim & Nível do Fator & Coeficiente beta & P-valor \\
\hline 1 & 72.522 .437 & 72.522 .941 & CNV3 & 0,011 & $3,2 \mathrm{e}-05$ \\
1 & 72.522 .942 & 72.528 .701 & CNV3 & 0,011 & $3,2 \mathrm{e}-05$ \\
3 & 177.365 .650 & 177.366 .443 & CNV1 & 0,818 & 0,00011 \\
3 & 177.366 .444 & 177.370 .753 & CNV1 & 0,818 & 0,00011 \\
3 & 177.363 .445 & 177.365 .649 & CNV1 & 0,762 & 0,00046 \\
6 & 95.013 .278 & 95.013 .611 & CNV0 & $-0,815$ & 0,00058 \\
6 & 95.013 .612 & 95.014 .239 & CNV0 & $-0,815$ & 0,00058 \\
6 & 95.019 .273 & 95.022 .270 & CNV0 & $-0,557$ & 0,00072 \\
6 & 95.014 .240 & 95.015 .708 & CNV0 & $-0,816$ & 0,00081 \\
6 & 128.369 .454 & 128.375 .929 & CNV0 & 0,051 & 0,001 \\
6 & 95.015 .709 & 95.019 .272 & CNV0 & $-0,561$ & 0,0013 \\
7 & 11.712 .040 & 11.714 .189 & CNV0 & 0,034 & 0,002 \\
7 & 97.233 .397 & 97.233 .445 & CNV0 & $-0,497$ & 0,0022 \\
12 & 89.987 .153 & 89.990 .576 & CNV1 & 0,784 & 0,0023 \\
8 & 8.027 .374 & 8.027 .704 & CNV1 & $-0,877$ & 0,0026 \\
3 & 177.370 .754 & 177.377 .701 & CNV1 & 0,451 & 0,003 \\
21 & 13.374 .734 & 13.378 .287 & CNV3 & $-0,521$ & 0,0032 \\
21 & 13.378 .288 & 13.386 .250 & CNV3 & $-0,521$ & 0,0032 \\
3 & 177.377 .702 & 177.378 .387 & CNV1 & 0,446 & 0,0033 \\
4 & 30.048 .496 & 30.049 .257 & CNV1 & 0,772 & 0,0037 \\
\hline
\end{tabular}


Tabela 4.18: Os 20 CNVs (covariável categórica) com os menores p-valores nos testes de associação com invWK MET.

\begin{tabular}{cccccc}
\hline \hline Cromossomo & Começo & Fim & Nível do Fator & Coeficiente beta & P-valor \\
\hline 6 & 95.019 .273 & 95.022 .270 & CNV0 & $-0,614$ & $4,1 \mathrm{e}-06$ \\
6 & 95.013 .278 & 95.013 .611 & CNV0 & $-0,876$ & $4,9 \mathrm{e}-06$ \\
6 & 95.013 .612 & 95.014 .239 & CNV0 & $-0,876$ & $4,9 \mathrm{e}-06$ \\
6 & 95.014 .240 & 95.015 .708 & CNV0 & $-0,876$ & $5,8 \mathrm{e}-06$ \\
6 & 95.015 .709 & 95.019 .272 & CNV0 & $-0,616$ & $1,2 \mathrm{e}-05$ \\
7 & 11.712 .040 & 11.714 .189 & CNV0 & 0,079 & 0,00011 \\
6 & 128.369 .454 & 128.375 .929 & CNV0 & $-0,033$ & 0,00013 \\
4 & 61.098 .077 & 61.098 .872 & CNV0 & $-0,698$ & 0,00015 \\
4 & 112.092 .131 & 112.098 .054 & CNV0 & $-0,169$ & 0,00028 \\
21 & 16.089 .237 & 16.096 .268 & CNV0 & $-0,426$ & 0,00033 \\
7 & 11.719 .857 & 11.720 .617 & CNV0 & 0,124 & 0,00037 \\
7 & 11.719 .723 & 11.719 .856 & CNV0 & $-0,019$ & 0,00038 \\
9 & 30.581 .833 & 30.582 .521 & CNV0 & $-0,729$ & 0,00041 \\
6 & 97.092 .253 & 97.103 .331 & CNV0 & $-0,448$ & 0,00046 \\
3 & 177.365 .650 & 177.366 .443 & CNV1 & 0,704 & 0,00061 \\
3 & 177.366 .444 & 177.370 .753 & CNV1 & 0,704 & 0,00061 \\
2 & 212.870 .414 & 212.870 .593 & CNV1 & 0,816 & 0,00067 \\
2 & 212.870 .594 & 212.872 .288 & CNV1 & 0,816 & 0,00067 \\
7 & 84.045 .697 & 84.046 .808 & CNV0 & $-0,175$ & 0,00072 \\
7 & 84.037 .854 & 84.038 .043 & CNV0 & $-0,149$ & 0,00076 \\
\hline
\end{tabular}

Tabela 4.19: Os 20 CNVs (covariável categórica) com os menores p-valores nos testes de associação com invMVPA MET.

\begin{tabular}{cccccc}
\hline \hline Cromossomo & Começo & Fim & Nível do Fator & Coeficiente beta & P-valor \\
\hline 1 & 72.522 .437 & 72.522 .941 & CNV3 & 0,116 & $3,9 \mathrm{e}-05$ \\
1 & 72.522 .942 & 72.528 .701 & CNV3 & 0,116 & $3,9 \mathrm{e}-05$ \\
9 & 41.832 .530 & 41.844 .479 & CNV3 & 0,051 & $3 \mathrm{e}-04$ \\
19 & 48.394 .874 & 48.404 .090 & CNV3 & $-0,489$ & 0,00083 \\
9 & 41.882 .867 & 41.887 .112 & CNV3 & 0,005 & 0,001 \\
2 & 186.243 .870 & 186.246 .637 & CNV1 & 0,140 & 0,0012 \\
10 & 46.834 .288 & 46.839 .717 & CNV3 & $-0,434$ & 0,0013 \\
13 & 103.201 .725 & 103.203 .139 & CNV1 & 0,075 & 0,0013 \\
10 & 46.790 .325 & 46.790 .374 & CNV3 & $-0,430$ & 0,0014 \\
9 & 41.844 .480 & 41.882 .866 & CNV3 & 0,051 & 0,0016 \\
10 & 46.812 .339 & 46.834 .287 & CNV3 & $-0,432$ & 0,0016 \\
4 & 30.048 .496 & 30.049 .257 & CNV1 & 0,731 & 0,0017 \\
4 & 35.515 .167 & 35.515 .852 & CNV1 & $-0,058$ & 0,002 \\
4 & 35.515 .853 & 35.518 .479 & CNV1 & $-0,027$ & 0,002 \\
10 & 46.790 .375 & 46.812 .338 & CNV3 & $-0,425$ & 0,0021 \\
10 & 46.669 .594 & 46.684 .870 & CNV3 & $-0,416$ & 0,0023 \\
10 & 46.684 .871 & 46.790 .324 & CNV3 & $-0,415$ & 0,0023 \\
2 & 186.246 .638 & 186.248 .915 & CNV1 & 0,351 & 0,003 \\
2 & 186.248 .916 & 186.249 .178 & CNV1 & 0,434 & 0,003 \\
7 & 97.233 .397 & 97.233 .445 & CNV0 & $-0,262$ & 0,003 \\
\hline
\end{tabular}


Tabela 4.20: Os 20 CNVs (covariável categórica) com os menores p-valores nos testes de associação com invSB.

\begin{tabular}{cccccc}
\hline \hline Cromossomo & Começo & Fim & Nível do Fator & Coeficiente beta & P-valor \\
\hline 17 & 75.358 .872 & 75.362 .413 & CNV4 & 0,033 & 0,00068 \\
17 & 75.362 .414 & 75.364 .528 & CNV4 & $-0,217$ & 0,00069 \\
17 & 75.364 .529 & 75.371 .355 & CNV4 & $-0,217$ & 0,00069 \\
17 & 75.371 .356 & 75.375 .359 & CNV4 & $-0,190$ & 0,00069 \\
8 & 39.354 .761 & 39.365 .832 & CNV0 & $-0,004$ & 0,00078 \\
19 & 48.216 .171 & 48.221 .240 & CNV3 & 0,228 & 0,0011 \\
19 & 48.211 .203 & 48.216 .135 & CNV3 & 0,199 & 0,0015 \\
19 & 48.216 .136 & 48.216 .170 & CNV3 & 0,199 & 0,0015 \\
19 & 48.188 .582 & 48.192 .288 & CNV3 & 0,151 & 0,0017 \\
19 & 48.192 .289 & 48.198 .014 & CNV3 & 0,157 & 0,0017 \\
19 & 48.198 .015 & 48.201 .493 & CNV3 & 0,153 & 0,0017 \\
19 & 48.206 .028 & 48.211 .202 & CNV3 & 0,192 & 0,0017 \\
19 & 48.184 .303 & 48.188 .454 & CNV3 & 0,121 & 0,0018 \\
19 & 48.188 .455 & 48.188 .581 & CNV3 & 0,121 & 0,0018 \\
19 & 48.201 .494 & 48.206 .027 & CNV3 & 0,113 & 0,0018 \\
19 & 48.176 .776 & 48.181 .795 & CNV3 & 0,053 & 0,0019 \\
19 & 48.181 .796 & 48.184 .302 & CNV3 & 0,073 & 0,0019 \\
19 & 48.167 .337 & 48.171 .792 & CNV3 & 0,118 & 0,0023 \\
19 & 48.234 .672 & 48.240 .854 & CNV3 & 0,317 & 0,0024 \\
16 & 33.552 .840 & 33.555 .980 & CNV3 & $-0,501$ & 0,0027 \\
\hline
\end{tabular}

\subsubsection{GWAS com CNVs como covariáveis dicotômicas}

Os gráficos Manhattan mostrando a associação dos CNVs inseridos como covariáveis dicotômicas, com os p-valores para cada CNV nos modelos para os fenótipos transformados pela inversa normal são apresentados nas figuras 4.18, 4.19, 4.20 e 4.21 .

Assim como para os resultados relativos à inserção do CNV como covariável categórica, não foi encontrada qualquer associação significativa para os fenótipos transformados pela inversa normal avaliados sob o nível de significânica corrigido por Bonferroni $\left(5,68 \times 10^{-6}\right)$ (Tabelas 4.21, 4.22, 4.23 e 4.24). Entretanto, os 20 menores $p$-valores destas análises foram maiores que os encontrados nas anteriores, o que sugere que a dicotomização desse marcador dificulta a tarefa de achar picos de associação com os fenótipos de atividade física. Além disso, a utilização de um critério mais flexível $\left(10^{-3}\right)$, identificou menos CNVs candidatos quando da utilização do nível de significância de Bonferroni para os CNVs inseridos como covariáveis categóricas, o que reforça a importância da comparação dessas duas formas de inclusão dessa covariável genética no modelo misto poligênico a fim de diminuir as taxas de falso positivo ou mesmo as de falso negativo. 
invAFT MET (CNV como covariável dicotômica)

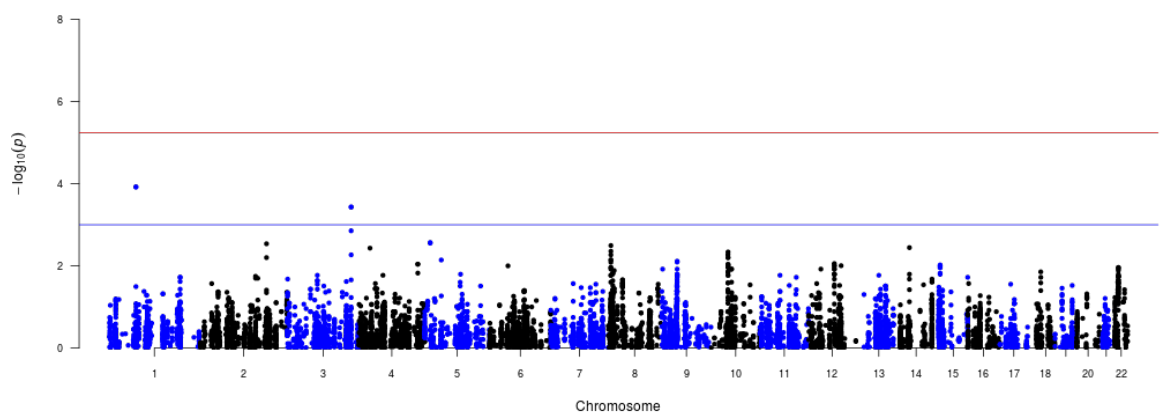

Figura 4.18: Gráfico Manhattan de associação de CNVs com atividade física total (invAFT MET). O eixo y indica o $-\log _{10}(p)$ valor dos testes de associação para cada CNV. Por sua vez, o eixo $x$ indica a posição central em pb dos CNVs ao longo dos 22 autossomos.

invWK MET (CNV como covariável dicotômica)

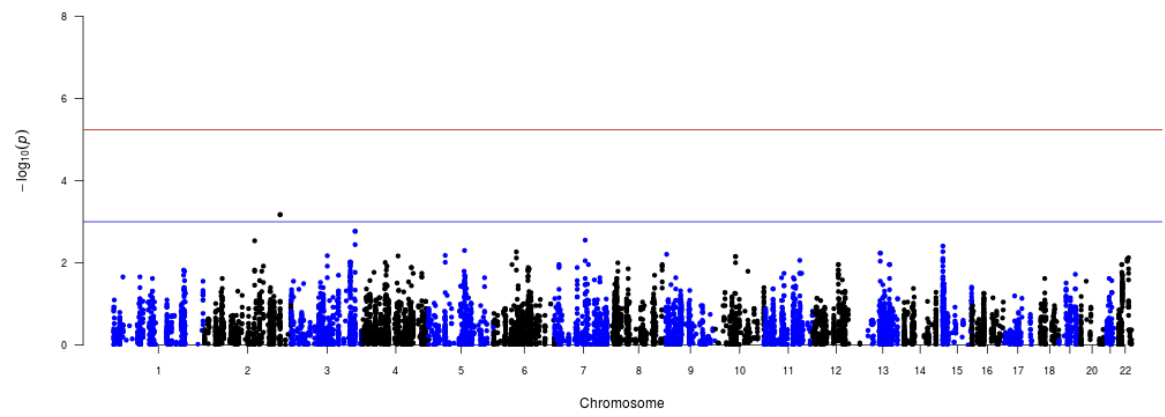

Figura 4.19: Gráfico Manhattan de associação de CNVs com atividade física total (invWK MET). O eixo y indica $o-\log _{10}(p)$ valor dos testes de associação para cada CNV. Por sua vez, o eixo $x$ indica a posição central em pb dos CNVs ao longo dos 22 autossomos.

invMVPA MET (CNV como covariável dicotômica)

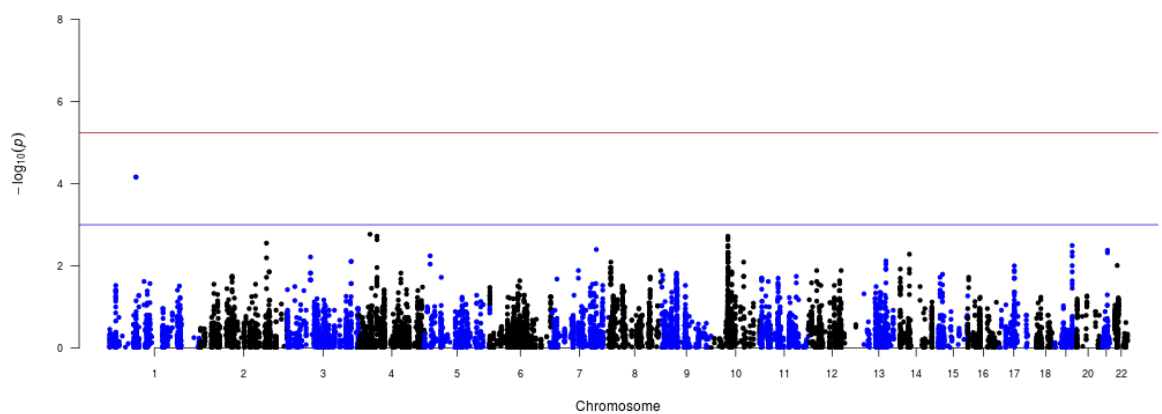

Figura 4.20: Gráfico Manhattan de associação de CNVs com atividade física total (invMVPA MET). O eixo y indica o $-\log _{10}(p)$ valor dos testes de associação para cada $C N V$. Por sua vez, o eixo $x$ indica a posição central em pb dos CNVs ao longo dos 22 autossomos. 
invSB (CNV como covariável dicotômica)

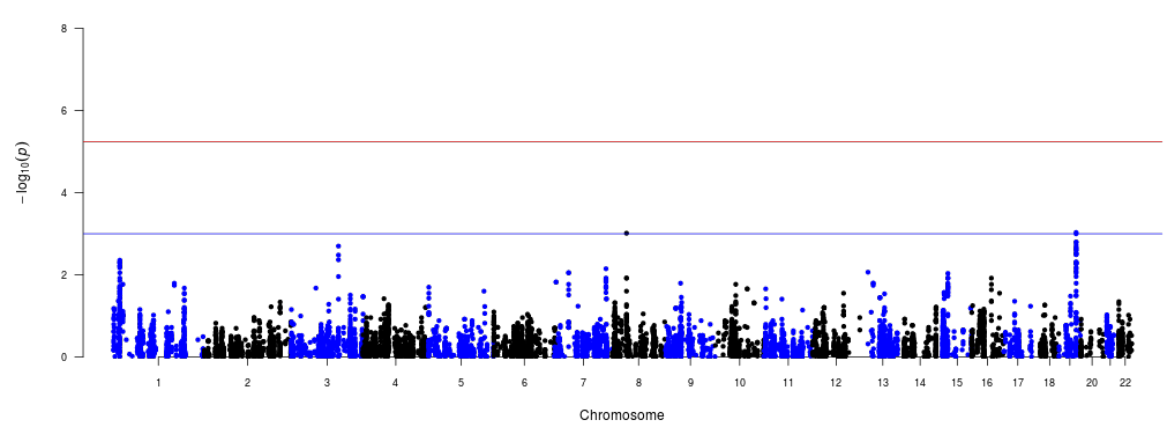

Figura 4.21: Gráfico Manhattan de associação de CNVs com atividade física total (invSB). O eixo y indica $o-\log _{10}(p)$ valor dos testes de associação para cada CNV. Por sua vez, o eixo $x$ indica a posição central em pb dos CNVs ao longo dos 22 autossomos.

Tabela 4.21: Os 20 CNVs (covariável dicotômica) com os menores p-valores nos testes de associação com invAFT MET.

\begin{tabular}{ccccc}
\hline \hline Cromossomo & Começo & Fim & Coeficiente beta & P-Valor \\
\hline 1 & 72.522 .437 & 72.522 .941 & $-0,866$ & 0,00012 \\
1 & 72.522 .942 & 72.528 .701 & $-0,866$ & 0,00012 \\
3 & 177.365 .650 & 177.366 .443 & $-0,785$ & 0,00037 \\
3 & 177.366 .444 & 177.370 .753 & $-0,785$ & 0,00037 \\
3 & 177.363 .445 & 177.365 .649 & $-0,788$ & 0,0014 \\
5 & 15.773 .076 & 15.773 .597 & $-0,647$ & 0,0027 \\
5 & 15.772 .223 & 15.773 .075 & $-0,627$ & 0,0028 \\
2 & 186.248 .916 & 186.249 .178 & $-0,789$ & 0,0029 \\
8 & 7.225 .314 & 7.225 .429 & $-0,824$ & 0,0032 \\
14 & 43.609 .181 & 43.611 .392 & $-0,870$ & 0,0036 \\
4 & 30.048 .496 & 30.049 .257 & $-0,825$ & 0,0037 \\
8 & 7.213 .847 & 7.225 .313 & $-0,826$ & 0,0044 \\
10 & 47.173 .620 & 47.174 .643 & $-0,743$ & 0,0046 \\
10 & 46.839 .718 & 47.011 .195 & $-0,747$ & 0,0053 \\
3 & 177.370 .754 & 177.377 .701 & $-0,852$ & 0,0054 \\
8 & 7.209 .592 & 7.212 .778 & $-0,830$ & 0,0054 \\
2 & 186.246 .638 & 186.248 .915 & $-0,790$ & 0,0063 \\
10 & 47.122 .810 & 47.134 .343 & $-0,740$ & 0,0063 \\
10 & 47.134 .344 & 47.148 .455 & $-0,740$ & 0,0063 \\
5 & 46.306 .766 & 46.309 .259 & $-0,875$ & 0,0072 \\
\hline
\end{tabular}


Tabela 4.22: Os 20 CNVs (covariável dicotômica) com os menores p-valores nos testes de associação com invWK MET.

\begin{tabular}{ccccc}
\hline \hline Cromossomo & Começo & Fim & Coeficiente beta & P-Valor \\
\hline 2 & 212.870 .414 & 212.870 .593 & $-1,441$ & 0,00067 \\
2 & 212.870 .594 & 212.872 .288 & $-1,441$ & 0,00067 \\
3 & 177.365 .650 & 177.366 .443 & $-1,306$ & 0,0017 \\
3 & 177.366 .444 & 177.370 .753 & $-1,306$ & 0,0017 \\
7 & 84.034 .195 & 84.034 .760 & $-1,404$ & 0,0028 \\
2 & 142.508 .384 & 142.520 .179 & $-1,299$ & 0,0029 \\
3 & 177.363 .445 & 177.365 .649 & $-1,306$ & 0,0036 \\
15 & 18.838 .436 & 18.841 .465 & $-1,385$ & 0,0039 \\
5 & 99.568 .346 & 99.569 .865 & $-1,226$ & 0,005 \\
15 & 18.841 .579 & 18.846 .002 & $-1,364$ & 0,0053 \\
6 & 62.264 .678 & 62.292 .491 & $-1,313$ & 0,0054 \\
13 & 56.496 .280 & 56.497 .681 & $-1,356$ & 0,0058 \\
13 & 56.497 .682 & 56.500 .151 & $-1,356$ & 0,0058 \\
9 & 5.375 .784 & 5.388 .011 & $-1,499$ & 0,0062 \\
5 & 46.309 .260 & 46.313 .969 & $-1,315$ & 0,0066 \\
3 & 100.434 .525 & 100.436 .451 & $-1,329$ & 0,0067 \\
4 & 96.633 .346 & 96.635 .185 & $-1,393$ & 0,0068 \\
10 & 56.834 .708 & 56.835 .151 & $-1,364$ & 0,007 \\
10 & 56.835 .152 & 56.837 .699 & $-1,364$ & 0,007 \\
22 & 41.287 .233 & 41.287 .765 & $-1,374$ & 0,0075 \\
\hline
\end{tabular}

Tabela 4.23: Os 20 CNVs (covariável dicotômica) com os menores p-valores nos testes de associação com invMVPA MET.

\begin{tabular}{ccccc}
\hline \hline Cromossomo & Começo & Fim & Coeficiente beta & P-Valor \\
\hline 1 & 72.522 .437 & 72.522 .941 & 0,260 & $6,9 \mathrm{e}-05$ \\
1 & 72.522 .942 & 72.528 .701 & 0,260 & $6,9 \mathrm{e}-05$ \\
4 & 30.048 .496 & 30.049 .257 & 0,290 & 0,0017 \\
4 & 49.344 .549 & 49.353 .369 & 0,266 & 0,0019 \\
10 & 46.834 .288 & 46.839 .717 & 0,388 & 0,0019 \\
10 & 46.790 .325 & 46.790 .374 & 0,350 & 0,0021 \\
4 & 49.338 .521 & 49.344 .548 & 0,264 & 0,0023 \\
10 & 46.812 .339 & 46.834 .287 & 0,386 & 0,0023 \\
2 & 186.248 .916 & 186.249 .178 & 0,346 & 0,0028 \\
10 & 46.790 .375 & 46.812 .338 & 0,386 & 0,0032 \\
19 & 48.394 .874 & 48.404 .090 & 0,264 & 0,0032 \\
10 & 46.669 .594 & 46.684 .870 & 0,341 & 0,0034 \\
10 & 46.684 .871 & 46.790 .324 & 0,341 & 0,0034 \\
7 & 125.833 .852 & 125.834 .117 & 0,278 & 0,004 \\
21 & 22.579 .430 & 22.586 .529 & 0,338 & 0,0042 \\
19 & 48.445 .351 & 48.448 .077 & 0,242 & 0,0046 \\
10 & 47.044 .287 & 47.114 .766 & 0,382 & 0,0047 \\
10 & 47.114 .767 & 47.122 .809 & 0,382 & 0,0047 \\
21 & 22.577 .636 & 22.579 .429 & 0,343 & 0,0048 \\
10 & 46.573 .926 & 46.669 .593 & 0,340 & 0,0049 \\
\hline
\end{tabular}


Tabela 4.24: Os 20 CNVs (covariável dicotômica) com os menores p-valores nos testes de associação com invSB.

\begin{tabular}{ccccc}
\hline \hline Cromossomo & Começo & Fim & Coeficiente beta & P-Valor \\
\hline 19 & 48.216 .171 & 48.221 .240 & 0,792 & 0,00093 \\
8 & 39.349 .817 & 39.354 .760 & 0,314 & 0,00097 \\
19 & 48.234 .672 & 48.240 .854 & 0,809 & 0,001 \\
19 & 48.211 .203 & 48.216 .135 & 0,802 & 0,0016 \\
19 & 48.216 .136 & 48.216 .170 & 0,802 & 0,0016 \\
19 & 48.206 .028 & 48.211 .202 & 0,807 & 0,0019 \\
3 & 131.288 .927 & 131.289 .688 & 0,747 & 0,002 \\
19 & 48.221 .241 & 48.226 .746 & 0,790 & 0,0022 \\
19 & 48.226 .747 & 48.229 .218 & 0,790 & 0,0022 \\
19 & 48.229 .219 & 48.230 .618 & 0,779 & 0,0025 \\
19 & 48.230 .619 & 48.234 .671 & 0,779 & 0,0025 \\
19 & 48.192 .289 & 48.198 .014 & 0,812 & 0,003 \\
19 & 48.295 .212 & 48.320 .670 & 0,773 & 0,003 \\
19 & 48.188 .582 & 48.192 .288 & 0,813 & 0,0032 \\
19 & 48.198 .015 & 48.201 .493 & 0,807 & 0,0032 \\
3 & 131.282 .358 & 131.288 .926 & 0,807 & 0,0033 \\
3 & 131.289 .689 & 131.291 .501 & 0,707 & 0,0043 \\
1 & 16.918 .046 & 16.918 .348 & 0,633 & 0,0044 \\
1 & 16.921 .067 & 16.929 .044 & 0,648 & 0,0048 \\
19 & 48.184 .303 & 48.188 .454 & 0,814 & 0,0049 \\
\hline
\end{tabular}

A ausência de marcadores significativamente associados para a maioria dos fenótipos de atividade física no presente estudo não é de todo surpreendente. A maior parte dos estudos de associação genômica tem dificuldades em encontrar picos de associação com $p$-valores menores que o nível de significância estabelecido, mesmo possuindo alto poder estatístico, elevados números amostrais e utilizando fenótipos de natureza menos subjetiva que variáveis de questionários como o IPAQ-SF. Por exemplo, utilizando 91.105 participantes do banco de dados UK Biobank, Doherty et al. [2018] encontraram 7 loci significantes associados com atividade física medida por acelerômetro, dentre 9.926.106 SNPs avaliados. Semelhantemente, usando dados desse mesmo banco, Klimentidis et al. [2018] fizeram o maior GWAS de AF conhecido até a presente data, tendo encontrado 8 loci associados com MVPA. De igual modo, alguns outros estudos realizados com outros fenótipos, seja relacionados à atividade física ou não, avaliaram um grande número de marcadores para um elevado número de indivíduos e mesmo assim encontraram poucas variantes associadas, por vezes, nenhuma [Kim et al., 2014, 2017, Lambert et al., 2013, Rankinen et al., 2016, Zillikens et al., 2017].

Por outro lado, embora tenham utilizado um pool bem menor de marcadores, Vasan et al. [2007] avaliaram aproximadamente o mesmo número de indivívuos que no presente estudo e, ainda que não tenham encontrado SNPs significativamente associados, reportaram também os 20 menores $p$ - 
valores desses marcadores. Essa documentação dos 20 menores $p$-valores poderá ser de grande valia para se comparar os resultados aqui encontrados com análises futuras que utilizem $\mathrm{N}$ amostrais maiores, as quais poderão encontrar marcadores outrora não associados aos fenótipos autorreportados de $\mathrm{AF}$.

Outra consideração importante é que os GWAS são desenhos experimentais que se baseiam no princípio de desequilíbrio de ligação (do inglês Linkage Desequilibrium), uma medida estatística de associação não aleatória entre marcadores que estão localizados em regiões próximas no genoma [Ardlie et al., 2002]. Dessa forma, os picos de associação encontrados para muitos marcadores são em sua maioria decorrentes de outras variantes que com eles estão em LD e são as verdadeiras variantes causais. Por conta desse princípio, faz-se necessária uma etapa posterior de avaliação das funções biológicas dos picos de associações e se os mesmos encontram-se próximos de outros marcadores que estejam envolvidos em mecanismos biológicos relevantes para o fenótipo avaliado. Além disso, é de fundamental importância mencionar que, caso a variante causal tenha frequências alélicas muito pequenas (variantes raras), ela terá um LD muito baixo com a variante genotipada e analisada no GWAS, o que impedirá sua detecção [Visscher et al., 2012]. Essa se configura como uma das principais limitações das análises de mapeamento gênico, especialmente as que se utilizam da tecnologia de microarranjo, como a utilizada no Projeto Corações de Baependi, pois essa tecnologia é apropriada para a deteç̧ão de variantes comuns, não de raras [Visscher et al., 2012, 2017].

Um último aspecto relevante é que, apesar do nível de significância genômica $\left(p<5 \times 10^{-8}\right)^{1}$ utilizado na maioria dos estudos, alguns autores sugerem a utilização de outros valores de corte. Kanai et al. [2016], por exemplo, estimaram empiricamente os $p$-valores significantes para populações de diferentes ancestralidades, tendo obtido valores maiores do que o padrão. Para uma população americana altamente miscigenada, foi encontrado um critério de $1,83 \times 10^{-7}$, indicando que o $p$-valor de corte empregado para a população de Baependi pode ter sido por demais restritivo, o que explicaria parcialmente o número bastante reduzido de marcadores e regiões associadas encontrado. Isso sugere que o SNP presente no cromossomo 4 muito próximo ao valor de corte nos testes de associação com invAFT pode ser um falso negativo, que teria sido outrora apontado como significante caso um valor de corte menos restritivo tivesse sido adotado. Dessa forma, faz-se necessária a construção de outros critérios de corte mais específicos à população brasileira e sua comparação em mapeamentos gênicos dos fenótipos de atividade física, já que poderiam ser encontrados novos SNPs ou CNVs associados cuja relevância biológica para as características avaliadas possa ser investigada e atestada em estudos futuros.

\footnotetext{
${ }^{1}$ Esse valor é um número padrão dado que o número de marcadores é 1.000 .000
} 
Vale salientar também que, considerando que nosso $\mathrm{N}$ amostral foi de apenas 910, dos quais aproximadamente 760 dispunham de dados fenotípicos, é possível que os sinais presentes nos Manhattan plots para as variáveis transformadas pela inversa normal assim como para a maioria das transformadas pelo logaritmo natural tivessem sido significantes caso o $\mathrm{N}$ fosse maior. De qualquer forma, nota-se que, para o presente banco de dados, a transformação logarítmica forneceu picos de associação que não foram outrora significantes para as variáveis transformadas pela inversa normal. Isso indica que esses picos de associação com MVPA MET podem ser falsos positivos e ressalta a importância do estabelecimento de critérios para comparação e seleção de transformações adequadas para as variáveis resposta avaliadas. 


\section{Capítulo 5}

\section{Conclusão e Considerações Finais}

O presente trabalho buscou elucidar a influência genética na atividade física por meio de duas abordagens complementares:

- Estimativas de herdabilidade utilizando o método de componentes de variância.

- Mapeamento gênico de marcadores SNPs e CNVs (GWAS).

Este estudo, o qual se insere no Projeto Corações de Baependi, está dentre os poucos de estrutura familiar com enfoque em atividade física e, até onde se conhece, é pioneiro em investigar o papel das variantes genéticas CNVs em fenótipos de atividade física autorreportada na população brasileira. Dessa forma, este trabalho apresenta contribuições sobre a arquitetura genética subjacente a esses traços, o que é de suma importância considerando a relevância da atividade física para a manutenção de uma vida saudável e de qualidade.

Com a abordagem proposta estimamos a herdabilidade desses fenótipos e encontramos valores baixos a moderados, para a maior parte das características avaliadas. Entretanto, a estratificação dos componentes de variância pelo sexo forneceu estimativas mais elevadas, com homens tendo herdabilidades maiores no fenótipo moderado-vigoroso e mulheres no fenótipo leve. Dessa forma, a estratificação pelo sexo nessas estimativas indicou um componente genético herdável moderado a forte nos fenótipos de atividade física autorreportada.

Além disso, os estudos de mapeamento (GWAS) indicaram alguns marcadores associados sob o nível de significância genômica corrigido por Bonferroni e especialmente, dezenas de marcadores candidatos após a utilização de um critério mais flexível, tanto para SNPs como CNVs. Por meio de procedimentos iniciais de anotação, constatou-se que elas encontram-se principalmente nos cromossomos 3, 5 e 6 e encontrou-se alguns indícios dos possíveis mecanismos moleculares pelos quais essas variantes podem influenciar a prática de atividade física. 
Algumas limitações foram presentes no desenvolvimento dessa pesquisa. Por exemplo, não foi possível utilizar o mesmo $\mathrm{N}$ amostral para as estimativas de herdabilidade e mapeamento gênico, fazendo com que os testes de estimativas de herdabilidade feitos para conjunto de dados de diferentes tamanhos fornecessem resultados consideravelmente discrepantes. Apesar do conjunto de 910 indivíduos, com dados disponíveis tanto para os marcadores genéticos como para os fenótipos de atividade física, ser proveniente do conjunto maior de aproximadamente 2300, ele provavelmente não foi representativo do conjunto maior, o que explica as diferenças de estimativas encontradas.

Vale salientar também que essas estimativas são baseadas no ajuste de modelos que dependem da distribuição fenotípica da variável de interesse, a qual se assume ser normal sob o modelo linear misto. Assim, é importante se utilizar uma transformação que atenda aos pressupostos do modelo, o que, em geral, é feito baseado na análise de resíduos. Além disso, essas análises devem ser feitas para um mesmo conjunto de dados de forma a evitar viezes ou problemas amostrais como os encontrados no presente estudo.

Não obstante a limitação referente à amostragem, nessa investigação, as estimativas de herdabilidade utilizaram um $\mathrm{N}$ amostral compatível e por vezes maior que os estudos de Diego et al. [2015], Schutte et al. [2016a] e Zhai et al. [2004], por exemplo. Dessa forma, o presente trabalho fornece forte evidência da presença de componentes genéticos herdáveis influenciando a atividade física de uma amostra da população brasileira e estabelece um território firme para os estudos de mapeamento gênico desses fenótipos. Quanto a essas análises, sugere-se a utilização de um conjunto maior de indivíduos no mapeamento gênico, o que aumentará o poder da análise para encontrar picos de associação tanto de SNPs como CNVs.

Como destacado por Bush e Moore [2012], a delimitação precisa e padronizada dos fenótipos avaliados nos estudos de mapeamento gênico é essencial para seu sucesso. Assim, sugere-se uma melhor definição e caracterização dos fenótipos de atividade física. Isto pode ser alcançado por meio da utilização da Análise de Componentes Principais (PCA, do inglês Principal Component Analysis), a qual cria variáveis latentes, que são combinações lineares das originais. Essas componentes podem contribuir com informações adicionais àquelas obtidas pelas variáveis ponderadas por medidas de gasto calórico tradicionalmente empregadas. Uma vez que a definição dos fenótipos de atividade física é melhorada, espera-se encontrar estimativas de herdabilidade mais efetivas e eventualmente maiores como as encontradas para tantos outros fenótipos quantitativos e relacionados à atividade física [de Oliveira et al., 2008, Schutte et al., 2016a,b].

Para validação dos picos de associação encontrados, é recomendado realizar análises adicionais às análises uniloco bem como uma verificação de falsos negativos, afim de avaliar a associação con- 
junta de blocos de SNPs e CNVs nos fenótipos de interesse. Tal feito pode ser alcançado por meio de ajustes de múltiplos locos incluídos no modelo seguidos de procedimentos de seleção de covariáveis. Um dos procedimentos bastante utilizado é o LASSO penalizado (do inglês Least Absolute Shrinkage and Selection Operator), uma técnica que permite a seleção regularizada e penalizada de variáveis melhorando a acurácia da predição e interpretabilidade do modelo utilizado [Tibshirani, 1996, Witten e Tibshirani, 2009]. Em outras palavras, a técnica LASSO identifica quais conjuntos ou conjunto de marcadores estão associados e consequentemente melhor predizem as variáveis resposta, que no presente são os fenótipos de atividade física e sedentarismo. Esse tipo de abordagem e métodos semelhantes podem ajudar a identificar SNPs que isoladamente não atingiriam o nível de significância nos testes de associação com atividade física, como mostrado por Kim et al. [2014]. Pode-se ainda utilizar extensões multivariadas do modelo linear misto na construção de fenótipos multivariados da atividade física, como os modelos formulados em Oualkacha et al. [2012].

Outro questionamento interessante a ser respondido em pesquisas futuras é a relação entre SNPs e CNVs, a qual poderia ser investigada primeiramente por meio de procedimentos de integração de bancos de dados supervisionados. Além disso, uma vez que encontramos estratificação para o sexo nas herdabilidades, é interessante realizar o mapeamento gênico sob os modelos estratificados, a fim de avaliar se os marcadores associados aos fenótipos de AF e SB diferem entre homens e mulheres. A estratificação dos modelos pode ainda se estender a outras covariáveis, como IMC, tabagismo, depressão, o que pode gerar resultados importantes, ainda por serem explorados.

Uma vez que encontramos estimativas de herdabilidades consideráveis para AF e SB, surge o questionamento de como os SNPs e CNVs podem explicar essa herdabilidade. Nesse contexto, almeja-se estimar a variação na herdabilidade $\left(\Delta h^{2}\right)$ decorrente da inclusão desses marcadores nos modelos avaliados. A porcentagem da herdabilidade explicada pelos SNPs (denominada no inglês de SNP-heritability) tem despertado grande interesse nos estudos genéticos e estimativas bastante eficazes e promissoras têm sido propostas [Hou et al., 2019].

Vale destacar também que a obtenção de respostas mais robustas aos questionamentos supracitados só será possível caso se utilize $\mathrm{N}$ amostrais maiores em futuros GWAS, já que quanto maior o $\mathrm{N}$ amostral mais poderosas essas análises se tornam e mais variantes associadas tendem a ser descobertas [Duncan et al., 2019]. 
Apêndice A

Questionário Internacional de Atividade Física - Versão Curta (IPAQ-SF) 


\section{QUESTIONÁRIO INTERNACIONAL DE ATTVIDADE FÍSICA-IPAQ VERSÃO CURTA}

Nós estamos interessados em saber çe tipos de atividade frica as pessoas fasean como parte do seu dia a dia. Este projeto az parte de un prasde estudo gae esti seado feito em diferestes paises ao redor do mando. Suas respostas pos ajodurào a eutesder que tio atros nós somos em relaço à pessoas de outros paises. As perguntas estio relacionadas ao teupo que vocé pasta fazendo atividade fisica na ULTHMA semana. As pergunfas inchem as atividades que vocé far no traballbo, para ir de um lugar a outro, por lazer, por esporte, por exercicio ou como parte das sus atividades em casa ou no jardim Suas respostas sio MUTrO importantes. Por favor, responda cada questio mesmo que considere que nio seja ativo. Obrieado pela sua participaçb!

Para rempender as questies bmbre çu:

7. Atridades Firicas VTGOROS.AS th aquelas que preciam de um pasde esforco fhico e que Grem repirar MUTHO mais forte ģae o normal

> Atrvidades Fisicas MODERADAS sio aguelas que precisam de algum esforpo frico e çae facem respirar UM POUCO mois forte çe o normal

Para respooder as perguntas pense socrente nas atividades gee vocé realiza por pelo menos 10 misutos continuos de cada vez.

1-A) En quantos dias da úlima semun voce CAMTINHOU por pelo mesos 10 minutos coetinuos em casa ou no traballbo, como forma de transporte para ir de um luga para outro, por baer, por praser ou como brma de exercicis? IPAQ-1A

dias por SEMLANA () Nenlum

1-B) Nos dis em gue vocé caminhou por pelo mesos 10 minutos continaos quarto teapo no tolal vocé pastou caminhando por dia? IPAQ-1B

boras: Minutos:

2-A) Em quantos dias da última semana, vocé realirou atrídades MODERADAS por pelo menos 10 minutos contínos, como por excupplo pedalar leve na bicicleta, nadar, dançar, facer ginástica aeróbica leve, jogar vólei recreativo, carepar pesos leves, faser servicos domésticos na casa, no guintal ou do

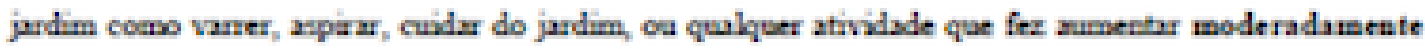

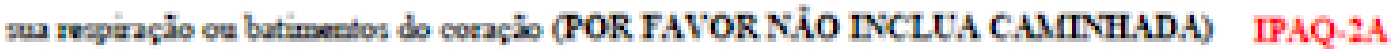
dias Dor SEMANA

() Nenlum 
2-B) Nos dias ex que voce fez essas atridades moderadas per peb mesos 10 minutos coetimes, gumto tempo no tokal vocé gastoe Leesdo essas atridudes por dia? IPAQ-2B

boras: Mintos:

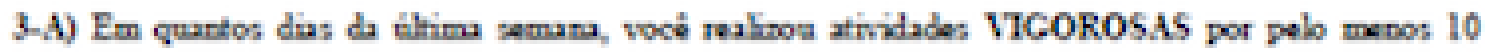
minutos coutimos, como por exerplo correr, fazer einástica aerobica, jogar futebol, pedalur rípido na bicicleta, jopr basquete, frzer servigos domesticos pesados em casa, no cquintal ou crvoucar so jardim, canegar pesos elevados ou çalguer atividade que fez aumentar MUITO sua respiraçio ou batimentos do coraçion. IPAQ-3A

dias por SEMANA

() Nenhum

3-B) Nos das ea que você Sez essas atividades vigotosas por pelo mesos 10 minutos coetimos quanto tempo no tocal vecé gastoe beesdo essas atividades por dia? IPAQ-3B

bora: Mintos:

Estas uhimas questles sko sotre o tempo que vock permunece sentado todo dia, no traballo, na escola ou ficuldade, em casa e durante seu tempo live. Isto inchin o tempo sentado estudindo, sentado expranto descansa, faseodo liço de casa visitando um amigo, leodo, seatado ou deitado assistindo TV. Nïo inchu o teapo gasto sectando durante o transporte em ónibus, trem, metsô ou carro.

4-A) Quato tempo so total voci gath sectado derante um dia de semsas? IPAQ-4A boras minutos

4B) Quanto ternpo so total vocé gata sertado durate un dia de fias de semana? IPAQ-4B boras minutos 


\section{Apêndice B}

\section{Ajuste Inicial de Modelos para os fenótipos de AF do IPAQ-SF}

Tabela B.1: Seleção inicial forward. Herdabilidades com modelos em comum para os fenótipos de atividade física coletados pelo IPAQ-SF. ${ }^{*}=$ p-valor $d a h^{2}<0,05$.

\begin{tabular}{cccccc}
\hline \hline & $\mathrm{h}^{2} A F T M E T$ & $\mathrm{~h}^{2} W K M E T$ & $\mathrm{~h}^{2} M P A M E T$ & $\mathrm{~h}^{2} V P A M E T$ & $\mathrm{~h}^{2} S B$ \\
\hline Sem cov & $0.143 *$ & 0.04 & $0.191 *$ & 0.012 & 0.067 \\
SexI & $0.128 *$ & 0.04 & $0.193 *$ & 0.01 & 0.06 \\
SexI+IMC & $0.12 *$ & 0.03 & $0.191 *$ & 0.018 & 0.07 \\
SexI+IMC+C.Cint. & 0.105 & 0.04 & $0.198 *$ & - & 0.06 \\
SexI+IMC+C.Cint.+Fumo & 0.1248 & 0.04 & 0.191 & - & 0.069 \\
SexI+IMC+C.Cintura+Fumo+Dep. & $0.1285 *$ & 0.04 & $0.188 *$ & - & 0.069 \\
\hline
\end{tabular}




\section{Apêndice C}

\section{Dicionário de Variáveis}

Tabela C.1: Dicionário de Variáveis

\begin{tabular}{l|l} 
IPAQ_1_ A & N de dias da semana de pratica de atividade leve
\end{tabular}

IPAQ_1_B $\quad$ Horas:minutos de atv leve a cada dia da semana em que se pratica

IPAQ_ ${ }_{2}^{-} \mathrm{A} \quad \mathrm{N}$ de dias da semana de pratica de atividade moderada

IPAQ_2_B Horas:minutos de atv moderada a cada dia da semana em que se pratica

IPAQ_3_A $\quad \mathrm{N}$ de dias da semana de pratica de atividade vigorosa

IPAQ_3 ${ }_{3}^{-}$B Horas:minutos de atv vigorosa a cada dia da semana em que se pratica

IPAQ_4_A Tempo total horas:min gasto sentado durante um dia da semana

IPAQ_4 ${ }^{-} \mathrm{B} \quad$ Tempo total horas:min gasto sentado durante um final de semana

IPAQ1_- $\overline{\mathrm{B} T}$

IPAQ2-BT

IPAQ3_-BT

AFT

WK MET

MPA_MET

VPA ${ }^{-} \mathrm{MET}$

AFT_MET

$\mathrm{SB}$

C_CINTURA

$\mathrm{C}^{-}$QUADRIL

$\mathrm{C}^{-} \mathrm{PESCOCO}$

$\mathrm{IMC}$

V13

V14

Variavel combinada min/sem de IPAQ_1_A e IPAQ_1_B (atv. Fis leve min/sem)

Variavel combinada min/sem de IPAQ_2 _ A e IPAQ ${ }_{2}{ }_{-}$B (atv. Fis moderada min/sem)

Variavel combinada min/sem de IPAQ_3_A e IPAQ_3_B(atv. Fis vigorosa min/sem)

Atv fisica total em min/sem (soma das var. combinadas leve, moderada e vigorosa)

Atv fisica leve METs*min/sem

Atv fisica moderada METs*min/sem

Atv fisica vigorosa METs*min/sem

Atv fisica total METs*min/sem (WK_MET + MPA_MET + VPA_MET)

$\mathrm{Min} /$ sem de sedentarismo (tempo sentado- combinação de IPAQ_4 ${ }_{-} \mathrm{A}$ e IPAQ_4_B)

Circunferência da cintura

Circunferencia do quadril

Circunferencia do pescoço

Indice de Massa Corporea

Se o indivíduo já fumou cigarros

Idade quando o indivíduo parou de fumar

Fumo

V16

Média de cigarros que o indivíduo fuma/fumava por dia

V17

Depressão

Idade que o indivíduo tinha quando começou a fumar regularmente

Se o indivíduo fica em ambientes fechados com fumantes e por quanto tempo em horas

Score de depressão retirado de Questionário Psicológico 


\section{Apêndice D}

\section{Gráficos Manhattan de SNPs e de CNVs para variáveis transformadas pelo log}

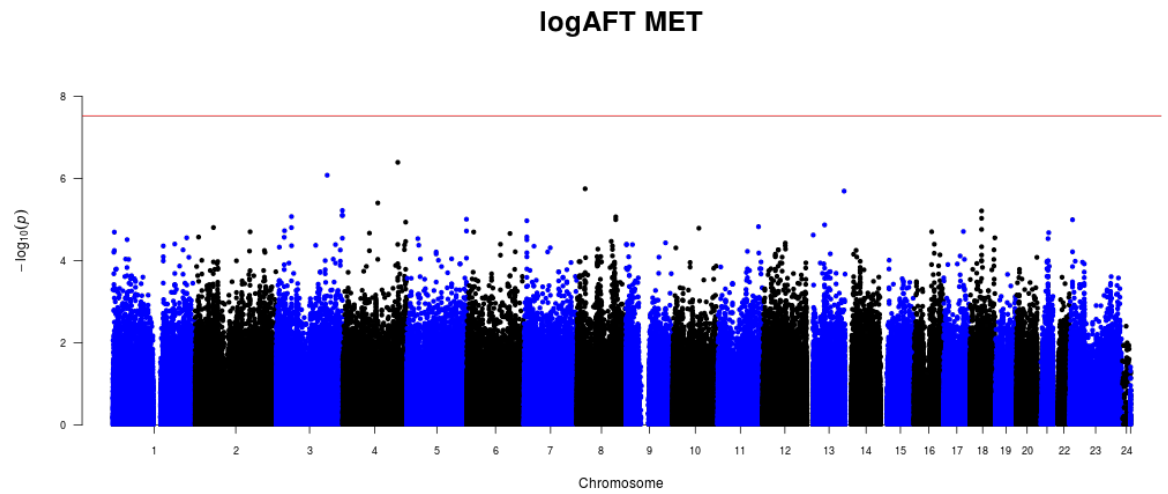

Figura D.1: Gráfico Manhattan de associação de SNPs com atividade física leve (logAFT $M E T)$. O eixo y indica o $-\log _{10}(p)$ valor dos testes de associação para cada SNP. Por sua vez, o eixo x indica em $p b$ dos SNPs ao longo dos 22 autossomos.

logWK MET

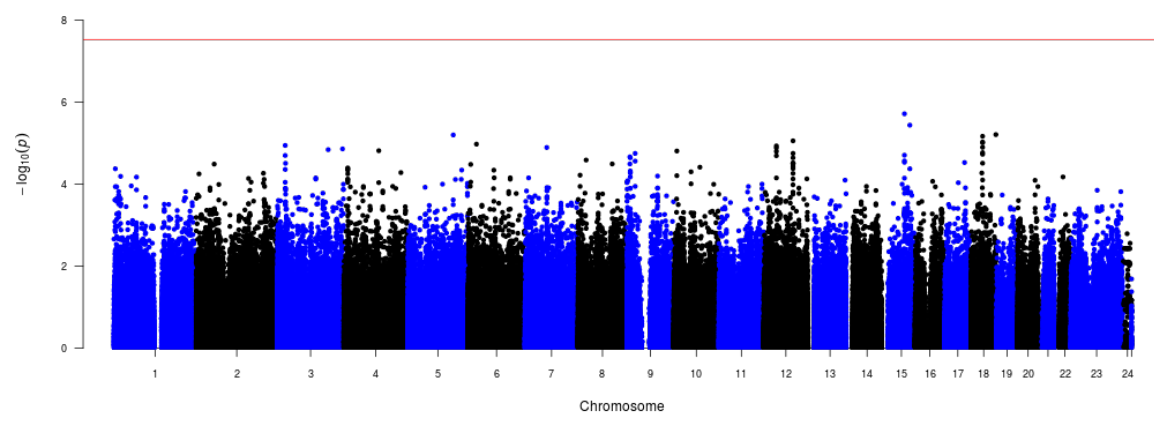

Figura D.2: Gráfico Manhattan de associação de SNPs com atividade física leve (logWK $M E T)$. O eixo y indica o - $\log _{10}(p)$ valor dos testes de associação para cada SNP. Por sua vez, o eixo $x$ indica em $p b$ dos SNPs ao longo dos 22 autossomos. 
logMVPA MET

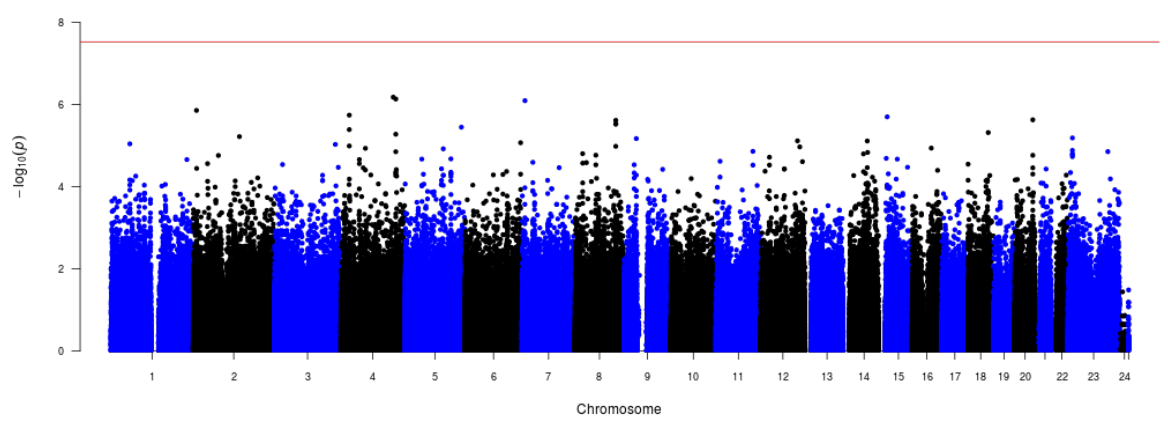

Figura D.3: Gráfico Manhattan de associação de SNPs com atividade física leve (logMVPA $M E T)$. O eixo y indica o- $\log _{10}(p)$ valor dos testes de associação para cada SNP. Por sua vez, o eixo $x$ indica em pb dos SNPs ao longo dos 22 autossomos.

$\log \mathrm{B}$

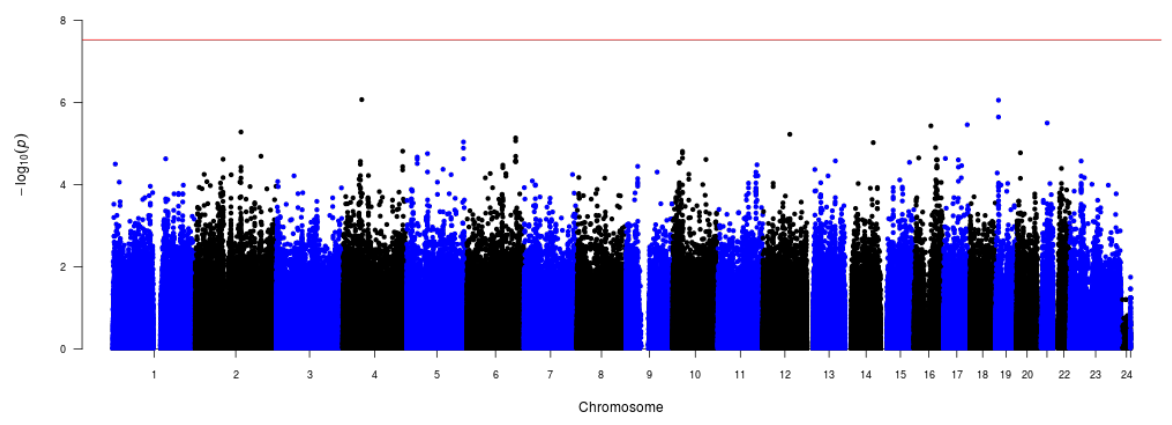

Figura D.4: Gráfico Manhattan de associação de SNPs com atividade física leve (logSB). O eixo y indica o $-\log _{10}(p)$ valor dos testes de associação para cada SNP. Por sua vez, o eixo $x$ indica em pb dos SNPs ao longo dos 22 autossomos.

Log de AFT MET (CNV como covariável categórica)

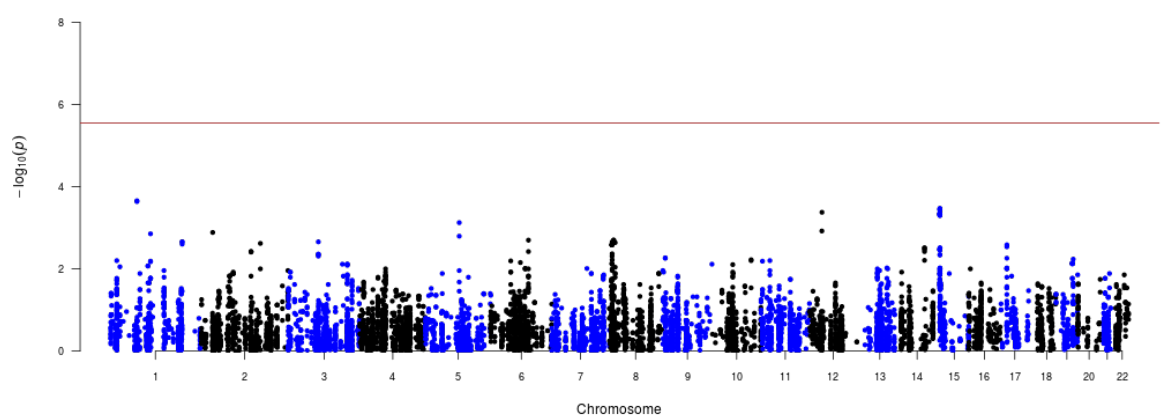

Figura D.5: Gráfico Manhattan de associação de CNVs com atividade física total (log AFT MET). O eixo y indica o $-\log _{10}(p)$ valor dos testes de associação para cada $C N V$. Por sua vez, o eixo $x$ indica a posição central em pb dos CNVs ao longo dos 22 autossomos. 
Log de WK MET (CNV como covariável categórica)

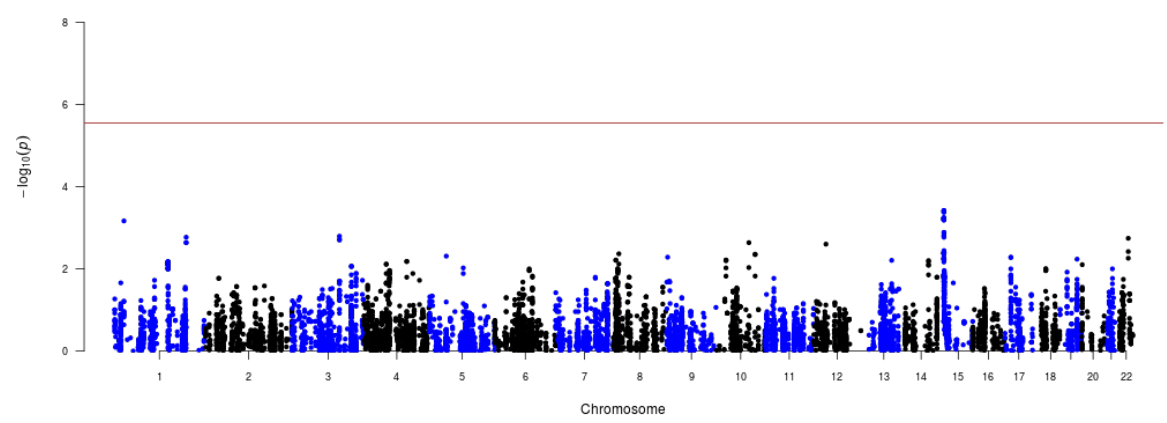

Figura D.6: Gráfico Manhattan de associação de CNVs com atividade física leve (log WK MET). O eixo y indica o $-\log _{10}(p)$ valor dos testes de associação para cada CNV. Por sua vez, o eixo $x$ indica a posição central em pb dos CNVs ao longo dos 22 autossomos.

Log de MVPA (CNV como covariável categórica)

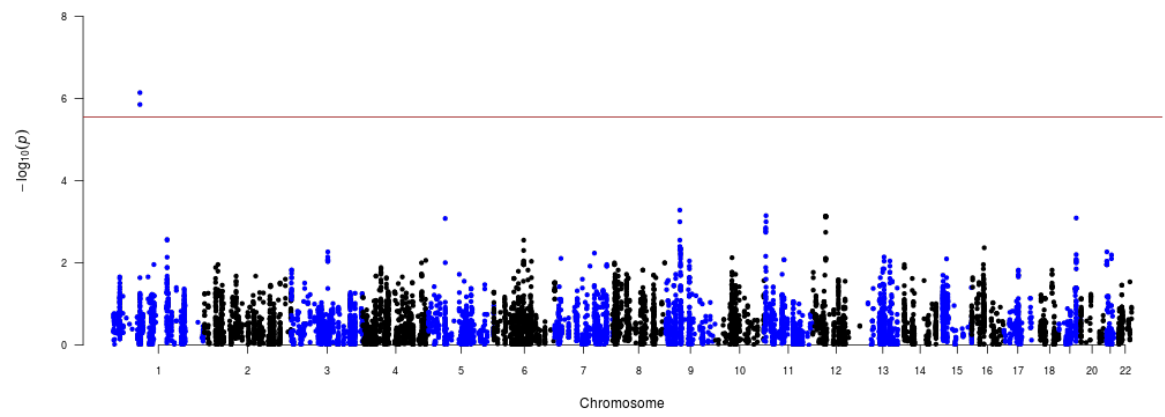

Figura D.7: Gráfico Manhattan de associação de CNVs com atividade física moderada-vigorosa ( $\log$ MVPA). O eixo y indica o $-\log _{10}(p)$ valor dos testes de associação para cada CNV. Por sua vez, o eixo $x$ indica a posição central em pb dos CNVs ao longo dos 22 autossomos.

log de SB (CNV como covariável categórica)

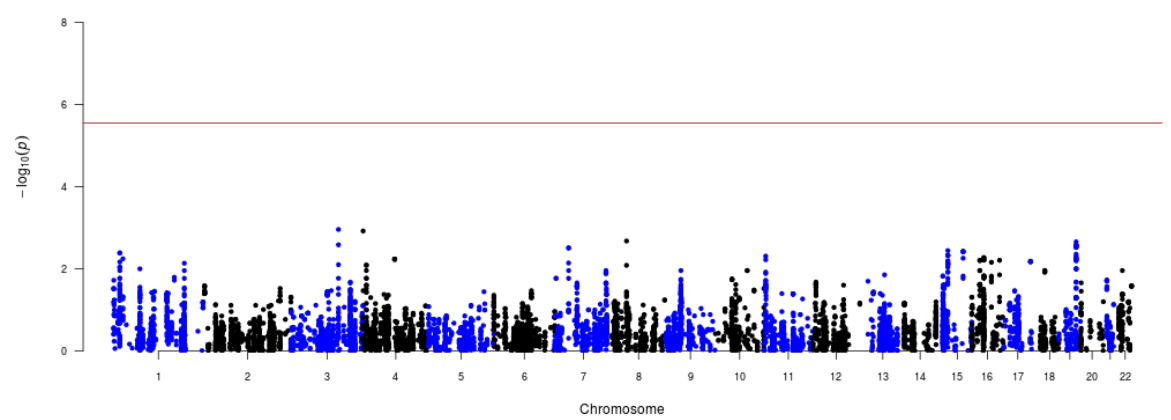

Figura D.8: Gráfico Manhattan de associação de CNVs com sedentarismo (log SB). O eixo y indica o $-\log _{10}(p)$ valor dos testes de associação para cada $C N V$. Por sua vez, o eixo $x$ indica a posição central em pb dos CNVs ao longo dos 22 autossomos. 


\section{Apêndice E}

\section{Tabelas dos 20 menores $p$-valores dos GWAS de SNPs e de CNVs para variáveis transformadas pelo log}

Tabela E.1: $O s$ 20 CNVs (covariável categórica) com os menores p-valores nos testes de associação com log AFT MET.

\begin{tabular}{cccccc}
\hline \hline Cromossomo & Começo & Fim & Nível do Fator & Coeficiente beta & P-valor \\
\hline 1 & 72.522 .437 & 72.522 .941 & CNV3 & $-1,337$ & 0,00022 \\
1 & 72.522 .942 & 72.528 .701 & CNV3 & $-1,341$ & 0,00023 \\
15 & 18.829 .966 & 18.834 .172 & CNV4 & $-5,226$ & 0,00034 \\
15 & 18.834 .173 & 18.837 .449 & CNV4 & $-5,231$ & 0,00034 \\
15 & 18.837 .450 & 18.838 .175 & CNV4 & $-5,212$ & 0,00036 \\
15 & 18.838 .436 & 18.841 .465 & CNV4 & $-5,208$ & 0,00036 \\
15 & 18.838 .176 & 18.838 .435 & CNV4 & $-5,197$ & 0,00037 \\
12 & 34.467 .978 & 34.469 .565 & CNV3 & $-6,216$ & 0,00042 \\
15 & 18.714 .274 & 18.728 .578 & CNV4 & $-5,144$ & 0,00044 \\
15 & 18.728 .579 & 18.748 .350 & CNV4 & $-5,147$ & 0,00044 \\
15 & 18.706 .153 & 18.714 .273 & CNV4 & $-5,139$ & 0,00045 \\
15 & 18.700 .553 & 18.706 .152 & CNV4 & $-5,129$ & 0,00046 \\
15 & 18.771 .169 & 18.782 .353 & CNV4 & $-5,127$ & 0,00046 \\
15 & 18.816 .445 & 18.829 .965 & CNV4 & $-5,121$ & 0,00046 \\
15 & 18.748 .351 & 18.753 .439 & CNV4 & $-5,121$ & 0,00047 \\
15 & 18.809 .893 & 18.816 .444 & CNV4 & $-5,117$ & 0,00047 \\
15 & 18.753 .440 & 18.771 .168 & CNV4 & $-5,115$ & 0,00048 \\
15 & 18.792 .632 & 18.801 .994 & CNV4 & $-5,117$ & 0,00048 \\
15 & 18.782 .354 & 18.792 .631 & CNV4 & $-5,099$ & $5 \mathrm{e}-04$ \\
15 & 18.801 .995 & 18.809 .892 & CNV4 & $-5,098$ & $5 \mathrm{e}-04$ \\
\hline
\end{tabular}


Tabela E.2: Os $20 \mathrm{CNVs}$ (covariável categórica) com os menores p-valores nos testes de associação com log WK MET.

\begin{tabular}{cccccc}
\hline \hline Cromossomo & Começo & Fim & Nível do Fator & Coeficiente beta & P-valor \\
\hline 15 & 18.829 .966 & 18.834 .172 & CNV4 & $-5,046$ & 0,00038 \\
15 & 18.834 .173 & 18.837 .449 & CNV4 & $-5,051$ & 0,00038 \\
15 & 18.837 .450 & 18.838 .175 & CNV4 & $-5,035$ & $4 \mathrm{e}-04$ \\
15 & 18.838 .176 & 18.838 .435 & CNV4 & $-5,023$ & 0,00041 \\
15 & 18.838 .436 & 18.841 .465 & CNV4 & $-5,015$ & 0,00042 \\
15 & 18.728 .579 & 18.748 .350 & CNV4 & $-4,908$ & 0,00057 \\
15 & 18.816 .445 & 18.829 .965 & CNV4 & $-4,906$ & 0,00057 \\
15 & 18.771 .169 & 18.782 .353 & CNV4 & $-4,899$ & 0,00058 \\
15 & 18.700 .553 & 18.706 .152 & CNV4 & $-4,894$ & 0,00059 \\
15 & 18.706 .153 & 18.714 .273 & CNV4 & $-4,889$ & $6 \mathrm{e}-04$ \\
15 & 18.714 .274 & 18.728 .578 & CNV4 & $-4,889$ & $6 \mathrm{e}-04$ \\
15 & 18.809 .893 & 18.816 .444 & CNV4 & $-4,886$ & 0,00061 \\
15 & 18.748 .351 & 18.753 .439 & CNV4 & $-4,881$ & 0,00062 \\
15 & 18.792 .632 & 18.801 .994 & CNV4 & $-4,879$ & 0,00062 \\
15 & 18.753 .440 & 18.771 .168 & CNV4 & $-4,874$ & 0,00063 \\
15 & 18.801 .995 & 18.809 .892 & CNV4 & $-4,868$ & 0,00064 \\
15 & 18.782 .354 & 18.792 .631 & CNV4 & $-4,866$ & 0,00065 \\
1 & 25.519 .574 & 25.534 .799 & CNV3 & 0,390 & 0,00068 \\
15 & 19.055 .355 & 19.080 .081 & CNV4 & $-4,169$ & 0,0013 \\
15 & 19.080 .082 & 19.090 .388 & CNV4 & $-4,169$ & 0,0013 \\
\hline
\end{tabular}

Tabela E.3: $\mathrm{Os} 20 \mathrm{CNVs}$ (covariável categórica) com os menores p-valores nos testes de associação com log MVPA.

\begin{tabular}{cccccc}
\hline \hline Cromossomo & Começo & Fim & Nível do Fator & Coeficiente beta & P-valor \\
\hline 1 & 72.522 .437 & 72.522 .941 & CNV3 & $-0,121$ & $7,2 \mathrm{e}-07$ \\
1 & 72.522 .942 & 72.528 .701 & CNV3 & $-0,131$ & $1,4 \mathrm{e}-06$ \\
9 & 41.832 .530 & 41.844 .479 & CNV3 & 0,425 & 0,00052 \\
11 & 5.756 .407 & 5.759 .488 & CNV3 & $-0,009$ & 0,00071 \\
12 & 36.320 .626 & 36.339 .406 & CNV1 & $-0,331$ & 0,00073 \\
12 & 36.358 .361 & 36.358 .753 & CNV1 & $-0,331$ & 0,00073 \\
12 & 36.339 .407 & 36.340 .430 & CNV1 & $-0,389$ & 0,00074 \\
12 & 36.340 .431 & 36.358 .360 & CNV1 & $-0,389$ & 0,00074 \\
12 & 36.358 .754 & 36.367 .548 & CNV1 & $-0,422$ & 0,00074 \\
12 & 36.367 .549 & 36.367 .550 & CNV1 & $-0,422$ & 0,00074 \\
12 & 36.367 .551 & 36.393 .846 & CNV1 & $-0,601$ & 0,00076 \\
12 & 36.393 .847 & 36.394 .320 & CNV1 & $-0,627$ & 0,00077 \\
19 & 48.394 .874 & 48.404 .090 & CNV3 & $-2,797$ & 0,00081 \\
5 & 46.306 .766 & 46.309 .259 & CNV1 & 0,527 & 0,00083 \\
9 & 41.882 .867 & 41.887 .112 & CNV3 & 0,250 & 0,001 \\
11 & 5.754 .190 & 5.756 .406 & CNV3 & $-0,016$ & 0,001 \\
11 & 4.929 .672 & 4.930 .605 & CNV1 & $-2,912$ & 0,0014 \\
11 & 4.928 .582 & 4.929 .671 & CNV1 & $-2,906$ & 0,0015 \\
11 & 4.926 .820 & 4.926 .943 & CNV1 & $-2,918$ & 0,0017 \\
11 & 4.926 .944 & 4.928 .581 & CNV1 & $-2,901$ & 0,0018 \\
\hline
\end{tabular}


Tabela E.4: Os 20 CNVs (covariável categórica) com os menores p-valores nos testes de associação com log $S B$.

\begin{tabular}{cccccc}
\hline \hline Cromossomo & Começo & Fim & Nível do Fator & Coeficiente beta & P-valor \\
\hline 3 & 131.282 .358 & 131.288 .926 & CNV1 & $-0,499$ & 0,0011 \\
4 & 2.282 & 11.426 & CNV1 & $-1,228$ & 0,0012 \\
8 & 39.354 .761 & 39.365 .832 & CNV0 & 0,002 & 0,0021 \\
19 & 48.216 .171 & 48.221 .240 & CNV3 & 0,219 & 0,0022 \\
3 & 131.288 .927 & 131.289 .688 & CNV3 & $-0,303$ & 0,0026 \\
19 & 48.188 .582 & 48.192 .288 & CNV3 & 0,153 & 0,0027 \\
19 & 48.192 .289 & 48.198 .014 & CNV3 & 0,160 & 0,0027 \\
19 & 48.198 .015 & 48.201 .493 & CNV3 & 0,155 & 0,0027 \\
19 & 48.206 .028 & 48.211 .202 & CNV3 & 0,195 & 0,0027 \\
19 & 48.211 .203 & 48.216 .135 & CNV3 & 0,197 & 0,0027 \\
19 & 48.216 .136 & 48.216 .170 & CNV3 & 0,197 & 0,0027 \\
19 & 48.184 .303 & 48.188 .454 & CNV3 & 0,124 & 0,0028 \\
19 & 48.188 .455 & 48.188 .581 & CNV3 & 0,124 & 0,0028 \\
19 & 48.201 .494 & 48.206 .027 & CNV3 & 0,123 & 0,0029 \\
19 & 48.176 .776 & 48.181 .795 & CNV3 & 0,073 & 0,003 \\
19 & 48.181 .796 & 48.184 .302 & CNV3 & 0,090 & 0,003 \\
7 & 38.285 .865 & 38.291 .966 & CNV1 & $-0,684$ & 0,0031 \\
7 & 38.291 .967 & 38.292 .303 & CNV1 & $-0,684$ & 0,0031 \\
15 & 32.583 .096 & 32.587 .887 & CNV3 & $-0,296$ & 0,0036 \\
15 & 74.678 .683 & 74.678 .796 & CNV0 & $-0,255$ & 0,0038 \\
\hline
\end{tabular}

Tabela E.5: Os 20 SNPs com os menores p-valores nos testes de associação com $\log A F T$ MET

\begin{tabular}{cccccc}
\hline \hline SNP & Cromossomo & pb & Alelo & Coeficiente beta & P-valor \\
\hline rs1441720 & 4 & 164.577 .424 & $\mathrm{~T}$ & $-1,569$ & $4,03462 \mathrm{e}-07$ \\
rs16863264 & 3 & 152.427 .224 & $\mathrm{~A}$ & $-1,355$ & $8,31278 \mathrm{e}-07$ \\
rs870033 & 8 & 24.163 .410 & $\mathrm{~A}$ & $-1,558$ & $1,77327 \mathrm{e}-06$ \\
rs7329033 & 13 & 111.118 .490 & $\mathrm{C}$ & $-4,328$ & $2,02186 \mathrm{e}-06$ \\
rs11945670 & 4 & 104.624 .813 & $\mathrm{~T}$ & $-4,850$ & $3,94124 \mathrm{e}-06$ \\
rs843530 & 3 & 197.965 .421 & $\mathrm{G}$ & 1,190 & $5,9688 \mathrm{e}-06$ \\
rs16971305 & 18 & 34.797 .900 & $\mathrm{G}$ & 1,864 & $6,12531 \mathrm{e}-06$ \\
rs1104375 & 3 & 197.960 .440 & $\mathrm{G}$ & 1,173 & $7,90009 \mathrm{e}-06$ \\
rs9826214 & 3 & 197.962 .610 & $\mathrm{~T}$ & 1,173 & $7,90009 \mathrm{e}-06$ \\
rs13075121 & 3 & 45.579 .163 & $\mathrm{G}$ & 1,124 & $8,43901 \mathrm{e}-06$ \\
rs2884249 & 8 & 115.860 .432 & $\mathrm{~T}$ & 1,318 & $8,55668 \mathrm{e}-06$ \\
rs16971255 & 18 & 34.785 .253 & $\mathrm{C}$ & 1,833 & $9,28419 \mathrm{e}-06$ \\
rs6895677 & 5 & 178.949 .270 & $\mathrm{~A}$ & $-1,311$ & $9,78921 \mathrm{e}-06$ \\
rs7843119 & 8 & 115.858 .530 & $\mathrm{~T}$ & 1,418 & $1,00342 \mathrm{e}-05$ \\
rs7892812 & 23 & 8.354 .253 & $\mathrm{~T}$ & 0,995 & $1,00965 \mathrm{e}-05$ \\
rs7776569 & 7 & 8.525 .597 & $\mathrm{G}$ & $-1,243$ & $1,06451 \mathrm{e}-05$ \\
rs370915 & 4 & 188.055 .250 & $\mathrm{G}$ & $-1,238$ & $1,15158 \mathrm{e}-05$ \\
rs7140116 & 13 & 52.762 .445 & $\mathrm{~T}$ & $-1,152$ & $1,34434 \mathrm{e}-05$ \\
rs11218568 & 11 & 121.650 .021 & $\mathrm{~A}$ & 1,844 & $1,48874 \mathrm{e}-05$ \\
rs6545417 & 2 & 54.585 .718 & $\mathrm{C}$ & $-5,925$ & $1,55894 \mathrm{e}-05$ \\
\hline & & & & &
\end{tabular}


Tabela E.6: Os $20 \mathrm{SNPs}$ com os menores p-valores nos testes de associação com $\log W K M E T$

\begin{tabular}{cccccc}
\hline \hline SNP & Cromossomo & $\mathrm{pb}$ & Alelo & Coeficiente beta & P-valor \\
\hline rs2196072 & 15 & $68,353,343$ & $\mathrm{C}$ & 1.197 & $1.9206 \mathrm{e}-06$ \\
rs11635258 & 15 & $84,523,763$ & $\mathrm{~A}$ & -1.255 & $3.6374 \mathrm{e}-06$ \\
rs2175424 & 18 & $74,578,854$ & $\mathrm{G}$ & -3.011 & $6.18327 \mathrm{e}-06$ \\
rs17521509 & 5 & $136,399,410$ & $\mathrm{~T}$ & 1.280 & $6.30225 \mathrm{e}-06$ \\
rs16971305 & 18 & $34,797,900$ & $\mathrm{G}$ & 1.808 & $6.79319 \mathrm{e}-06$ \\
rs1352947 & 12 & $87,484,858$ & $\mathrm{G}$ & 1.392 & $8.76828 \mathrm{e}-06$ \\
rs16971322 & 18 & $34,809,783$ & $\mathrm{~A}$ & 2.276 & $9.35682 \mathrm{e}-06$ \\
rs16971248 & 18 & $34,781,837$ & $\mathrm{~T}$ & 2.106 & $9.78334 \mathrm{e}-06$ \\
rs9295648 & 6 & $25,294,547$ & $\mathrm{~A}$ & -1.208 & $1.05458 \mathrm{e}-05$ \\
rs6765292 & 3 & $23,846,734$ & $\mathrm{~T}$ & -1.389 & $1.13421 \mathrm{e}-05$ \\
rs1356266 & 12 & $37,689,848$ & $\mathrm{G}$ & -1.211 & $1.16724 \mathrm{e}-05$ \\
rs16971255 & 18 & $34,785,253$ & $\mathrm{C}$ & 1.759 & $1.26481 \mathrm{e}-05$ \\
rs4433015 & 7 & $65,277,158$ & $\mathrm{C}$ & 1.095 & $1.27484 \mathrm{e}-05$ \\
rs5017082 & 12 & $37,600,831$ & $\mathrm{C}$ & -1.212 & $1.30365 \mathrm{e}-05$ \\
rs13094499 & 3 & $195,462,549$ & $\mathrm{G}$ & 1.145 & $1.37916 \mathrm{e}-05$ \\
rs16863264 & 3 & $152,427,224$ & $\mathrm{~A}$ & -1.177 & $1.43871 \mathrm{e}-05$ \\
rs11945670 & 4 & $104,624,813$ & $\mathrm{~T}$ & -4.448 & $1.52777 \mathrm{e}-05$ \\
rs12245931 & 10 & $9,341,698$ & $\mathrm{~A}$ & -3.361 & $1.55468 \mathrm{e}-05$ \\
rs7131749 & 12 & $37,691,729$ & $\mathrm{G}$ & -1.191 & $1.58509 \mathrm{e}-05$ \\
rs7232733 & 18 & $34,767,008$ & $\mathrm{G}$ & 1.109 & $1.70191 \mathrm{e}-05$ \\
\hline
\end{tabular}

Tabela E.7: $\mathrm{Os} 20 \mathrm{SNPs}$ com os menores p-valores nos testes de associação com $\log M V P A$ MET

\begin{tabular}{cccccc}
\hline \hline SNP & Cromossomo & $\mathrm{pb}$ & Alelo & Coeficiente beta & P-valor \\
\hline rs7667749 & 4 & $156,750,782$ & $\mathrm{G}$ & 4.934 & $6.60546 \mathrm{e}-07$ \\
rs1441720 & 4 & $164,577,424$ & $\mathrm{~T}$ & -1.514 & $7.32839 \mathrm{e}-07$ \\
rs17427703 & 7 & $8,806,235$ & $\mathrm{C}$ & 3.612 & $8.04086 \mathrm{e}-07$ \\
rs17363477 & 2 & $9,848,545$ & $\mathrm{C}$ & -1.548 & $1.38998 \mathrm{e}-06$ \\
rs10517083 & 4 & $25,317,039$ & $\mathrm{~T}$ & -1.245 & $1.81605 \mathrm{e}-06$ \\
rs745331 & 15 & $25,602,742$ & $\mathrm{C}$ & 1.361 & $1.99423 \mathrm{e}-06$ \\
rs6064348 & 20 & $54,199,726$ & $\mathrm{~T}$ & 1.328 & $2.35284 \mathrm{e}-06$ \\
rs9969585 & 8 & $121,918,562$ & $\mathrm{~T}$ & 1.205 & $2.42794 \mathrm{e}-06$ \\
rs7017161 & 8 & $121,921,861$ & $\mathrm{~T}$ & 1.191 & $2.97298 \mathrm{e}-06$ \\
rs7017040 & 8 & $121,921,916$ & $\mathrm{~T}$ & 1.191 & $2.97298 \mathrm{e}-06$ \\
rs6883589 & 5 & $169,825,162$ & $\mathrm{~T}$ & 1.588 & $3.55629 \mathrm{e}-06$ \\
rs10018315 & 4 & $25,314,542$ & $\mathrm{G}$ & -1.215 & $4.0801 \mathrm{e}-06$ \\
rs9963329 & 18 & $60,762,809$ & $\mathrm{~A}$ & 3.301 & $4.81088 \mathrm{e}-06$ \\
rs6851444 & 4 & $164,502,535$ & $\mathrm{G}$ & -1.486 & $5.28026 \mathrm{e}-06$ \\
rs16839873 & 2 & $138,383,949$ & $\mathrm{C}$ & 2.593 & $6.02386 \mathrm{e}-06$ \\
rs5934153 & 23 & $14,073,370$ & $\mathrm{G}$ & -1.223 & $6.50609 \mathrm{e}-06$ \\
rs4483247 & 9 & $37,035,825$ & $\mathrm{C}$ & 1.715 & $6.73321 \mathrm{e}-06$ \\
rs2238149 & 12 & $109,796,312$ & $\mathrm{G}$ & 1.198 & $7.67465 \mathrm{e}-06$ \\
rs8008338 & 14 & $72,312,223$ & $\mathrm{C}$ & 2.630 & $7.71421 \mathrm{e}-06$ \\
rs3127351 & 6 & $166,517,803$ & $\mathrm{G}$ & 4.211 & $8.51124 \mathrm{e}-06$ \\
\hline
\end{tabular}


Tabela E.8: Os 20 SNPs com os menores p-valores nos testes de associação com $\log S B$

\begin{tabular}{cccccc}
\hline \hline SNP & Cromossomo & $\mathrm{pb}$ & Alelo & Coeficiente beta & P-valor \\
\hline rs4865055 & 4 & $56,681,169$ & $\mathrm{C}$ & -0.313 & $8.50263 \mathrm{e}-07$ \\
rs1433060 & 19 & $9,407,329$ & $\mathrm{~A}$ & -0.417 & $8.78403 \mathrm{e}-07$ \\
rs8104971 & 19 & $9,241,978$ & $\mathrm{C}$ & -0.297 & $2.25544 \mathrm{e}-06$ \\
rs9981332 & 21 & $28,912,488$ & $\mathrm{C}$ & -0.534 & $3.14853 \mathrm{e}-06$ \\
rs1994718 & 17 & $70,457,440$ & $\mathrm{C}$ & -0.233 & $3.4735 \mathrm{e}-06$ \\
rs1155459 & 16 & $50,319,243$ & $\mathrm{C}$ & -2.076 & $3.70036 \mathrm{e}-06$ \\
rs12612658 & 2 & $136,931,217$ & $\mathrm{G}$ & -0.230 & $5.2135 \mathrm{e}-06$ \\
rs17009197 & 12 & $80,983,130$ & $\mathrm{~T}$ & -0.281 & $5.93305 \mathrm{e}-06$ \\
rs500566 & 6 & $145,644,112$ & $\mathrm{G}$ & 0.318 & $7.25309 \mathrm{e}-06$ \\
rs494020 & 6 & $145,644,809$ & $\mathrm{C}$ & 0.345 & $8.57354 \mathrm{e}-06$ \\
rs10076795 & 5 & $170,013,947$ & $\mathrm{C}$ & -0.381 & $9.12053 \mathrm{e}-06$ \\
rs11159676 & 14 & $84,214,187$ & $\mathrm{~T}$ & -0.338 & $9.44382 \mathrm{e}-06$ \\
rs11649061 & 16 & $64,155,001$ & $\mathrm{~T}$ & 0.196 & $1.2509 \mathrm{e}-05$ \\
rs10039227 & 5 & $170,023,873$ & $\mathrm{C}$ & -0.371 & $1.28606 \mathrm{e}-05$ \\
rs1711372 & 4 & $179,199,162$ & $\mathrm{C}$ & -0.207 & $1.52744 \mathrm{e}-05$ \\
rs7910778 & 10 & $29,131,964$ & $\mathrm{~A}$ & -0.198 & $1.54882 \mathrm{e}-05$ \\
rs2144148 & 20 & $11,048,677$ & $\mathrm{G}$ & -0.333 & $1.67302 \mathrm{e}-05$ \\
rs10763668 & 10 & $29,130,755$ & $\mathrm{G}$ & 0.197 & $1.6877 \mathrm{e}-05$ \\
rs1915847 & 5 & $62,290,424$ & $\mathrm{~T}$ & -0.285 & $1.75498 \mathrm{e}-05$ \\
rs11887664 & 2 & $196,866,874$ & $\mathrm{~T}$ & -0.514 & $2.0226 \mathrm{e}-05$ \\
\hline
\end{tabular}




\section{Apêndice F}

\section{Anotação de SNPs candidatos sob critério flexível}

Tabela F.1: SNPs candidatos associados a invSB sob o critério de $10^{-5}$.

$\begin{array}{llllllll}\text { SNP } & \text { Chromosome } & \text { Position } & \text { Alleles } & \text { Gene } & \text { Feature } & \text { Left_gene } & \text { Righ } \\ \text { rs11079826 } & 17 & 43952047 & \mathrm{C} / \mathrm{T} & \text { NA } & \text { NA } & \text { SKAP1 } & \text { HOX } \\ \text { rs11651168 } & 17 & 43952192 & \mathrm{~A} / \mathrm{G} & \text { NA } & \text { NA } & \text { SKAP1 } & \text { HOX } \\ \text { rs1994718 } & 17 & 70457440 & \mathrm{C} / \mathrm{T} & \text { OTOP3 } & \text { near-gene-3[NM_178233.1] } & \text { OTOP3 } & \text { C170 } \\ \text { rs8104971 } & 19 & 9241978 & \mathrm{~A} / \mathrm{G} & \text { NA } & \text { NA } & \text { OR7E19P } & \text { OR7 } \\ \text { rs1433060 } & 19 & 9407329 & \mathrm{G} / \mathrm{T} & \text { ZNF266 } & \text { near-gene-5[NM_198058.1] } & \text { ZNF266 } & \text { ZNF } \\ \text { rs4865055 } & 4 & 56681169 & \mathrm{C} / \mathrm{G} & \text { NA } & \text { NA } & \text { CEP135 } & \text { KIA } \\ \text { rs1046625 } & 5 & 31595233 & \mathrm{~A} / \mathrm{G} & \text { NA } & \text { NA } & \text { C5orf22 } & \text { PDZ } \\ \text { rs6891195 } & 5 & 31602359 & \text { G/T } & \text { NA } & \text { NA } & \text { C5orf22 } & \text { PDZ } \\ \text { rs6869981 } & 5 & 31602404 & \mathrm{C} / \mathrm{G} & \text { NA } & \text { NA } & \text { C5orf22 } & \text { PDZ } \\ \text { rs10076795 } & 5 & 170013947 & \mathrm{~A} / \mathrm{G} & \text { KCNIP1 } & \text { intron[NM_014592.2] } & \text { KCNMB1 } & \text { LOC } \\ & & & & \text { KCNIP1 } & \text { intron[NM_001034837.1] } & & \\ \text { rs10039227 } & 5 & 170023873 & \mathrm{C} / \mathrm{G} & \text { KCNIP1 } & \text { intron[NM_001034838.1] } & \text { KCNMB1 } & \text { LOC } \\ \text { rs500566 } & 6 & 145644112 & \mathrm{~A} / \mathrm{G} & \text { NA } & \text { NA } & \text { UTRN } & \text { LOC } \\ \text { rs494020 } & 6 & 145644809 & \mathrm{C} / \mathrm{T} & \text { NA } & \text { NA } & \text { UTRN } & \text { LOC } \\ & & & & & & & \end{array}$




\section{Referências Bibliográficas}

Affymetrix(2017) Affymetrix. Genome-Wide Human SNP Array 6.0, 2017. URL http://www. affymetrix.com/support/technical/byproduct.affx?product=genomewidesnp_6. Citado na pág. 13

Ahmad et al.(2013) Shafqat Ahmad, Gull Rukh, Tibor V. Varga, Ashfaq Ali, Azra Kurbasic, Dmitry Shungin, Ulrika Ericson, Robert W. Koivula, Audrey Y. Chu, Lynda M. Rose, Andrea Ganna, Qibin Qi, Alena Stančáková, Camilla H. Sandholt, Cathy E. Elks, Gary Curhan, Majken K. Jensen, Rulla M. Tamimi, Kristine H. Allin, Torben Jørgensen, Soren Brage, Claudia Langenberg, Mette Aadahl, Niels Grarup, Allan Linneberg, Guillaume Paré, Patrik K. E. Magnusson, Nancy L. Pedersen, Michael Boehnke, Anders Hamsten, Karen L. Mohlke, Louis T. Pasquale, Oluf Pedersen, Robert A. Scott, Paul M. Ridker, Erik Ingelsson, Markku Laakso, Torben Hansen, Lu Qi, Nicholas J. Wareham, Daniel I. Chasman, Göran Hallmans, Frank B. Hu, Frida Renström, Marju Orho-Melander e Paul W. Franks. Gene Physical Activity Interactions in Obesity: Combined Analysis of 111,421 Individuals of European Ancestry. PLoS Genetics, 9(7):e1003607. ISSN 15537404. doi: 10.1371/journal.pgen.1003607. URL http://dx.plos.org/10.1371/journal.pgen.1003607. Citado na pág. 3,8

Almasy e Blangero(2010) L. Almasy e J. Blangero. Variance Component Methods for Analysis of Complex Phenotypes. Cold Spring Harbor Protocols, 2010(5):pdb.top77-pdb.top77. ISSN 15596095. doi: 10.1101/pdb.top77. URL http://www.cshprotocols.org/cgi/doi/10.1101/pdb.top77. Citado na pág. 17, 18, 21

Almasy e Blangero(1998) Laura Almasy e John Blangero. Multipoint Quantitative-Trait Linkage Analysis in General Pedigrees. The American Journal of Human Genetics, 62(5):11981211. ISSN 00029297. doi: 10.1086/301844. URL http://linkinghub.elsevier.com/retrieve/pii/ S0002929707615420. Citado na pág. 17

Almeida et al.(2012) Jeeser Alves Almeida, Daniel Alexandre Boullosa, Emerson Pardono, Ricardo Moreno Lima, Pâmella Karoline Morais, Benedito Sérgio Denadai, Vinícius Carolino Souza, Otávio Toledo Nóbrega, Carmem Silvia Grubert Campbell e Herbert Gustavo Simões. A influência do genótipo da ECA sobre a aptidão cardiovascular de jovens do sexo masculino moderadamente ativos. Arquivos Brasileiros de Cardiologia, 98(4):315-320. ISSN 0066-782X. doi: 10.1590/S0066-782X2012005000029. URL http://www.scielo.br/scielo.php? script $=$ sci $\left\{\_\right\}$arttext $\{\&\}$ pid $=$ S0066-782X2012000400005 $\{\&\} \operatorname{lng}=$ pt $\{\&\}$ nrm $=$ iso $\{\&\} \operatorname{tng}=$ en. Citado na pág. 2,10

Amorim et al.(2013) Tales Amorim, Alan Knuth, Danielle Cruz, Deborah Malta, Rodrigo Reis e Pedro Hallal. Description of the physical activity promotion programs funded by the brazilian ministry of health. Revista Brasileira de Atividade Física ES Saúde, 18(1):63-74. Citado na pág. 4

Ardlie et al.(2002) Kristin G Ardlie, Leonid Kruglyak e Mark Seielstad. Patterns of linkage disequilibrium in the human genome. Nature Reviews Genetics, 3(4):299. Citado na pág. 54

Arya et al.(2018) Rector Arya, Vidya S. Farook, Sharon P. Fowler, Sobha Puppala, Geetha Chittoor, Roy G. Resendez, Srinivas Mummidi, Jairam Vanamala, Laura Almasy, Joanne E. Curran, Anthony G. Comuzzie, Donna M. Lehman, Christopher P. Jenkinson, Jane L. Lynch, Ralph A. 
DeFronzo, John Blangero, Daniel E. Hale, Ravindranath Duggirala e Vincent P. Diego. Genetic and environmental (physical fitness and sedentary activity) interaction effects on cardiometabolic risk factors in Mexican American children and adolescents. Genetic Epidemiology. ISSN 07410395. doi: 10.1002/gepi.22114. URL http://doi.wiley.com/10.1002/gepi.22114. Citado na pág. 31

Ball et al.(2010) Alexander D Ball, Jessica Stapley, Deborah A Dawson, Tim R Birkhead, Terry Burke e Jon Slate. A comparison of snps and microsatellites as linkage mapping markers: lessons from the zebra finch (taeniopygia guttata). BMC genomics, 11(1):218. Citado na pág. 2

Bauman et al.(2009) Adrian Bauman, Fiona Bull, Tien Chey, Cora L Craig, Barbara E Ainsworth, James F Sallis, Heather R Bowles, Maria Hagstromer, Michael Sjostrom e Michael Pratt. The international prevalence study on physical activity: results from 20 countries. International journal of behavioral nutrition and physical activity, 6(1):21. Citado na pág. 16

Beasley et al.(2009) T Mark Beasley, Stephen Erickson e David B Allison. Rank-based inverse normal transformations are increasingly used, but are they merited? Behavior genetics, 39(5): 580. Citado na pág. 31

Behrens et al.(2018) Gundula Behrens, Thomas Gredner, Christian Stock, Michael F Leitzmann, Hermann Brenner e Ute Mons. Cancers due to excess weight, low physical activity, and unhealthy diet: Estimation of the attributable cancer burden in germany. Deutsches Ärzteblatt International, 115(35-36):578. Citado na pág. 8

Blangero et al.(2013) John Blangero, Vincent P Diego, Thomas D Dyer, Marcio Almeida, Juan Peralta, Jack W Kent Jr, Jeff T Williams, Laura Almasy e Harald HH Göring. A kernel of truth: statistical advances in polygenic variance component models for complex human pedigrees. Em Advances in genetics, volume 81, páginas 1-31. Elsevier. Citado na pág. 19

Blazek et al.(2016) Alisa D Blazek, Jin Nam, Rohan Gupta, Meera Pradhan, Priyangi Perera, Noah L Weisleder, Timothy E Hewett, Ajit M Chaudhari, Beth S Lee, Binnaz Leblebicioglu et al. Exercise-driven metabolic pathways in healthy cartilage. Osteoarthritis and cartilage, 24 (7):1210-1222. Citado na pág. 41

Bush e Moore(2012) William S Bush e Jason H Moore. Genome-wide association studies. PLoS computational biology, 8(12):e1002822. Citado na pág. 11, 13, 20, 37, 57

Buss e Dachs(2018) Linda A Buss e Gabi U Dachs. The role of exercise and hyperlipidaemia in breast cancer progression. Exercise immunology review, 24. Citado na pág. 8

Butchbach(2016) Matthew E. R. Butchbach. Copy Number Variations in the Survival Motor Neuron Genes: Implications for Spinal Muscular Atrophy and Other Neurodegenerative Diseases. Frontiers in Molecular Biosciences, 3. ISSN 2296-889X. doi: 10.3389/fmolb.2016.00007. URL http://journal.frontiersin.org/Article/10.3389/fmolb.2016.00007/abstract. Citado na pág. 4, 12

Celis-Morales et al.(2018) Carlos A Celis-Morales, Paul Welsh, Donald M Lyall, Lewis Steell, Fanny Petermann, Jana Anderson, Stamatina Iliodromiti, Anne Sillars, Nicholas Graham, Daniel F Mackay, Jill P Pell, Jason M R Gill, Naveed Sattar e Stuart R Gray. Associations of grip strength with cardiovascular, respiratory, and cancer outcomes and all cause mortality: prospective cohort study of half a million UK Biobank participants. BMJ (Clinical research ed.), 361:k1651. ISSN 1756-1833. URL http://www.ncbi.nlm.nih.gov/pubmed/29739772http: //www.pubmedcentral.nih.gov/articlerender.fcgi?artid=PMC5939721. Citado na pág. 8

Chagdes et al.(2013) James R. Chagdes, Shirley Rietdyk, M. Haddad Jeffrey, N. Zelaznik Howard e Arvind Raman. Dynamic stability of a human standing on a balance board. Journal of Biomechanics, 46(15):2593-2602. ISSN 00219290. doi: 10.1016/j.jbiomech.2013.08.012. URL http://linkinghub.elsevier.com/retrieve/pii/S0021929013003928. Citado na pág. 3, 7 
Chekroud et al.(2018) Sammi R Chekroud, Ralitza Gueorguieva, Amanda B Zheutlin, Martin Paulus, Harlan M Krumholz, John H Krystal e Adam M Chekroud. Association between physical exercise and mental health in 1. 2 million individuals in the usa between 2011 and 2015: a crosssectional study. The Lancet Psychiatry, 5(9):739-746. Citado na pág. 9

Chen et al.(2017) Chia-Hsiang Chen, Hsin-I Chen, Wei-Hsien Chien, Ling-Hui Li, Yu-Yu Wu, YenNan Chiu, Wen-Che Tsai e Susan Shur-Fen Gau. High resolution analysis of rare copy number variants in patients with autism spectrum disorder from taiwan. Scientific reports, 7(1):11919. Citado na pág. 12

Chibnik et al.(2018) Lori B Chibnik, Charles C White, Shubhabrata Mukherjee, Towfique Raj, Lei Yu, Eric B Larson, Thomas J Montine, C Dirk Keene, Joshua Sonnen, Julie A Schneider et al. Susceptibility to neurofibrillary tangles: role of the ptprd locus and limited pleiotropy with other neuropathologies. Molecular psychiatry, 23(6):1521. Citado na pág. 40

Chu et al.(2017) Audrey Y Chu, Adrienne Tin, Pascal Schlosser, Yi-An Ko, Chengxiang Qiu, Chen Yao, Roby Joehanes, Morgan E Grams, Liming Liang, Caroline A Gluck et al. Epigenome-wide association studies identify dna methylation associated with kidney function. Nature communications, 8(1):1286. Citado na pág. 31

Chu e Huang(2017) Su Hee Chu e Yen-Tsung Huang. Integrated genomic analysis of biological gene sets with applications in lung cancer prognosis. BMC Bioinformatics, 18(1):336. ISSN 1471-2105. doi: 10.1186/s12859-017-1737-2. URL http://bmcbioinformatics.biomedcentral.com/ articles/10.1186/s12859-017-1737-2. Citado na pág. 17

Ciconelle(2018) Ana Cláudia Martins Ciconelle. Detecção de copy number variation (cnv) e sua caracterização na população brasileira. Dissertação de Mestrado, Instituto de Matemática e Estatística, Universidade de São Paulo, Brasil. Citado na pág. viii, 12, 13, 14, 16

Cox et al.(2012) Hannah C Cox, Rod A Lea, Claire Bellis, Dale R Nyholt, Thomas D Dyer, Larisa M Haupt, Jac Charlesworth, Elizabeth Matovinovic, John Blangero e Lyn R Griffiths. Heritability and genome-wide linkage analysis of migraine in the genetic isolate of norfolk island. Gene, 494(1):119-123. Citado na pág. 30

Craig et al.(2003) Cora L Craig, Alison L Marshall, Michael Sjöström, Adrian E Bauman, Michael L Booth, Barbara E Ainsworth, Michael Pratt, ULF Ekelund, Agneta Yngve, James F Sallis et al. International physical activity questionnaire: 12 -country reliability and validity. Medicine E science in sports $\&$ exercise, 35(8):1381-1395. Citado na pág. 16, 34

Cupeiro et al.(2012) Rocío Cupeiro, Domingo González-Lamuño, Teresa Amigo, Ana B. Peinado, Jonatan R. Ruiz, Francisco B. Ortega e Pedro J. Benito. Influence of the MCT1-T1470A polymorphism (rs1049434) on blood lactate accumulation during different circuit weight trainings in men and women. Journal of Science and Medicine in Sport, 15(6):541-547. ISSN 14402440. doi: 10.1016/j.jsams.2012.03.009. URL http://linkinghub.elsevier.com/retrieve/pii/ S1440244012000370. Citado na pág. 2

da Saúde. Secretaria de Políticas de Saúde(2002) Ministério da Saúde. Secretaria de Políticas de Saúde. Programa nacional de promoção da atividade física"agita brasil": atividade física e sua contribuição para a qualidade de vida. Rev Saúde Pública, 36(2):254-6. Citado na pág. 4

da Silva et al.(2018) Franciele Cascaes da Silva, Rodrigo da Rosa Iop, Laiana Cândido de Oliveira, Alice Mathea Boll, José Gustavo Souza de Alvarenga, Paulo José Barbosa Gutierres Filho, Lídia Mara Aguiar Bezerra de Melo, André Junqueira Xavier e Rudney da Silva. Effects of physical exercise programs on cognitive function in parkinson's disease patients: A systematic review of randomized controlled trials of the last 10 years. PloS one, 13(2):e0193113. Citado na pág. 9 
Dai et al.(2018) Meng-Hui Dai, Hui Zheng, Ling-Dan Zeng e Yan Zhang. The genes associated with early-onset Alzheimer's disease. Oncotarget. ISSN 1949-2553. doi: 10.18632/oncotarget.23738. URL http://www.oncotarget.com/fulltext/23738. Citado na pág. 1

de Andrade(2011) Alexandre Carvalho de Andrade. Aspectos socioambientais do município de baependi (mg): Subsídios para a gestão de uma unidade de conservação. Revista de GeografiaPPGEO-UFJF, 1(2). Citado na pág. 15

de Andrade et al.(1999) M de Andrade, C I Amos e T J Thiel. Methods to estimate genetic components of variance for quantitative traits in family studies. Genetic epidemiology, 17(1): 64-76. ISSN 0741-0395. doi: 10.1002/(SICI)1098-2272(1999)17:1<64::AID-GEPI5>3.0.CO;2-M. URL http://www.ncbi.nlm.nih.gov/pubmed/10323185. Citado na pág. 17

de Andrade et al.(2002) Mariza de Andrade, René Guéguen, Sophie Visvikis, Catherine Sass, Gérard Siest e Christopher I. Amos. Extension of variance components approach to incorporate temporal trends and longitudinal pedigree data analysis. Genetic Epidemiology, 22(3):221-232. ISSN 07410395. doi: 10.1002/gepi.01118. URL http://doi.wiley.com/10.1002/gepi.01118. Citado na pág. 17

De Andrade et al.(2015) Mariza De Andrade, Debashree Ray, Alexandre C. Pereira e Júlia P. Soler. Global Individual Ancestry Using Principal Components for Family Data. Human Heredity, 80(1):1-11. ISSN 14230062. doi: 10.1159/000381908. Citado na pág. 13, 21

de Araújo Lima et al.(2015) Felícia de Araújo Lima, Fernanda de Toledo Gonçalves e Cintia Fridman. Slc24a5 and asip as phenotypic predictors in brazilian population for forensic purposes. Legal Medicine, 17(4):261-266. Citado na pág. 2

de Klein et al.(1982) A de Klein, A G van Kessel, G Grosveld, C R Bartram, A Hagemeijer, D Bootsma, N K Spurr, N Heisterkamp, J Groffen e J R Stephenson. A cellular oncogene is translocated to the Philadelphia chromosome in chronic myelocytic leukaemia. Nature, 300 (5894):765-7. Citado na pág. 1

De Mello Costa e Slocombe(2012) Maria Fernanda De Mello Costa e Ron Slocombe. The use of angiotensin-i converting enzyme i/d genetic polymorphism as a biomarker of athletic performance in humans. Biosensors, 2(4):396-404. Citado na pág. 10

de Oliveira et al.(2008) Camila M de Oliveira, Alexandre C Pereira, Mariza de Andrade, Júlia M Soler e José E Krieger. Heritability of cardiovascular risk factors in a brazilian population: Baependi heart study. BMC Medical Genetics, 9(1):32. Citado na pág. 5, 17, 37, 57

Deshpande et al.(2019) Gaurang P Deshpande, Hugh-George Patterton e M Faadiel Essop. The human transketolase-like proteins tktl1 and tktl2 are bona fide transketolases. BMC structural biology, 19(1):2. Citado na pág. 40

Diego et al.(2015) Vincent P Diego, Raquel Nichele de Chaves, John Blangero, Michele Caroline de Souza, Daniel Santos, Thayse Natacha Gomes, Fernanda Karina dos Santos, Rui Garganta, Peter T Katzmarzyk e José AR Maia. Sex-specific genetic effects in physical activity: results from a quantitative genetic analysis. BMC medical genetics, 16(1):58. Citado na pág. 17, 30, 31, 33, $34,36,57$

Doherty et al.(2018) Aiden Doherty, Karl Smith-Byrne, Teresa Ferreira, Michael V Holmes, Chris Holmes, Sara L Pulit e Cecilia M Lindgren. Gwas identifies 14 loci for device-measured physical activity and sleep duration. Nature communications, 9(1):5257. Citado na pág. 12, 53

Duggal et al.(2008) Priya Duggal, Elizabeth M Gillanders, Taura N Holmes e Joan E BaileyWilson. Establishing an adjusted p-value threshold to control the family-wide type 1 error in genome wide association studies. BMC genomics, 9(1):516. Citado na pág. 20 
Dumas et al.(2007) L. Dumas, Y. H. Kim, A. Karimpour-Fard, M. Cox, J. Hopkins, J. R. Pollack e J. M. Sikela. Gene copy number variation spanning 60 million years of human and primate evolution. Genome Research, 17(9):1266-1277. ISSN 1088-9051. doi: 10.1101/gr.6557307. URL http://www.genome.org/cgi/doi/10.1101/gr.6557307. Citado na pág. 3, 7, 12

Duncan et al.(2019) Laramie E Duncan, Michael Ostacher e Jacob Ballon. How genome-wide association studies (gwas) made traditional candidate gene studies obsolete. Neuropsychopharmacology, página 1. Citado na pág. 58

EBI(2019) EBI. The nhgri-ebi catalog of published genome-wide association studies. https:// www.ebi.ac.uk/gwas/search?query=physical $\$ \% 20$ activity, 2019. Último acesso em 28/05/2019. Citado na pág. 12

Egan et al.(2016) Kieren J Egan, Malcolm von Schantz, André B Negrão, Hadassa C Santos, Andréa R V R Horimoto, Nubia E Duarte, Guilherme C Gonçalves, Júlia M P Soler, Mariza de Andrade, Geraldo Lorenzi-Filho, Homero Vallada, Tâmara P Taporoski, Mario Pedrazzoli, Ana P Azambuja, Camila M de Oliveira, Rafael O Alvim, José E Krieger e Alexandre C Pereira. Cohort profile: the Baependi Heart Study — a family-based, highly admixed cohort study in a rural Brazilian town. BMJ Open, 6(10):e011598. ISSN 2044-6055. doi: 10.1136/bmjopen-2016-011598. URL http://bmjopen.bmj.com/lookup/doi/10.1136/bmjopen-2016-011598. Citado na pág. 5, 16

Ekelund et al.(2006) Ulf Ekelund, Hanna Sepp, Sören Brage, Wulf Becker, Rupert Jakes, Mark Hennings e Nicholas J Wareham. Criterion-related validity of the last 7-day, short form of the international physical activity questionnaire in swedish adults. Public health nutrition, 9(2): 258-265. Citado na pág. 34

Fenesi et al.(2017) Barbara Fenesi, Hanna Fang, Ana Kovacevic, Mark Oremus, Parminder Raina e Jennifer J Heisz. Physical exercise moderates the relationship of apolipoprotein e (apoe) genotype and dementia risk: a population-based study. Journal of Alzheimer's Disease, 56(1):297-303. Citado na pág. 9

Floegel e Perez(2016) Theresa A Floegel e G Adriana Perez. An integrative review of physical activity/exercise intervention effects on function and health-related quality of life in older adults with heart failure. Geriatric Nursing, 37(5):340-347. Citado na pág. 9

Folley et al.(2018) Stephanie Folley, Ang Zhou e Elina Hyppönen. Information bias in measures of self-reported physical activity. International Journal of Obesity, 42(12):2062. Citado na pág. 34

Foulkes(2009) Andrea S. Foulkes. Applied Statistical Genetics with R. Springer New York, New York, NY. ISBN 978-0-387-89553-6. doi: 10.1007/978-0-387-89554-3. URL http://link.springer. com/10.1007/978-0-387-89554-3. Citado na pág. 2

Friedenreich et al.(2010) Christine M Friedenreich, Heather K Neilson e Brigid M Lynch. State of the epidemiological evidence on physical activity and cancer prevention. European journal of cancer, 46(14):2593-2604. Citado na pág. 8

Galeandro et al.(2017) V Galeandro, A Notarnicola, A Bianco, S Tafuri, L Russo, V Pesce, B Moretti e V Petruzzella. ACTN3/ACE genotypes and mitochondrial genome in professional soccer players performance. Journal of biological regulators and homeostatic agents, 31(1):207213. ISSN 0393-974X. URL http://www.ncbi.nlm.nih.gov/pubmed/28337894. Citado na pág. 3

Giolo et al.(2010) Suely R Giolo, Alexandre C Pereira, Mariza de Andrade, José E Krieger e Júlia P Soler. Evaluating gene by sex and age interactions on cardiovascular risk factors in Brazilian families. BMC Medical Genetics, 11(1):132. ISSN 1471-2350. doi: 10.1186/1471-2350-11-132. URL http://bmcmedgenet.biomedcentral.com/articles/10.1186/1471-2350-11-132. Citado na pág. 18, 19, 30 
Gonzalez-Brito e Bixby(2006) Manuel R Gonzalez-Brito e John L Bixby. Differential activities in adhesion and neurite growth of fibronectin type iii repeats in the ptp- $\delta$ extracellular domain. International journal of developmental neuroscience, 24(7):425-429. Citado na pág. 40

Gourraud et al.(2013) Pierre-Antoine Gourraud, Michael Sdika, Pouya Khankhanian, Roland G Henry, Azadeh Beheshtian, Paul M Matthews, Stephen L Hauser, Jorge R Oksenberg, Daniel Pelletier e Sergio E Baranzini. A genome-wide association study of brain lesion distribution in multiple sclerosis. Brain, 136(4):1012-1024. Citado na pág. 2

Haines et al.(2005) Jonathan L Haines, Michael A Hauser, Silke Schmidt, William K Scott, Lana M Olson, Paul Gallins, Kylee L Spencer, Shu Ying Kwan, Maher Noureddine, John R Gilbert et al. Complement factor $\mathrm{h}$ variant increases the risk of age-related macular degeneration. Science, 308 (5720):419-421. Citado na pág. 11

Halbert et al.(1999) JA Halbert, CA Silagy, P Finucane, RT Withers e PA Hamdorf. Exercise training and blood lipids in hyperlipidemic and normolipidemic adults: a meta-analysis of randomized, controlled trials. European Journal of Clinical Nutrition, 53(7):514. Citado na pág. 7

Hallal et al.(2012) Pedro C Hallal, Lars Bo Andersen, Fiona C Bull, Regina Guthold, William Haskell e Ulf Ekelund. Global physical activity levels: surveillance progress, pitfalls, and prospects. The Lancet, 380(9838):247-257. ISSN 01406736. doi: 10.1016/S0140-6736(12)60646-1. URL http://linkinghub.elsevier.com/retrieve/pii/S0140673612606461. Citado na pág. 20, 26, 27

Halper-Stromberg et al.(2017) Eitan Halper-Stromberg, Michael H Cho, Carla Wilson, Dipti Nevrekar, James D Crapo, George Washko, Raúl San José Estépar, David A Lynch, Edwin K Silverman, Sonia Leach et al. Visual assessment of chest computed tomographic images is independently useful for genetic association analysis in studies of chronic obstructive pulmonary disease. Annals of the American Thoracic Society, 14(1):33-40. Citado na pág. 2

Hands e Parker(2016) Beth Hands e Helen Parker. Male and Female Differences in Health Benefits Derived from Physical Activity: Implications for Exercise Prescription. Journal of Womens Health, Issues and Care, 5(4). ISSN 23259795. doi: 10.4172/2325-9795.1000238. URL http://www.scitechnol.com/peer-review/ male-and-female-differences-in-health-benefits-derived-from-physical-activity-implications-for-exercise-presc php?article\{_\}id=5030. Citado na pág. 20, 35, 36

Hirschhorn e Daly(2005) Joel N. Hirschhorn e Mark J. Daly. Genome-wide association studies for common diseases and complex traits. Nature Reviews Genetics, 6(2):95-108. ISSN 1471-0056. doi: 10.1038/nrg1521. URL http://www.nature.com/articles/nrg1521. Citado na pág. 2

Horimoto et al.(2011) Andréa RVR Horimoto, Suely R Giolo, Camila M Oliveira, Rafael O Alvim, Júlia P Soler, Mariza de Andrade, José E Krieger e Alexandre C Pereira. Heritability of physical activity traits in Brazilian families: the Baependi Heart Study. BMC Medical Genetics, 12(1): 155. ISSN 1471-2350. doi: 10.1186/1471-2350-12-155. URL http://bmcmedgenet.biomedcentral. com/articles/10.1186/1471-2350-12-155. Citado na pág. 5, 19, 26, 27, 30, 34, 36

Hou et al.(2019) Kangcheng Hou, Kathryn S Burch, Arunabha Majumdar, Huwenbo Shi, Nicholas Mancuso, Yue Wu, Sriram Sankararaman e Bogdan Pasaniuc. Accurate estimation of snp-heritability from biobank-scale data irrespective of genetic architecture. bioRxiv, página 526855. Citado na pág. 58

Iafrate et al.(2004) A John Iafrate, Lars Feuk, Miguel N Rivera, Marc L Listewnik, Patricia K Donahoe, Ying Qi, Stephen W Scherer e Charles Lee. Detection of large-scale variation in the human genome. Nature Genetics, 36(9):949-951. ISSN 1061-4036. doi: 10.1038/ng1416. URL http://www.nature.com/articles/ng1416. Citado na pág. 4 
IBGE(2010) IBGE. Brasil/Minas Gerais/Baependi/Panorama, 2010. URL https://cidades.ibge. gov.br/brasil/mg/baependi/panorama. Último acesso em 12/04/2019. Citado na pág. 15

Ikegawa(2012) Shiro Ikegawa. A short history of the genome-wide association study: where we were and where we are going. Genomics 6 informatics, 10(4):220. Citado na pág. 11

Innes et al.(2018) Josie Innes, Lisa Reali, Jill Clayton-Smith, Georgina Hall, Derek HK Lim, George J Burghel, Kim French, Unzela Khan, Daniel Walker, Fiona Lalloo et al. Cnvs affecting cancer predisposing genes (cpgs) detected as incidental findings in routine germline diagnostic chromosomal microarray (cma) testing. Journal of medical genetics, 55(2):89-96. Citado na pág. 12

Jacobs et al.(2009) Damon T Jacobs, Roberto Weigert, Kyle D Grode, Julie G Donaldson e Richard E Cheney. Myosin vc is a molecular motor that functions in secretory granule trafficking. Molecular biology of the cell, 20(21):4471-4488. Citado na pág. 40

Junqueira et al.(2013) Luis C Junqueira, Anthony L Mescher et al. Junqueira's basic histology: text $\&$ atlas/Anthony L. Mescher. New York [etc.]: McGraw-Hill Medical,. Citado na pág. 8

Kachman e Stroup(1994) Stephen D. Kachman e Walter W. Stroup. GENERALIZED LINEAR MIXED MODELS: AN APPLICATION. Conference on Applied Statistics in Agriculture, páginas 98-111. ISSN 2475-7772. doi: 10.4148/2475-7772.1352. URL https://newprairiepress.org/ agstatconference/1994/proceedings/8. Citado na pág. 17

Kahan(2015) David Kahan. Adult physical inactivity prevalence in the Muslim world: Analysis of 38 countries. Preventive Medicine Reports, 2:71-75. ISSN 22113355. doi: 10.1016/j.pmedr.2014. 12.007. URL http://linkinghub.elsevier.com/retrieve/pii/S221133551400028X. Citado na pág. 26

Kanai et al.(2016) Masahiro Kanai, Toshihiro Tanaka e Yukinori Okada. Empirical estimation of genome-wide significance thresholds based on the 1000 genomes project data set. Journal of human genetics, 61(10):861. Citado na pág. 54

Kim et al.(2014) Jayoun Kim, Jaehee Kim, Haesook Min, Sohee Oh, Yeonjung Kim, Andy Lee e Taesung Park. Joint identification of genetic variants for physical activity in korean population. International journal of molecular sciences, 15(7):12407-12421. Citado na pág. 53, 58

Kim et al.(2017) Stuart Kim, John Kleimeyer, Marwa Ahmed, Andy Avins, Michael Fredericson, Jason Dragoo e John Ioannidis. A Genetic Marker Associated with Shoulder Dislocation. International Journal of Sports Medicine. ISSN 0172-4622. doi: 10.1055/s-0043-106190. URL http://www.thieme-connect.de/DOI/DOI?10.1055/s-0043-106190. Citado na pág. 1, 53

Klimentidis et al.(2018) Yann C. Klimentidis, David A. Raichlen, Jennifer Bea, David O. Garcia, Nathan E. Wineinger, Lawrence J. Mandarino, Gene E. Alexander, Zhao Chen e Scott B. Going. Genome-wide association study of habitual physical activity in over 377,000 UK Biobank participants identifies multiple variants including CADM2 and APOE. International Journal of Obesity, 42(6):1161-1176. ISSN 0307-0565. doi: 10.1038/s41366-018-0120-3. URL http://www.nature.com/articles/s41366-018-0120-3. Citado na pág. 32, 41, 45, 53

Kris $M$ et al.(2013) Jamsen Kris M, Sophie G Zaloumis, Katrina Scurrah J e Lyle Gurrin C. Specification of Generalized Linear Mixed Models for Family Data using Markov Chain Monte Carlo Methods. Journal of Biometrics \& Biostatistics, S1(003). ISSN 21556180. doi: 10.4172/2155-6180.S1-003. URL https://www.omicsonline.org/ specification-of-generalized-linear-mixed-models-for-family-data-using-markov-chain-monte-carlo-methods-215 S1-003.php?aid $=7229$. Citado na pág. 17

Lambert et al.(2013) Jean-Charles Lambert, Carla A Ibrahim-Verbaas, Denise Harold, Adam C Naj, Rebecca Sims, Céline Bellenguez, Gyungah Jun, Anita L DeStefano, Joshua C Bis, Gary W Beecham et al. Meta-analysis of 74,046 individuals identifies 11 new susceptibility loci for alzheimer's disease. Nature genetics, 45(12):1452. Citado na pág. 53 
Lewontin(1974) Richard C Lewontin. Annotation: the analysis of variance and the analysis of causes. American journal of human genetics, 26(3):400. Citado na pág. 38

Lima et al.(2015) Giscard HO Lima, Elton Dias Silva, João Paulo Pereira Rosa, Sandro Soares Almeida, Paulo Roberto Correia, Chiaretto Costa e João Bosco Pesquero. Association between gene actn3 and basketball position in elite athletes of brazilian league: 1597 board\# 1 may 28, 100 pm-300 pm. Medicine $\& 3$ Science in Sports \& Exercise, 47(5S):424. Citado na pág. 4

Lourenco et al.(2019) Mychael V Lourenco, Rudimar L Frozza, Guilherme B de Freitas, Hong Zhang, Grasielle C Kincheski, Felipe C Ribeiro, Rafaella A Gonçalves, Julia R Clarke, Danielle Beckman, Agnieszka Staniszewski et al. Exercise-linked fndc5/irisin rescues synaptic plasticity and memory defects in alzheimer's models. Nature medicine, 25(1):165. Citado na pág. 9

Lush et al.(1943) Jay Laurence Lush et al. Animal breeding plans. Animal breeding plans., (Edn 2). Citado na pág. 38

MacArthur et al.(2008) D. G. MacArthur, J. T. Seto, S. Chan, K. G.R. Quinlan, J. M. Raftery, N. Turner, M. D. Nicholson, A. J. Kee, E. C. Hardeman, P. W. Gunning, G. J. Cooney, S. I. Head, N. Yang e K. N. North. An Actn3 knockout mouse provides mechanistic insights into the association between -actinin-3 deficiency and human athletic performance. Human Molecular Genetics, 17(8):1076-1086. ISSN 0964-6906. doi: 10.1093/hmg/ddm380. URL https://academic. oup.com/hmg/article-lookup/doi/10.1093/hmg/ddm380. Citado na pág. 3, 11

MacDonald et al.(2014) Jeffrey R MacDonald, Robert Ziman, Ryan K C Yuen, Lars Feuk e Stephen W Scherer. The Database of Genomic Variants: a curated collection of structural variation in the human genome. Nucleic acids research, 42(Database issue):D986-92. ISSN 1362-4962. doi: 10.1093/nar/gkt958. URL http://www.ncbi.nlm.nih.gov/pubmed/24174537http: //www.pubmedcentral.nih.gov/articlerender.fcgi?artid=PMC3965079. Citado na pág. 4

Macé et al.(2017) Aurélien Macé, Marcus A Tuke, Patrick Deelen, Kati Kristiansson, Hannele Mattsson, Margit Nõukas, Yadav Sapkota, Ursula Schick, Eleonora Porcu, Sina Rüeger et al. Cnv-association meta-analysis in 191,161 european adults reveals new loci associated with anthropometric traits. Nature communications, 8(1):744. Citado na pág. 12

Maffulli et al.(2013) Nicola Maffulli, Katia Margiotti, Umile Giuseppe Longo, Mattia Loppini, Vito Michele Fazio e Vincenzo Denaro. The genetics of sports injuries and athletic performance. Muscles, ligaments and tendons journal, 3(3):17389. URL http://www.ncbi.nlm.nih.gov/pubmed/24367777http://www.pubmedcentral.nih.gov/ articlerender.fcgi?artid=PMC3838326. Citado na pág. 2, 3, 4, 11

Makuc et al.(2017) Jana Makuc, Maja Šeruga, Matej Završnik, Ines Cilenšek e Daniel Petrovič. Angiotensinogen (agt) gene missense polymorphisms (rs699 and rs4762) and diabetic nephropathy in caucasians with type 2 diabetes mellitus. Bosnian journal of basic medical sciences, 17(3):262. Citado na pág. 10

McCarthy et al.(2008) Mark I. McCarthy, Gonçalo R. Abecasis, Lon R. Cardon, David B. Goldstein, Julian Little, John P. A. Ioannidis e Joel N. Hirschhorn. Genome-wide association studies for complex traits: consensus, uncertainty and challenges. Nature Reviews Genetics, 9(5):356-369. ISSN 1471-0056. doi: 10.1038/nrg2344. URL http://www.nature.com/articles/nrg2344. Citado na pág. 2

Montgomery et al.(1997) Hugh E Montgomery, Peter Clarkson, Clare M Dollery, Krishna Prasad, Maria-Angela Losi, Harry Hemingway, Deborah Statters, Mick Jubb, Martin Girvain, Amanda Varnava et al. Association of angiotensin-converting enzyme gene i/d polymorphism with change in left ventricular mass in response to physical training. Circulation, 96(3):741-747. Citado na pág. 10 
Moore e Shenk(2017) David S Moore e David Shenk. The heritability fallacy. Wiley Interdisciplinary Reviews: Cognitive Science, 8(1-2):e1400. Citado na pág. 38

Muñoz et al.(2017) Angélica María Muñoz, Claudia María Velásquez, Gloria María Agudelo, Rosa Magdalena Uscátegui, Alejandro Estrada, Fredy Alonso Patiño, Beatriz Elena Parra, María Victoria Parra e Gabriel Bedoya. Examining for an association between candidate gene polymorphisms in the metabolic syndrome components on excess weight and adiposity measures in youth: a cross-sectional study. Genes $\mathbb{E}$ nutrition, 12(1):19. Citado na pág. 10

Nashner(1976) L M Nashner. Adapting reflexes controlling the human posture. Experimental Brain Research, 26(1):59-72. ISSN 0014-4819. doi: 10.1007/BF00235249. Citado na pág. 3, 7

NCBI(2019) NCBI. Npy5r neuropeptide y receptor y5 [homo sapiens (human)]. https://www. ncbi.nlm.nih.gov/gene/4889\#gene-expression, 2019. Último acesso em 21/05/2019. Citado na pág. 40

Nelson e $\operatorname{Cox}(2017)$ D. L Nelson e M. M. Cox. Lehninger Principles of Biochemistry. W.H.Freeman. Citado na pág. 1

Oualkacha et al.(2012) Karim Oualkacha, Aurelie Labbe, Antonio Ciampi, Marc-Andre Roy e Michel Maziade. Principal components of heritability for high dimension quantitative traits and general pedigrees. Statistical Applications in Genetics and Molecular Biology, 11(2). Citado na pág. 58

Oyeyemi et al.(2013) Adewale L Oyeyemi, Adetoyeje Y Oyeyemi, Zainab A Jidda e Fatima Babagana. Prevalence of Physical Activity Among Adults in a Metropolitan Nigerian City: A CrossSectional Study. Journal of Epidemiology, 23(3):169-177. ISSN 0917-5040. doi: 10.2188/jea. JE20120116. URL http://jlc.jst.go.jp/DN/JST.JSTAGE/jea/JE20120116?lang=en $\{\&\}$ from= CrossRef $\{\&\}$ type=abstract. Citado na pág. 26

Ozaki et al.(2002) Kouichi Ozaki, Yozo Ohnishi, Aritoshi Iida, Akihiko Sekine, Ryo Yamada, Tatsuhiko Tsunoda, Hiroshi Sato, Hideyuki Sato, Masatsugu Hori, Yusuke Nakamura et al. Functional snps in the lymphotoxin- $\alpha$ gene that are associated with susceptibility to myocardial infarction. Nature genetics, 32(4):650. Citado na pág. 11

Papadimitriou et al.(2016) Ioannis D. Papadimitriou, Alejandro Lucia, Yannis P. Pitsiladis, Vladimir P. Pushkarev, Dmitry A. Dyatlov, Evgeniy F. Orekhov, Guilherme G. Artioli, João Paulo L. F. Guilherme, Antonio H. Lancha, Valentina Ginevičienè, Pawel Cieszczyk, Agnieszka Maciejewska-Karlowska, Marek Sawczuk, Carlos A. Muniesa, Anastasia Kouvatsi, Myosotis Massidda, Carla Maria Calò, Fleur Garton, Peter J. Houweling, Guan Wang, Krista Austin, Anastasiya M. Druzhevskaya, Irina V. Astratenkova, Ildus I. Ahmetov, David J. Bishop, Kathryn N. North e Nir Eynon. ACTN3 R577X and ACE I/D gene variants influence performance in elite sprinters: a multi-cohort study. BMC Genomics, 17(1):285. ISSN 1471-2164. doi: 10.1186/s12864-016-2462-3. URL http://bmcgenomics.biomedcentral.com/articles/10.1186/ s12864-016-2462-3. Citado na pág. 2, 3, 4, 10, 11

Papadimitriou et al.(2018) Ioannis D. Papadimitriou, Sarah J. Lockey, Sarah Voisin, Adam J. Herbert, Fleur Garton, Peter J. Houweling, Pawel Cieszczyk, Agnieszka Maciejewska-Skrendo, Marek Sawczuk, Myosotis Massidda, Carla Maria Calò, Irina V. Astratenkova, Anastasia Kouvatsi, Anastasiya M. Druzhevskaya, Macsue Jacques, Ildus I. Ahmetov, Georgina K. Stebbings, Shane Heffernan, Stephen H. Day, Robert Erskine, Charles Pedlar, Courtney Kipps, Kathryn N. North, Alun G. Williams e Nir Eynon. No association between ACTN3 R577X and ACE I/D polymorphisms and endurance running times in 698 Caucasian athletes. BMC Genomics, 19(1): 13. ISSN 1471-2164. doi: 10.1186/s12864-017-4412-0. URL https://bmcgenomics.biomedcentral. com/articles/10.1186/s12864-017-4412-0. Citado na pág. 11 
Peng et al.(2007) Bo Peng, K Yu Robert, Kevin L DeHoff e Christopher I Amos. Normalizing a large number of quantitative traits using empirical normal quantile transformation. Em $B M C$ proceedings, volume 1, página S156. BioMed Central. Citado na pág. 31

Polman et al.(2005) Chris H Polman, Stephen C Reingold, Gilles Edan, Massimo Filippi, HansPeter Hartung, Ludwig Kappos, Fred D Lublin, Luanne M Metz, Henry F McFarland, Paul W O'Connor et al. Diagnostic criteria for multiple sclerosis: 2005 revisions to the "mcdonald criteria". Annals of Neurology: Official Journal of the American Neurological Association and the Child Neurology Society, 58(6):840-846. Citado na pág. 37

Popadic Gacesa et al.(2012) Jelena Z Popadic Gacesa, Milica Momcilovic, Igor Veselinovic, David A Brodie e Nikola G Grujic. Bradykinin type 2 receptor $-9 /-9$ genotype is associated with triceps brachii muscle hypertrophy following strength training in young healthy men. $B M C$ Musculoskeletal Disorders, 13(1):217. ISSN 1471-2474. doi: 10.1186/1471-2474-13-217. URL http: //bmcmusculoskeletdisord.biomedcentral.com/articles/10.1186/1471-2474-13-217. Citado na pág. 2, 10

Ran et al.(2013) Fa Ann Ran, Pd Patrick D Hsu, Jason Wright, Vineeta Agarwala, David a Scott e Feng Zhang. Genome engineering using the CRISPR-Cas9 system. Nature protocols, 8(11):2281-308. ISSN 1750-2799. doi: 10.1038/nprot.2013.143. URL http://www.ncbi.nlm.nih.gov/pubmed/24157548\{\%\}5Cnhttp://www.pubmedcentral.nih.gov/ articlerender.fcgi? artid $=3969860\{\&\}$ tool $=$ pmcentrez $\{\&\}$ rendertype $=$ abstract $\{\%\} 5$ Cnhttp: //www.ncbi.nlm.nih.gov/pubmed/24157548\{\%\}5Cnhttp://www.nature.com/nprot/journal/v8/ n11/abs/nprot.2013. Citado na pág. 1

Rankinen et al.(2016) Tuomo Rankinen, Noriyuki Fuku, Bernd Wolfarth, Guan Wang, Mark A. Sarzynski, Dmitry G. Alexeev, Ildus I. Ahmetov, Marcel R. Boulay, Pawel Cieszczyk, Nir Eynon, Maxim L. Filipenko, Fleur C. Garton, Edward V. Generozov, Vadim M. Govorun, Peter J. Houweling, Takashi Kawahara, Elena S. Kostryukova, Nickolay A. Kulemin, Andrey K. Larin, Agnieszka Maciejewska-Karłowska, Motohiko Miyachi, Carlos A. Muniesa, Haruka Murakami, Elena A. Ospanova, Sandosh Padmanabhan, Alexander V. Pavlenko, Olga N. Pyankova, Catalina Santiago, Marek Sawczuk, Robert A. Scott, Vladimir V. Uyba, Thomas Yvert, Louis Perusse, Sujoy Ghosh, Rainer Rauramaa, Kathryn N. North, Alejandro Lucia, Yannis Pitsiladis e Claude Bouchard. No Evidence of a Common DNA Variant Profile Specific to World Class Endurance Athletes. PLOS ONE, 11(1):e0147330. ISSN 1932-6203. doi: 10.1371/journal.pone.0147330. URL http://dx.plos.org/10.1371/journal.pone.0147330. Citado na pág. 53

Rauramaa et al.(2002) Rainer Rauramaa, Raimo Kuhanen, Timo A Lakka, Sari B Vaisanen, Pirjo Halonen, Markku Alén, Tuomo Rankinen e Claude Bouchard. Physical exercise and blood pressure with reference to the angiotensinogen m235t polymorphism. Physiological genomics, 10 (2):71-77. Citado na pág. 10

Ren et al.(2018) Yi-Ming Ren, Yuan-Hui Duan, Yun-Bo Sun, Tao Yang e Meng-Qiang Tian. Bioinformatics analysis of differentially expressed genes in rotator cuff tear patients using microarray data. Journal of orthopaedic surgery and research, 13(1):284. Citado na pág. 41

Rigat et al.(1990) Brigitte Rigat, Christine Hubert, Francois Alhenc-Gelas, Franmois Cambien, Pierre Corvol e Florent Soubrier. An insertion/deletion polymorphism in the angiotensin iconverting enzyme gene accounting for half the variance of serum enzyme levels. The Journal of clinical investigation, 86(4):1343-1346. Citado na pág. 10

Roth et al.(2008) Stephen M Roth, Sean Walsh, Dongmei Liu, E Jeffrey Metter, Luigi Ferrucci e Ben F Hurley. The ACTN3 R577X nonsense allele is under-represented in elite-level strength athletes. European Journal of Human Genetics, 16(3):391-394. ISSN 1018-4813. doi: 10.1038/sj. ejhg.5201964. URL http://www.nature.com/articles/5201964. Citado na pág. 3, 11 
Sattelmair et al.(2011) Jacob Sattelmair, Jeremy Pertman, Eric L Ding, Harold W Kohl III, William Haskell e I-Min Lee. Dose response between physical activity and risk of coronary heart disease: a meta-analysis. Circulation, 124(7):789-795. Citado na pág. 7

SCAN(2019) SCAN. Scan: Snp and cnv annotation database. http://www.scandb.org/ newinterface/about.html, 2019. Último acesso em 08/05/2019. Citado na pág. 39, 45, 46

Schechter(2008) a N Schechter. Hemoglobin research and the origins of molecular medicine. Blood, 112(10):3927-3938. doi: 10.1182/blood-BLOOD. URL http://www.embase.com/search/ results? subaction $=$ viewrecord $\{\&\}$ from $=\operatorname{export}\{\&\}$ id $=$ L354286189. Citado na pág. 1,2

Schutte et al.(2016a) Nienke M. Schutte, Ineke Nederend, James J. Hudziak, Meike Bartels e Eco J. C. de Geus. Twin-sibling study and meta-analysis on the heritability of maximal oxygen consumption. Physiological Genomics, 48(3):210-219. ISSN 1094-8341. doi: 10.1152/physiolgenomics. 00117.2015. URL http://www.physiology.org/doi/10.1152/physiolgenomics.00117.2015. Citado na pág. 37,57

Schutte et al.(2016b) Nienke M. Schutte, Ineke Nederend, James J. Hudziak, Eco J. C. de Geus e Meike Bartels. Differences in Adolescent Physical Fitness: A Multivariate Approach and Metaanalysis. Behavior Genetics, 46(2):217-227. ISSN 0001-8244. doi: 10.1007/s10519-015-9754-2. URL http://link.springer.com/10.1007/s10519-015-9754-2. Citado na pág. 32, 37, 57

Seabra et al.(2014) André F. Seabra, Denisa M. Mendonça, Harald H. H. Göring, Martine A. Thomis e José A. Maia. Genetic influences of sports participation in Portuguese families. European Journal of Sport Science, 14(5):510-517. ISSN 1746-1391. doi: 10.1080/17461391.2013.832801. URL http://www.tandfonline.com/doi/abs/10.1080/17461391.2013.832801. Citado na pág. 30

Sekar et al.(2016) Aswin Sekar, Allison R Bialas, Heather de Rivera, Avery Davis, Timothy R Hammond, Nolan Kamitaki, Katherine Tooley, Jessy Presumey, Matthew Baum, Vanessa Van Doren et al. Schizophrenia risk from complex variation of complement component 4. Nature, 530 (7589):177. Citado na pág. 12

Self e Liang(1987) Steven G. Self e Kung-Yee Liang. Asymptotic Properties of Maximum Likelihood Estimators and Likelihood Ratio Tests Under Nonstandard Conditions. Journal of the American Statistical Association, 82(398):605. ISSN 01621459. doi: 10.2307/2289471. URL https://www.jstor.org/stable/2289471?origin=crossref. Citado na pág. 19

Sinaki(2012) Mehrsheed Sinaki. Exercise for patients with osteoporosis: management of vertebral compression fractures and trunk strengthening for fall prevention. PMER, 4(11):882-888. Citado na pág. 9

Smerdu et al.(1994) VIKA Smerdu, ILENE Karsch-Mizrachi, MARINA Campione, LESLIE Leinwand e STEFANO Schiaffino. Type iix myosin heavy chain transcripts are expressed in type iib fibers of human skeletal muscle. American Journal of Physiology-Cell Physiology, 267 (6):C1723-C1728. Citado na pág. 11

Sophonnithiprasert et al.(2019) Thanet Sophonnithiprasert, Pensri Saelee e Tanett Pongtheerat. Gstm1 and gstt1 copy number variants and the risk to thai females of hepatocellular carcinoma. Journal of Gastrointestinal Oncology, 10(2):324. Citado na pág. 12

Tamari et al.(2013) Mayumi Tamari, ShotaTanaka e Tomomitsu Hirota. Genome-Wide Association Studies of Allergic Diseases. Allergology International, 62(1):21-28. ISSN 13238930. doi: 10.2332/allergolint.13-RAI-0539. URL http://linkinghub.elsevier.com/retrieve/ pii/S1323893015301040. Citado na pág. 1

Therneau e Sinnwell(2015) Terry M Therneau e Jason Sinnwell. kinship2: Pedigree Functions, 2015. URL https://cran.r-project.org/package=kinship2. Citado na pág. 21 
Therneau e Therneau(2015) Terry M Therneau e Maintainer Terry M Therneau. Package 'coxme'. $R$ package version, 2(5). Citado na pág. 21

Tibshirani(1996) Robert Tibshirani. Regression Shrinkage and Selection via the Lasso. Journal of the Royal Statistical Society. Series B (Methodological), 58(1):267-288. Citado na pág. 58

Van Praag et al.(1999) Henriette Van Praag, Gerd Kempermann e Fred H Gage. Running increases cell proliferation and neurogenesis in the adult mouse dentate gyrus. Nature neuroscience, 2(3):266. Citado na pág. 9

Vasan et al.(2007) Ramachandran S Vasan, Martin G Larson, Jayashri Aragam, Thomas J Wang, Gary F Mitchell, Sekar Kathiresan, Christopher Newton-Cheh, Joseph A Vita, Michelle J Keyes, Christopher J O'Donnell et al. Genome-wide association of echocardiographic dimensions, brachial artery endothelial function and treadmill exercise responses in the framingham heart study. BMC medical genetics, 8(1):S2. Citado na pág. 11, 53

Venter et al.(2001) J Craig Venter, Mark D Adams, Eugene W Myers, Peter W Li, Richard J Mural, Granger G Sutton, Hamilton O Smith, Mark Yandell, Cheryl A Evans, Robert A Holt et al. The sequence of the human genome. science, 291(5507):1304-1351. Citado na pág. 1

Visscher et al.(2012) Peter M Visscher, Matthew A Brown, Mark I McCarthy e Jian Yang. Five years of gwas discovery. The American Journal of Human Genetics, 90(1):7-24. Citado na pág. 54

Visscher et al.(2017) Peter M Visscher, Naomi R Wray, Qian Zhang, Pamela Sklar, Mark I McCarthy, Matthew A Brown e Jian Yang. 10 years of gwas discovery: biology, function, and translation. The American Journal of Human Genetics, 101(1):5-22. Citado na pág. 54

Wain et al.(2009) Louise V. Wain, Inti Pedroso, John E. Landers, Gerome Breen, Christopher E. Shaw, P. Nigel Leigh, Robert H. Brown, Martin D. Tobin e Ammar Al-Chalabi. The Role of Copy Number Variation in Susceptibility to Amyotrophic Lateral Sclerosis: Genome-Wide Association Study and Comparison with Published Loci. PLoS ONE, 4(12):e8175. ISSN 1932-6203. doi: 10.1371/journal.pone.0008175. URL http://dx.plos.org/10.1371/journal.pone.0008175. Citado na pág. 4,12

Wang et al.(2007) K. Wang, M. Li, D. Hadley, R. Liu, J. Glessner, S. F.A. Grant, H. Hakonarson e M. Bucan. PennCNV: An integrated hidden Markov model designed for high-resolution copy number variation detection in whole-genome SNP genotyping data. Genome Research, 17(11): 1665-1674. ISSN 1088-9051. doi: 10.1101/gr.6861907. URL http://www.genome.org/cgi/doi/10. 1101/gr.6861907. Citado na pág. 12

WHO(2018) WHO. Obesity and Overweight, 2018. URL https://www.who.int/en/news-room/ fact-sheets/detail/obesity-and-overweight. Último acesso em 11/05/2019. Citado na pág. 8

Willems et al.(2017) Sara M. Willems, Daniel J. Wright, Felix R. Day, Katerina Trajanoska, Peter K. Joshi, John A. Morris, Amy M. Matteini, Fleur C. Garton, Niels Grarup, Nikolay Oskolkov, Anbupalam Thalamuthu, Massimo Mangino, Jun Liu, Ayse Demirkan, Monkol Lek, Liwen Xu, Guan Wang, Christopher Oldmeadow, Kyle J. Gaulton, Luca A. Lotta, Eri Miyamoto-Mikami, Manuel A. Rivas, Tom White, Po-Ru Loh, Mette Aadahl, Najaf Amin, John R. Attia, Krista Austin, Beben Benyamin, Søren Brage, Yu-Ching Cheng, Paweł Cięszczyk, Wim Derave, KarlFredrik Eriksson, Nir Eynon, Allan Linneberg, Alejandro Lucia, Myosotis Massidda, Braxton D. Mitchell, Motohiko Miyachi, Haruka Murakami, Sandosh Padmanabhan, Ashutosh Pandey, Ioannis Papadimitriou, Deepak K. Rajpal, Craig Sale, Theresia M. Schnurr, Francesco Sessa, Nick Shrine, Martin D. Tobin, Ian Varley, Louise V. Wain, Naomi R. Wray, Cecilia M. Lindgren, Daniel G. MacArthur, Dawn M. Waterworth, Mark I. McCarthy, Oluf Pedersen, Kay-Tee Khaw, Douglas P. Kiel, Ling Oei, Hou-Feng Zheng, Vincenzo Forgetta, Aaron Leong, Omar S. Ahmad, 
Charles Laurin, Lauren E. Mokry, Stephanie Ross, Cathy E. Elks, Jack Bowden, Nicole M. Warrington, Anna Murray, Katherine S. Ruth, Konstantinos K. Tsilidis, Carolina Medina-Gómez, Karol Estrada, Joshua C. Bis, Daniel I. Chasman, Serkalem Demissie, Anke W. Enneman, YiHsiang Hsu, Thorvaldur Ingvarsson, Mika Kähönen, Candace Kammerer, Andrea Z. Lacroix, Guo Li, Ching-Ti Liu, Yongmei Liu, Mattias Lorentzon, Reedik Mägi, Evelin Mihailov, Lili Milani, Alireza Moayyeri, Carrie M. Nielson, Pack Chung Sham, Kristin Siggeirsdotir, Gunnar Sigurdsson, Kari Stefansson, Stella Trompet, Gudmar Thorleifsson, Liesbeth Vandenput, Nathalie van der Velde, Jorma Viikari, Su-Mei Xiao, Jing Hua Zhao, Daniel S. Evans, Steven R. Cummings, Jane Cauley, Emma L. Duncan, Lisette C. P. G. M. de Groot, Tonu Esko, Vilmundar Gudnason, Tamara B. Harris, Rebecca D. Jackson, J Wouter Jukema, Arfan M. A. Ikram, David Karasik, Stephen Kaptoge, Annie Wai Chee Kung, Terho Lehtimäki, Leo-Pekka Lyytikäinen, Paul Lips, Robert Luben, Andres Metspalu, Joyce B. J. van Meurs, Ryan L. Minster, Erick Orwoll, Edwin Oei, Bruce M. Psaty, Olli T. Raitakari, Stuart W. Ralston, Paul M. Ridker, John A. Robbins, Albert V. Smith, Unnur Styrkarsdottir, Gregory J. Tranah, Unnur Thorstensdottir, Andre G. Uitterlinden, Joseph Zmuda, M Carola Zillikens, Evangelia E. Ntzani, Evangelos Evangelou, John P. A. Ioannidis, David M. Evans, Claes Ohlsson, Yannis Pitsiladis, Noriyuki Fuku, Paul W. Franks, Kathryn N. North, Cornelia M. van Duijn, Karen A. Mather, Torben Hansen, Ola Hansson, Tim Spector, Joanne M. Murabito, J. Brent Richards, Fernando Rivadeneira, Claudia Langenberg, John R. B. Perry, Nick J. Wareham e Robert A. Scott. Large-scale GWAS identifies multiple loci for hand grip strength providing biological insights into muscular fitness. Nature Communications, 8:16015. ISSN 2041-1723. doi: 10.1038/ncomms16015. URL http://insights.ovid.com/crossref?an=00005768-900000000-96955http://www.nature.com/ doifinder/10.1038/ncomms16015. Citado na pág. 3, 4, 11

Wisløff et al.(2007) Ulrik Wisløff, Asbjørn Støylen, Jan P Loennechen, Morten Bruvold, Øivind Rognmo, Per Magnus Haram, Arnt Erik Tjønna, Jan Helgerud, Stig A Slørdahl, Sang Jun Lee et al. Superior cardiovascular effect of aerobic interval training versus moderate continuous training in heart failure patients: a randomized study. Circulation, 115(24):3086-3094. Citado na pág. 7

Witten e Tibshirani(2009) Daniela M Witten e Robert Tibshirani. Covariance-regularized regression and classification for high dimensional problems. Journal of the Royal Statistical Society: Series B (Statistical Methodology), 71(3):615-636. Citado na pág. 58

Wu et al.(2018) Yishuo Wu, Haitao Chen, Guangliang Jiang, Zengnan Mo, Dingwei Ye, Meilin Wang, Jun Qi, Xiaoling Lin, S Lilly Zheng, Ning Zhang et al. Genome-wide association study (gwas) of germline copy number variations (cnvs) reveal genetic risks of prostate cancer in chinese population. Journal of Cancer, 9(5):923. Citado na pág. 12

Wuyts et al.(2013) Wim Wuyts, Gregory A Schmale, Howard A Chansky e Wendy H Raskind. Hereditary multiple osteochondromas. Em GeneReviews@/Internet]. University of Washington, Seattle. Citado na pág. 41

Xiao e Fu(2016) Tao Xiao e Yun Feng Fu. Biomechanical Modeling of Human Body Movement. Journal of Biometrics \& Biostatistics, 7(3). ISSN 21556180. doi: 10.4172/2155-6180.1000309. URL https://www.omicsonline.org/open-access/ biomechanical-modeling-of-human-body-movement-2155-6180-1000309.php?aid=76243. $\quad$ Citado na pág. 3,7

Yang et al.(2012) Jian Yang, Ruth J. F. Loos, Joseph E. Powell, Sarah E. Medland, Elizabeth K. Speliotes, Daniel I. Chasman, Lynda M. Rose, Gudmar Thorleifsson, Valgerdur Steinthorsdottir, Reedik Mägi, Lindsay Waite, Albert Vernon Smith, Laura M. Yerges-Armstrong, Keri L. Monda, David Hadley, Anubha Mahajan, Guo Li, Karen Kapur, Veronique Vitart, Jennifer E. Huffman, Sophie R. Wang, Cameron Palmer, Tõnu Esko, Krista Fischer, Jing Hua Zhao, Ayşe Demirkan, Aaron Isaacs, Mary F. Feitosa, Jian'an Luan, Nancy L. Heard-Costa, Charles White, 
Anne U. Jackson, Michael Preuss, Andreas Ziegler, Joel Eriksson, Zoltán Kutalik, Francesca Frau, Ilja M. Nolte, Jana V. Van Vliet-Ostaptchouk, Jouke-Jan Hottenga, Kevin B. Jacobs, Niek Verweij, Anuj Goel, Carolina Medina-Gomez, Karol Estrada, Jennifer Lynn Bragg-Gresham, Serena Sanna, Carlo Sidore, Jonathan Tyrer, Alexander Teumer, Inga Prokopenko, Massimo Mangino, Cecilia M. Lindgren, Themistocles L. Assimes, Alan R. Shuldiner, Jennie Hui, John P. Beilby, Wendy L. McArdle, Per Hall, Talin Haritunians, Lina Zgaga, Ivana Kolcic, Ozren Polasek, Tatijana Zemunik, Ben A. Oostra, M. Juhani Junttila, Henrik Grönberg, Stefan Schreiber, Annette Peters, Andrew A. Hicks, Jonathan Stephens, Nicola S. Foad, Jaana Laitinen, Anneli Pouta, Marika Kaakinen, Gonneke Willemsen, Jacqueline M. Vink, Sarah H. Wild, Gerjan Navis, Folkert W. Asselbergs, Georg Homuth, Ulrich John, Carlos Iribarren, Tamara Harris, Lenore Launer, Vilmundur Gudnason, Jeffrey R. O'Connell, Eric Boerwinkle, Gemma Cadby, Lyle J. Palmer, Alan L. James, Arthur W. Musk, Erik Ingelsson, Bruce M. Psaty, Jacques S. Beckmann, Gerard Waeber, Peter Vollenweider, Caroline Hayward, Alan F. Wright, Igor Rudan, Leif C. Groop, Andres Metspalu, Kay Tee Khaw, Cornelia M. van Duijn, Ingrid B. Borecki, Michael A. Province, Nicholas J. Wareham, Jean-Claude Tardif, Heikki V. Huikuri, L. Adrienne Cupples, Larry D. Atwood, Caroline S. Fox, Michael Boehnke, Francis S. Collins, Karen L. Mohlke, Jeanette Erdmann, Heribert Schunkert, Christian Hengstenberg, Klaus Stark, Mattias Lorentzon, Claes Ohlsson, Daniele Cusi, Jan A. Staessen, Melanie M. Van der Klauw, Peter P. Pramstaller, Sekar Kathiresan, Jennifer D. Jolley, Samuli Ripatti, Marjo-Riitta Jarvelin, Eco J. C. de Geus, Dorret I. Boomsma, Brenda Penninx, James F. Wilson, Harry Campbell, Stephen J. Chanock, Pim van der Harst, Anders Hamsten, Hugh Watkins, Albert Hofman, Jacqueline C. Witteman, M. Carola Zillikens, André G. Uitterlinden, Fernando Rivadeneira, M. Carola Zillikens, Lambertus A. Kiemeney, Sita H. Vermeulen, Goncalo R. Abecasis, David Schlessinger, Sabine Schipf, Michael Stumvoll, Anke Tönjes, Tim D. Spector, Kari E. North, Guillaume Lettre, Mark I. McCarthy, Sonja I. Berndt, Andrew C. Heath, Pamela A. F. Madden, Dale R. Nyholt, Grant W. Montgomery, Nicholas G. Martin, Barbara McKnight, David P. Strachan, William G. Hill, Harold Snieder, Paul M. Ridker, Unnur Thorsteinsdottir, Kari Stefansson, Timothy M. Frayling, Joel N. Hirschhorn, Michael E. Goddard e Peter M. Visscher. FTO genotype is associated with phenotypic variability of body mass index. Nature, 490(7419):267-272. ISSN 0028-0836. doi: 10.1038/nature11401. URL http://www.nature.com/doifinder/10.1038/nature11401. Citado na pág. 31

Yoshizaki et al.(2017) Amanda Yoshizaki, Ednei Luiz Antonio, José Antonio Silva Junior, Renato Oliveira Crajoinas, Flavio André Silva, Adriana Castello Costa Girardi, Danilo Sales Bocalini, Leslie Andrews Portes, Luis Felipe Neves dos Santos, Fernando Pereira Carlos et al. Swimming training improves myocardial mechanics, prevents fibrosis, and alters expression of ca2+ handling proteins in older rats. The Journals of Gerontology: Series A, 73(4):468-474. Citado na pág. 8

Zhai et al.(2004) Guangju Zhai, James Stankovich, Changhai Ding, Fiona Scott, Flavia Cicuttini e Graeme Jones. The genetic contribution to muscle strength, knee pain, cartilage volume, bone size, and radiographic osteoarthritis: a sibpair study. Arthritis \& Rheumatism, 50(3):805-810. Citado na pág. 57

Zhang et al.(2009) Feng Zhang, Wenli Gu, Matthew E. Hurles e James R. Lupski. Copy Number Variation in Human Health, Disease, and Evolution. Annual Review of Genomics and Human Genetics, 10(1):451-481. ISSN 1527-8204. doi: 10.1146/annurev.genom.9.081307.164217. URL http://www.annualreviews.org/doi/10.1146/annurev.genom.9.081307.164217. Citado na pág. 4

Zillikens et al.(2017) M Carola Zillikens, Serkalem Demissie, Yi-Hsiang Hsu, Laura M YergesArmstrong, Wen-Chi Chou, Lisette Stolk, Gregory Livshits, Linda Broer, Toby Johnson, Daniel L Koller et al. Large meta-analysis of genome-wide association studies identifies five loci for lean body mass. Nature communications, 8(1):80. Citado na pág. 53 